\title{
Versuche über die gemeinsame Verrottung von Müll und Klärschlamm
}

\author{
Von Rudolf Braun und Hans Allenspach \\ Mitteilung aus der Eidgenössischen Anstalt für Wasserversorgung, \\ Abwasserreinigung und Gewässerschutz an der ETH, Zürich \\ Direktor: Prof. Dr. O. JAAG
}

Manuskript eingegangen am 27. November 1957

\section{INHALTSVERZEICHNIS}

Erster Teil

Das Problem der Beseitigung und Vermertung fester Siedlungsabfalle unter scbmeizeriscben Verbältnissen . . . . . . . . . . . . . . . . . . . . . . . . . 62

A. Allgemeines .. . . . . . . . . . . . . . . . . . . . 62

B. Was ist Kompostierung? . . . . . . . . . . . . . . . . . . . . . . 66

C. Möglichkeiten für den Einsatz von Müllkompost in der Schwciz . . . . . 69

D. Die Vorteile einer gemeinsamen Aufbereitung von Müll und Klärschlamm $\quad{ }_{73}$

\section{Zweiter Teil}

Versucbe über die gemeinsame Verrottung von Müll und Klärscblamm in der Dano-Anlage in Rüscblikon . . . . . . . . . . . . . . . . . . . . . . . . . . . 75

A. Allgemeines . . . . . . . . . . . . . . . 75

B. Versuchsprogramm . . . . . . . . . . . . . . . 76

C. Beschreibung der Versuchsanlage . . . . . . . . . . . . . . . . . 78

D. Die Durchführung der Versuche . . . . . . . . . . . . . . . . . . . 79

I. Installationsarbeiten ... . . . . . . . . . . 8r

a) Klärschlammbeimischung . . . . . . . . . . . . . . . $8 \pi$

b) Mietenplätze . . . . . . . . . . . . . . . . . . 8r

2. Tastversuche. . . . . . . . . . . . . . . . . 82

3. Grossversuche .................. 85 
E. Vergleich der Müll-Klärschlamm-Mengen ' . . . . . . . . 88

F. Untersuchungsresultate und Beobachtungen ......... . 90

I. Untersuchungsmethodik . . . . . . . . . . . . . 90

a) Periodische Mietenkontrolle . . . . . . . . . . . . . 90

b) Chemische Untersuchung des Kompostes . . . . . . . . . . . 92

2. Der Gang der Verrottung in den Mieten . . . . . . . . . . 93

a) Erster Grossversuch . . . . . . . . . . . . . . . . . . . 93

b) Zweiter Grossversuch . . . . . . . . . . . . . . . . . . . . . 99

c) Dritter Grossversuch . . . . . . . . . . . . . . . . I04

G. Die chemische Zusammensetzung und die Bewertung des Kompostes . . 106

I. Der Wassergehalt . . . . . . . . . . . . . I08

2. Glühverlust, wirksame organische Substanz und Humusstoffe . . . I08

3. Der Gehalt an Stickstoff, Phosphor und Kali . . . . . . . . . . . I Io

4. Der Kalkgehalt und der $\mathrm{pH}-$ Wert . . . . . . . . . . . . III

s. Fremdbestandteile . . . . . . . . . . . . . I12

H. Der Reifegrad des Kompostes . . . . . . . . . . . . . . II4

J. Die hygienische Frage und die Verunkrautungsgefahr . . . . . . I I6

\section{Dritter Teil}

I. Scblussfolgerungen für die Praxis . . . . . . . . . . . . I18

A. Beimischung von Klärschlamm . . . . . . . II8

B. Die Mietengärung . . . . . . . . . . . . . II9

I. Die Mietenunterlage . . . . . . . . . . . . . . . I19

2. Die Mietenform . . . . . . . . . . . . . . . II9

3. Die Umarbeitung . . . . . . . . . . . . . I20

4. Die Bestimmung des Reifegrades. . . . . . . . . . . . . 122

5. Die Qualität des Müll-Klärschlamm-Kompostes . . . . . . . 122 Einige Erfahrungszahlen aus dem Betrieb der Anlage Rüschlikon . . 122

II. Vorscbläge für Weiterentwicklung . . . . . . . . . . . . 123 


\section{Erster Teil}

\section{Das Problem der Beseitigung und Verwertung fester Siedlungs- abfälle unter schweizerischen Verhältnissen}

\section{A. Allgemeines}

Die Beseitigung fester und flüssiger Abfallstoffe ist heute bei einer Vielzahl öffentlicher Aufgaben einer Gemeinde wohl eines der dringlichsten Probleme. Durch die rapid steigenden Bevölkerungszahlen in manchen Regionen und Gemeinden werden die Sorgen um die Beschaffung des wichtigsten Nahrungsmittels, nämlich des Trinkwassers, immer grösser. $\mathrm{Da}$ gutes Trinkwasser direkt zu einer Mangelware zu werden droht, wenn nicht zweckentsprechende Massnahmen zur Reinhaltung der oberund unterirdischen Gewässer getroffen werden, sind die grossen Anstrengungen auf dem Gebiete des Gewässerschutzes mit allen Mitteln zu fördern. Sind die schädlichen Einwirkungen flüssiger Abfallstoffe auf unsere Gewässer offensichtlich und meistens sofort wahrnehmbar, so treten die Beeinflussungen der Gewässer durch die mehr oder weniger wahllose Ablagerung fester Abfälle in der Regel erst nach einer gewissen Zcit, dafür aber um so nachhaltender, auf.

In direktem Zusammenhang mit der Reinhaltung der Gewässer steht also das Problem der unschädlichen Beseitigung der festen Siedlungsabfälle, bestehend aus dem Hausmüll (im schweizerischen Sprachgebrauch «Kehricht» genannt) und dem Strassenkehricht, im folgenden zusammenfassend als Müll bezeichnet. Die Dringlichkeit des Müllproblems ist ebenso unbestritten wie diejenige der Gewässersanierung. In der Schweiz stehen schätzungsweise 2000 grössere und kleinere Gemeinden vor der Notwendigkeit, ihre Müllbeseitigung zu verbessern. Der grösste Teil dieser Gemeinden schüttet heute noch den Müll in Kiesgruben und Geländevertiefungen, an Strassen- und Waldränder oder an die Ufer der Seen und Flüsse. Selbst berühmte Kurorte scheuen sich nicht, ihre Zufahrtstrassen und Waldränder mit hässlichen Müllablagerungen zu verunstalten. Solche Bilder vermögen sicher nicht dem erholungsuchenden Gast seinen Aufenthalt zu verschönern.

Dass die Müllbeseitigung in unserem Lande unbefriedigend ist, ging schon vor fast 20 Jahren aus einem von Ing. PETER erstellten Kehrichtkataster mit aller Deutlichkeit hervor. Von den darin erfasstẹn $380 \mathrm{Ge}$ meinden mit Einwohnerzahlen zwischen 250 und 25000 aus verschiedenen 
Teilen der Schweiz besassen nur 272 eine geregelte kommunale Müllabfuhr. Bei $7 \mathrm{I} \%$ der untersuchten Mülldeponien wurden Geruchsbelästigungen, Staubplagen und Rauchentwicklung, bei $76 \%$ Ungezieferplagen, bei $25 \%$ Waldbrandgefahr und bei $88 \%$ Verschandelung des Landschaftsbildes festgestellt. Weitere Erhebungen PETERS in den vergangenen zehn Jahren zeigten ein noch ungünstigeres Bild der Verhältnisse.

Was aber das Müllproblem zu einem integrierenden Bestandteil der Gewässersanierung werden lässt, ist die Tatsache, dass durch unsachgemässe Mülldeponie, wie sie in der Schweiz noch sehr häufig angetroffen wird, unter Umständen die ober- und unterirdischen Gewässer geschädigt werden. Bei Ablagerungen von Müll an See- und Flussufern gelangen gelöste und ungelöste Stoffe ins Wasser. Beispiele solcher Gewässerverschmutzungen gibt es mehr als genug.

Noch schwerwiegender ist jedoch die Gefahr der Verunreinigung des Grundwassers, wenn Müll über einem offenen Grundwasserträger abgelagert wird. Durch die auslaugende Wirkung des Regenwassers können wasserlösliche Stoffe und Abbauprodukte der organischen Substanz des Mülls ins Grundwasser gelangen. Diese Gefahr wird namentlich akut bei Mülldeponien in alten, ausgebeuteten Kiesgruben, in denen eine filtrierende und absorbierende Humusschicht fehlt.

Nach PeTER sollen von den in seinem bereits erwähnten Kataster erfassten Müllablagerungen $30 \%$ das Grundwasser gefährden, namentlich dort, wo Müll in Gruben abgelagert wird, in denen das Grundwasser ansteht. Diese Verunreinigungen sind deshalb so schwerwiegend, weil das Selbstreinigungsvermögen im Grundwasser auf ein Minimum beschränkt ist. Es dauert Jahre, mitunter Jahrzehnte, bis sich ein verdorbenes Grundwasser wieder einigermassen erholt hat. Wir können also tatsächlich von einer «Müllgefahr» sprechen.

Für eine einwandfreie Siedlungspolitik ist also nicht nur die Abwasserbeseitigung von eminenter Bedeutung, sondern die schadlose Beseitigung und zum Teil Wiederverwertung von flüssigen und festen Abfallstoffen ist die eigentliche Problemstellung. So kann die Frage der Abroasserbeseitigung im allgemeinen nicht getrennt zperden von der Frage der Müllbeseitigung.

Die fliissigen Abfallstoffe werden in den Kläranlagen behandelt. Der anfallende Schlamm muss entweder einer Verwertung zugeführt oder in einen für die Deponie unschädlichen Zustand gebracht werden.

Die festen Abfallstoffe können auf folgende Arten beseitigt oder verwertet werden, ohne dass dabei Schäden für Mensch und Tier, Landschaft und Gewässer entstehen: 
I. Geordnete Deponie;

2. Verbrennung;

3. Faulung;

4. Brikettierung;

5. Kompostierung.

\section{Geordnete Deponie}

Sie kommt nur für Gebiete in Frage, wo keine Grundwasserbeeinträchtigung zu befürchten ist. Selbstverständlich darf die Deponie auch nicht in der Nähe von oberirdischen Gewässern angelegt werden. Nach der jeweiligen Beschickung der Deponie mit frischem Müll muss dieser sofort mit einer Schicht Humus, Sand oder Bauschutt bedeckt werden, um Geruchsbelästigung, Brand- und Rauchgefahr, Ungeziefer- und Rattenplagen zu verhindern. Die geordnete Deponie ist eine Notlösung.

Eine sachgemässe geordnete Deponie ist in der Praxis mit Schwierigkeiten verbunden. Sie kann richtig sein für eine Schütthalde gleichbleibender und nicht übermässiger Höhe, so dass ein ständiges Abdecken mit Aushub-oder Humusmaterial möglich ist. Dies setzt aber voraus, dass dieses Material fortwährend in den notwendigen Mengen zur Verfügung steht. Die Gefahr ist dabei gross, dass die Mülldeponie bald überwiegend zu einer Aushubmaterialdeponie wird.

Wenn das auf die Deponie gebrachte Müllmaterial jedoch nicht abgedeckt wird, ist die lästige Brandgefahr ausserordentlich gross. Viele Gemeinden sind heute noch gezwungen, ihre Abfälle auf solche Deponien zu schütten, bis eine definitive Lösung der Müllbeseitigung verwirklicht werden kann. Wir möchten an dieser Stelle eine provisorische Übergangslösung vorschlagen, welche vornehmlich den lästigen Qualm und den widerlichen Geruch verhindert.

In der Gemeinde Horgen wurden Versuche durchgeführt, um den Müll mit einfachen und behelfsmässigen Mitteln in eine Form überzuführen, die ein Brennen bzw. Motten verunmöglicht. Der Rohmüll wurde bei diesem Versuch in einer alten, ausrangierten Betonmischmaschine zerkleinert und zermalmt. 2-3 Pflastersteine in der Mischtrommel beschleunigten diesen Vorgang. Der Rohmüll wurde mit Wasser befeuchtet, da der Wintermüll sehr trocken war. Nach etwa Io Minuten Laufzeit konnte das Material der Mischtrommel entnommen werden. Das Volumen des Mülls reduzierte sich durch diese Behandlung auf einen Bruchteil, die 
Papieranteile waren praktisch nicht mehr erkennbar, und das Müllmaterial zeigte ein einigermassen homogenes Aussehen.

Wenn ein derart vorbehandeltes Material nun auf die Deponie gebracht wird, dürfte die Brandgefahr gebannt sein. Ein weiterer Vorteil besteht in der starken Verminderung des Volumens. Humus-, Aushub- und Bauschuttmaterial zur Abdeckung sind in diesem Falle nicht mehr notwendig. Das Material kann aber auch in Form von Mieten kompostiert werden.

\section{Verbrennung}

Die radikalste Methode der Müllbeseitigung, die überdies den hygienischen Anforderungen am besten entspricht, ist zweifellos die Verbrennung. Die entstehende Überschusswärme wird einem möglichst nahe gelegenen Konsumenten nutzbringend zugeführt. Die bei derVerbrennung anfallenden Schlacken- und Ascheteile gelangen auf eine Deponie. Die Verbrennung kommt nach den bisherigen Erfahrungen jedoch infolge der hohen Kosten nur für Gemeinwesen von mehr als 50000 Einwohnern in Frage.

\section{Faulung}

Der vorsortierte, maschinell zerkleinerte Müll wird gemeinsam mit Abwasserschlamm in den Faulräumen der Kläranlagen ausgefault. Zu diesem Zweck müssen jedoch die Faulkammern grösser dimensioniert werden, dafür ist die Ausbeute an Faulgas höher. In der Schweiz besitzen wir bis heute noch keine ausgedehnten Erfahrungen auf diesem Gebiet. Den Belangen des Gewässerschutzes ist dabei besonders Rechnung zu tragen.

\section{Brikettierung}

Der Müll wird durch Zerkleinerung bzw. Zerfaserung in einen brikettierfähigen Zustand gebracht und unter hohen Drucken gepresst. Die Briketts können sodann ebenfalls für Wärmezwecke verwendet werden. Somit wird die aus dem Müll gewonnene Wärmeenergie nicht in Form von Dampf wie unter 2. in Rohrleitungen transportiert, sondern in Form von Briketts, was die Standortfrage einer Müllaufbereitungsanlage wesentlich erleichtern dürfte. Auf die Möglichkeiten einer Kombination von Verbrennung und Kompostierung wird im letzten Teil dieser Arbeit (Vorschläge für Weiterentwicklung) hingewiesen. 


\section{Kompostierung}

Im Ausland, namentlich in Holland und gewissen Teilen Deutschlands, sicht man vom volkswirtschaftlichen Standpunkt aus das Ziel einer sinnvollen Müllbeseitigung in der Aufarbeitung zu einem brauchbaren Bodenverbesserungsmittel. In den letzten Jahren hat daher die Kompostierung des Mülls sehr stark an Bedeutung gewonnen, namentlich auch seit sich die Industrie dafür zu interessieren begann und zweckentsprechende Anlagen entwickelte. Der Müll wird in einer solchen Anlage zu Kompost verarbeitet. Die nicht kompostierbaren, aber brennbaren Anteile werden in einem cinfachen Ofen innerhalb der Anlage verbrannt und die weder brenn- noch kompostierbaren Materialien mitsamt der Asche aus dem Ofen auf eine Deponie gebracht, soweit sie nicht der Altstoffverwertung (Metalle usw.) zugeführt werden können. Auf die verschiedenen Verfahren der Kompostierung wollen wir an dieser Stelle nicht weiter eingehen.

Die Müllkompostierung ist namentlich für kleinere und mittlere Gemeinwesen angebracht, wo eine Verbrennung aus Gründen der Wirtschaftlichkeit nicht in Frage kommt und wo ein Bedarf an Kompost besteht.

\section{B. Was ist Kompostierung?}

Wenn organische Abfallstoffe (tierische und pflanzliche Substanzen) auf oder in den Boden gelangen, unterliegen sie bestimmten Zersetzungsund Umwandlungsprozessen, welche zur Hauptsache durch den Stoffwechsel von Mikroorganismen und erdbewohnenden Tieren ausgelöst werden. Bei diesen Vorgängen handelt es sich in erster Linie um eine Oxydation, um einen Verbrennungsprozess. Sauerstoffärmere, energiereiche Kohlenstoffverbindungen der organischen Substanz werden dabei in sauerstoffreichere Verbindungen umgewandelt, was unter Abgabe von Energie geschieht, welche von den Mikroorganismen ausgenutzt wird. Im Endstadium dieses Umwandlungsprozesses entstehen schliesslich aus der ursprünglichen organischen Substanz Kohlensäure, Wasser und Mineralsalze. Geschieht dieser Prozess mit Hilfe des Luftsauerstoffes, so sprechen wir von aerober Zersetzung oder Verrottung. Fehlt jedoch der freie Luftsauerstoff, das heisst, wird zu dieser Zersetzung der gebundene Sauerstoff verwendet, so spricht man von anaerober Zersetzung oder Fäulnis.

Bei dieser Umwandlung der organischen Abfallstoffe im natürlichen Boden laufen beide Prozesse, Verrottung und Fäulnis, nebeneinander her. Bald überwiegt der eine, bald der andere Prozess, je nach der Durch- 
lüftung des Bodens. Der Abbauprozess durch Verrottung geht im allgemeinen rascher vor sich als derjenige der Fäulnis, bei der überdies als Zwischenprodukt Schwefelwasserstoff entsteht, der für manche Lebewesen ein starkes Gift darstellt.

Im natürlichen Boden, namentlich aber im Waldboden, werden die obenerwähnten mikrobiologischen Zersetzungsprozesse unterstützt bzw. eingeleitet von mancherlei Tieren. So fressen zum Beispiel Asseln, Milben, Tausendfüssler, Springschwänze, Insektenlarven, hauptsächlich aber Würmer, frische oder in Zersetzung begriffene organische Substanz, entnehmen ihr Stoffe zur Ernährung, wie Zucker, Stärke, Fett, Eiweiss, usw., und geben den Rest als Kot wieder ab. Durch diesen "Aufschluss» leisten diese Tiere wertvolle Vorarbeit für die nachfolgende Tätigkeit der Bakterien und Pilze und begünstigen die erwünschte Krümelbildung des Bodens. Aber noch in weiterer Hinsicht ist die Tätigkeit dieser Tiere wertvoll: Durch ihre Wühlarbeit durchlüften sie den Boden.

Die Tätigkeit der Mikroorganismen ist dagegen weit komplizierter und zum Teil noch sehr wenig bekannt. Einerseits wandeln sie dabei mit Hilfe von spezifischen Enzymen komplizierte organische Verbindungen in einfache Stoffe um und gewinnen dabei die für ihren Lebensprozess notwendige Energic. Man spricht daher auch von Betriebsstoffipechsel. Wird dieser Abbau zu Ende geführt, das heisst bis zur Bildung von pflanzenaufnehmbaren Verbindungen, wie Kohlensäure, Ammoniak, Wasser und Mineralsalzen, so spricht man von Mineralisierung. Anderseits aber verwenden die Mikroorganismen bereits abgebaute oder frische organische Substanz als Nahrung zum Aufbau ihrer Körpersubstanz, wobei wieder der umgekehrte Vorgang eintritt: Einfache organische und anorganische Stoffe werden in komplizierte organische Verbindungen, nämlich in Organismenleiber, umgewandelt. In diesem Falle spricht man von Baustoffipechsel.

Die organische Substanz, wie sie als Abfälle auf oder in den Boden gelangt, besteht aus zahlreichen, teils leicht, teils schwer zersetzlichen chemischen Verbindungen. So sind Kohlehydrate (Zucker, Stärke, Zellulose, Hemizellulose, Pektin), ferner Eiweiss und Eiweissderivate leicht zersetzlich, Lignin, Fette, Wachse und Harze dagegen schwer zersetzlich bzw. angreifbar durch Mikroorganismen.

Wenn auch gewisse Abbaustufen nur von ganz bestimmten Mikroorganismen vorgenommen werden, so geschieht der Gesamtabbau der organischen Substanz durch ein Heer verschiedenster Arten von Organismen. Es handelt sich dabei um eine Art Kettenreaktion, um eine Arbeit 
am laufenden Band, wobei eine bestimmte Organismenart die Stoffe zu einem gewissen Punkt verarbeitet und dann das Produkt an andere Arten weiterleitet. Die eine Organismengruppe schafft also erst die Voraussetzung für die Weiterverarbeitung durch die andere. $\mathrm{Zu}$ dieser Tätigkeit benötigen aber die Mikroorganismen genügende Feuchtigkeit.

WITTICH $[s]^{\mathrm{r}}$ ) und andere Forscher bezeichnen nun die Summe der zwischen der Ausgangssubstanz und den mineralischen Endstoffen auftretenden Zwischenprodukte als Humus. Es ist also ein Sammelbegriff für eine ganze Stoffgruppe. Man hat indessen erkannt, dass der Humus nicht nur aus diesen Zwischenprodukten besteht, sondern dass durch komplizierte synthetische Vorgänge, derẹn Natur noch keineswegs abgeklärt ist, neue Stoffe, die sogenannten ecbten Humusstoffe entstehen.

Über die hervorragende Rolle, die der Humus für unsere Böden und für den gesamten Stoffkreislauf des Lebens spielt, brauchen wir hier keine weiteren Worte zu verlieren.

Was wir soeben geschildert haben, waren die natürlichen Vorgänge, wie wir sie in jedem Acker- oder Waldboden antreffen [s].

Der Mensch versucht nun durch das Mittel der Kompostierung von Abfällen diese Verhältnisse in der Natur zu kopieren, sie räumlich und zeitlich zu konzentrieren, ganz ähnlich, wie dies in der Technik der Abwasserreinigung geschieht. Durch die Kompostierung will der Mensch jedoch nicht nur seine Abfälle beseitigen, sondern die in ihnen vorhandenen wertvollen organischen Stoffe verwerten und sie in Humus umwandeln, um diesen wiederum dem Boden zuzuführen, wenn er an ihm verarmt ist.

Da die Zersetzung der organischen Substanz und die Humusbildung in erster Linie ein mikrobiologischer Vorgang ist, brauchen wir also bloss den Mikroorganismen optimale Lebensbedingungen zu schaffen, um den natürlichen Verrottungsvorgang zu beschleunigen. Die wichtigste Voraussetzung für die Tätigkeit dieser Organismen sind neben der geeigneten Nahrung genügende Feuchtigkeit und Luftsauerstoff, denn wir erstreben eine aerobe Zersetzung des Materials, eine Verrottung, nicht eine Fäulnis, erstens, weil die aerobe Zersetzung rascher vor sich geht, zweitens, weil bei der anaeroben Fäulnis giftige Stoffwechselproduktc entstehen und drittens, weil wir eine biogene Wärmeentwicklung wünschen.

Wenn in der Natur organische Substanz abgebaut und verrottet wird, erfolgt in diesem Material eine leichte Temperaturerhöhung als Folge

1) Die Ziffern in eckigen Klammern verweisen auf das Literaturverzeichnis, Seite 134. 
des Betriebsstoffwechsels der Mikroorganismen. Auch Kohlensäure entsteht in diesem Material als Stoffwechselprodukt. Wenn wir aber den Verrottungsvorgang räumlich und zeitlich konzentrieren, wenn wir also die organischen Abfälle auf Haufen aufschichten und kompostieren, entstehen sehr hohe Temperaturen $\left(70^{\circ}\right.$ und mehr), weil dann die biogene Wärme nicht laufend entweicht wie auf einem Acker- oder Waldboden. Dasselbe gilt auch für die Kohlensäure. Es ist jedoch anzunehmen, dass neben der biogenen Wärme auch solche aus rein chemischen, exothermen Prozessen entsteht. Diese hohen Temperaturen, die nur bei der Verrottung, nicht aber bei der Faulung entstehen, sind für unsere Zwecke wertvoll, denn sie gewährleisten eine weitgehende Vernichtung der pathogenen Keime, Wurmeier und Unkrautsamen. Diese Organismen, Eier und Samen werden jedoch nicht nur allein durch die hohen Temperaturen vernichtet, sondern auch durch antibiotisch wirkende Stoffwechselprodukte der Rotteorganismen.

Hingegen muss eine zu starke Temperaturerhöhung vermieden werden, weil dann gewisse Mikrobengruppen absterben und dadurch der Verrottungsvorgang verzögert wird. Während der Kompostierung muss also die Temperatur, die Kohlensäure und der Wassergehalt genau kontrolliert werden. Ein Zuviel und ein Zuwenig ist schädlich.

Noch ein kurzes Wort über den Wassergehalt. Die Mikroorganismen benötigen eine bestimmte Menge Feuchtigkeit für ihre Tätigkeit. Wenn jedoch der Wassergehalt des zu kompostierenden Materials zu hoch ist, besteht die Gefahr, dass die aerobe Verrottung in anaerobe Fäulnis umschlägt. Die Erfahrung hat gezeigt, dass der optimale Wassergehalt um $40-50 \%$ liegt.

\section{Möglichkeiten für den Einsatz von Müllkompost in der Schweiz}

Steht eine Gemeinde vor der Wahl einer geeigneten Müllbeseitigungsmethode, so muss sie sich in erster Linie Rechenschaft ablegen über die Frage des Bedürfnisses nach Müllkompost, dessen Absatz auf alle Fälle gesichert sein muss, es sei denn, dass die Gemeinde selbst den Kompost zur Aufwertung von Ödland, zur Auffüllung von Geländevertiefungen oder für gemeindeeigene Anlagen verwenden will. Dabei darf nicht etwa die Illusion herrschen, mit der Müllbeseitigung sei ein Geschäft zu machen, auch wenn in manchen Gegenden zu gewissen Zeiten der Kompost sehr teuer verkauft werden kann. Im Zusammenhang mit der Bedürfnisfrage steht auch das Transportproblem. Es ist nicht damit getan, einen preis- 
lich günstigen, guten Müllkompost herzustellen, er muss auch in die Verbrauchergebiete transportiert werden. Die Transportkosten spielen daher ebenfalls eine wesentliche Rolle bei der Wahl eines Verfahrens. Als Verbraucher des Müllkompostes kommen in der Schweiz vorläufig wohl in erster Linie Gartenbaubetriebe in Betracht, also Handels- und Gemüsegärtnereien, sowie die grosse Zahl privater Gartenbesitzer. Da durch den immer deutlicher werdenden Rückgang der Pferdehaltung der Pferdemist zu einer Mangelware und dementsprechend teuer geworden ist, wird inskünftig als dessen Ersatz der Müllkompost immer mehr an Bedeutung gewinnen. Für den Gartenbau ist der Müllkompost wertvoll als Wärmespender für Frühbeetkästen und als Humusdünger bzw. Bodenverbesserungsmittel. Für die Verwendung als Wärmepackung darf der Kompost jedoch nicht verrottet sein, damit die durch die biologische Zersetzung der organischen Substanz entstehende Wärme ausgenutzt werden kann. Für die Verwendung im Freiland muss jedoch der Kompost «reif», das heisst gut verrottet sein, damit er seine Aufgabe als organischer Dünger erfüllen kann. Der Kompost soll in erster Linie die physikalischen und biologischen Eigenschaften des Bodens verbessern, ihn aufnahmefähiger machen für Wasser, Luft, Wärme und Pflanzennährstoffe, und günstige Lebensbedingungen für die Bodenorganismen schaffen. Neuere Untersuchungen lassen vermuten, dass manche Pflanzen durch die Behandlung mit Kompost widerstandsfähiger gegen gewisse bodengebundene Krankheiten werden.

Im Zusammenhang mit der Verwendung des Müllkompostes im Gartenund Gemüsebau seien auch einige Ergebnisse einer Fragebogenaktion erwähnt, welche unsere Anstalt in Zusammenarbeit mit der Gemüseproduzenten-Vereinigung des Kantons Zürich im Frühjahr 1956 durchgeführt hat. An die Kreise der Gemüseproduzenten und Handelsgärtnereien sowie an private Bezüger von Dano-Kompost aus den Müllverwertungsanlagen Küsnacht und Rüschlikon wurden Fragebogen verschickt, um Aufschluss zu erhalten über die Anforderungen, die Gärtner an einen guten Kompost stellen, welche Mängel an diesem Kompost beanstandet werden und welche Erfahrungen bisher mit dem aus den erwähnten Anlagen bezogenen Müllkompost gemacht wurden. So machten zum Beispiel von den Kompostbezügern der Anlage Rüschlikon $85 \%$ mit dem Material gute bis ausgezeichnete Erfahrungen. I5\% waren unzufrieden. Auf die Beanstandungen und die Forderungen, die die Praxis an einen guten Müllkompost stellt, kommen wir später zurück. Etwa $60 \%$ der Befragten verwenden den Kompost nur als Dünger im Freiland, $15 \%$ nur als Wärme- 
spender für Frühbeetkästen und $25 \%$ universell für Wärmepackung und Freilanddünger. Bei der letzteren Verwendung überwiegt bei weitem diejenige für den Gemüsebau, die Beerenkulturen, Blumen- und Staudenkulturen. Zahlreiche Bezüger vermissen eine Art Wegleitung für den Gebrauch von Kompost. Wir sind überzeugt, dass mancher Misserfolg hätte vermieden werden können, wenn die richtige Verwendungsmethode bekannt gewesen wäre. Auf die Frage, ob die Herstellung von gutem Müllkompost gefördert werden sollte, haben mehr als $99 \%$ der Befragten mit Ja geantwortet.

Auch für den Plantagen-Obstbau kommt die Verwendung von Müllkompost in Frage, namentlich in Gebicten mit geringen Niederschlägen. Dort müssen die Böden in den geschlossenen Buschobstanlagen ständig offengehalten werden, damit die Bodenfeuchtigkeit für die Bäume nutzbar gemacht werden kann. In solchen Fällen vermag der Müllkompost durch seine wasserhaltende Kraft gute Dienste zu leisten.

Im Weinbau wird voraussichtlich auch in der Schweiz der Müllkompost Verwendung finden, namentlich, seit die rojährigen, ausgezeichneten Erfahrungen der Staatlichen Lehr- und Versuchsanstalt für Wein- und Obstbau in Weinsberg (Deutschland) bekanntgeworden sind [2]. Namentlich im Weinbau ist die Frage der Humuszufuhr besonders aktuell. Durch die ständige Bodenbearbeitung, vor allem in den steileren, der Sonnenstrahlung stark ausgesetzten Lagen, erfolgt ein rascher Humusabbau, der jedoch nicht kompensiert wird durch Wurzelrückstände im Boden, wie dies zum Beispiel beim Ackerbau in der Fruchtfolgewirtschaft der Fall ist. Humusarme Böden verkrusten aber leicht, ihre Wasseraufnahmefähigkeit wird vermindert, was zu starken Abschwemmschäden führt. Die günstigen Eigenschaften eines gut mit Müllkompost versorgten Rebgeländes konnte KLENK (Weinsberg) wiederholt mit Versuchen schlagend beweisen, wo in einer Steillage ( $50 \%$ Steigung) zwei benachbarte Parzellen einmal mit Stallmist, im Vergleich dazu mit Müllkompost gedüngt wurden. Während die mit Stallmist geduingte Parzelle nach mehreren starken Platzregen jeweils tiefe, durch Abschwemmung des Feinmaterials verursachte Wasserfurchen aufwies, zeigten sich bei dem mit Müllkompost behandelten Teilstück keinerlei Abschwemmschäden. Müllkompost hat also in dieser Beziehung noch bessere Eigenschaften als Stallmist. Auf Grund dieser Erfahrungen war es möglich, eine mit mehreren kleinen Terrassen versehene Steillage ( $50 \%$ Steigung) so umzugestalten, dass die Mauern beseitigt und dadurch das ganze Gelände maschinell bearbeitet werden konnte, was sich erheblich verbilligend auf die Gestehungskosten des Weinbaus aus- 
wirkte. Die Vorteile bei der Kompostanwendung zur Verhinderung der Bodenabschwemmung lassen heute Möglichkeiten $z u$, an die man früher nicht zu denken wagte und die vermutlich auch im schweizerischen Weinbau ihre Bedeutung haben werden. Aber nicht nur die günstige Beeinflussung des Wasserhaushaltes durch den Kompost konnte bei den Versuchen in Weinsberg gezeigt werden. Auch die günstige Beeinflussung des Wärmehaushaltes der bodennahen Luftschichten ist ein weiterer Vorteil. So zeigte sich dort allgemein in den mit Kompost behandelten Anlagen eine bessere Reife und Gesundheit der Trauben, wodurch die Weinlese weiter hinausgeschoben werden konnte. Die Ernteergebnisse zeigten nicht nur cine beträchtliche Mengensteigerung in der Kompostparzelle, sondern ebenso auch eine Gütesteigerung.

Es ist schon lange bekannt, dass ein gut mit Humus versorgter Boden auch den Wirkungsgrad der mineralischen Düngung zu erhöhen vermag. Dadurch ist es möglich, die mineralische Nährstoffzufuhr erheblich zu steigern, ohne dass dann die bekannten Wachstums- und Ertragsdepressionen eintreten [I]. Die im Müllkompost mitgelieferten mineralischen Nährstoffe interessieren dabei weniger, denn diese können billiger in Form von Handelsdünger gekauft werden.

Obschon sich die Verhältnisse in Weinsberg nicht ohne weiteres mit den unsrigen vergleichen lassen, namentlich was die Art der Böden anbelangt, so ist es doch dringend erforderlich, dass auch bei uns diesbezügliche Versuche angestellt werden. Dies nicht nur im Hinblick auf den Weinbau, sondern auch, um Absatzmöglichkeiten für den Müllkompost zu schaffen.

Im $W$ aldbau ist in der Schweiz der Bedarf an Kompost gross, in erster Linie für die Forstgärten (Forstbaumschulen). Sehr häufig sind die dafür in Betracht kommenden Böden tonreich und humusarm. Solche Böden, wie bereits erwähnt, verkrusten leicht und wirken daher hemmend auf die Entwicklung der Saaten und die gewünschte Ausbildung von Ballenwurzeln, ausserdem sind sic schwer zu bearbeiten. Eine Verbesserung der Forstgartenböden ist also nur durch ständige Humusgaben zu erreichen, was entweder in Form von Müllkompost oder von im Walde selbst anfallenden kompostierten Abfällen (Laub, Tannenreisig usw.) geschehen könnte. Zur Strukturverbesserung dieser Forstgärten ist ein ständiger Humusnachschub notwendig, nicht nur weil der Kompost weiter abgebaut wird, sondern auch weil beim Verpflanzen eine beträchtliche Menge Humus durch Anhaften an den Wurzelballen aus dem Boden entfernt wird. Die Verrottung der Waldabfälle allein dauert jedoch infolge ihrer einseitigen Zusammensetzung und oft ungenügenden Bearbeitung sehr lange Zeit 
(2-3 Jahre). Unsere Anstalt führt in Zusammenarbeit mit der Eidgenössischen Anstalt für das forstliche Versuchswesen Untersuchungen durch, um die Frage der gemeinsamen Kompostierung von Müll und Waldabfällen abzuklären. Dadurch kann voraussichtlich die Verrottungszeit bedeutend verkürzt und ein neues Absatzgebict für Müllkompost geschaffen werden. Nach Mitteilung der forstlichen Versuchsanstalt ist heute schon mit einem jährlichen Kompostbedarf für die ganze Schweiz von etwa $40000 \mathrm{~m}^{3}$, in Zukunft aber von 80000 bis $100000 \mathrm{~m}^{3} \mathrm{zu}$ rechnen. Unsere schweizerische Waldwirtschaft ist also an weiteren Quellen für die Beschaffung von Kompostmaterial sehr interessiert.

Für die Verwendung in der Landwirtschaft spielt in der Schweiz der Müllkompost eine untergeordnete Rolle, im Gegensatz etwa zu Holland und gewissen Teilen Deutschlands. Die Humusversorgung der landwirtschaftlich genutzten Böden in der Schweiz ist, nach Ansicht unserer landwirtschaftlichen Sachverständigen, im allgemeinen gut, besonders in ausgesprochenen Graswirtschaftsgebieten, und wird durch die gemischten Landwirtschaftsbetriebe mit ihrem Anfall an Stallmist und Jauche sichergestellt. Von landwirtschaftlicher Seite aus kann also in der Schweiz, wenigstens heute noch, nicht mit einem nennenswerten Kompostverbrauch gerechnet werden.

Auf die namentlich im Ausland gemachten Erfahrungen mit der Anwendung von Müllkompost im Gartenbau, Obst- und Weinbau, in der Waldwirtschaft und Landwirtschaft, treten wir hier nicht näher ein, sondern verweisen auf die in der Schweizerischen Zeitschrift für Hydrologie [4] gedruckten Vorträge des Internationalen Kehrichtsymposiums in Zürich aus dem Jahre I95S sowie auf das periodisch erscheinende Informationsblatt der Internationalen Arbeitsgemeinschaft für Müllforschung.

\section{Die Vorteile einer gemeinsamen Aufarbeitung von Müll} und Klärschlamm

Im Interesse der Reinhaltung unserer Gewässer werden immer mehr Kläranlagen gebaut. Der in den Kläranlagen anfallende Schlamm muss weggeführt und möglichst nutzbringend wieder verwendet werden. Sind in einem bestimmten Gebiet nur ganz vereinzelt Kläranlagen im Betrieb, das heisst, verfügt eine Anlage bezüglich des Klärschlammabsatzes über ein sehr grosses «Hinterland», so werden vorerst kaum Schwierigkeiten auftreten. Die Anforderungen an den Klärschlamm steigen aber sicher Hand in Hand mit der Zunahme des Angebotes. Je mehr Kläranlagen in 
Betrieb kommen, desto grösser wird auch der Klärschlammanfall, und es kann ein ernsthaftes Problem bezüglich der sinngemässen Verwendung dieser Schlammengen entstehen. Das im Jahre 1955 in Kraft gesetzte Schweizerische Milchlieferungsregulativ sieht in der Verwendung von Klärschlamm zu Düngzwecken bestimmte Einschränkungen vor, indem während der Vegetationsperiode kein Klärschlamm auf Wiesland ausgebracht werden darf. Zur Zeit sind Untersuchungen im Gange, ob und wie weit die Verwendung von Klärschlamm auf die Milch- und Käsewirtschaft wirklich von schädlichem Einfluss ist. Bis heute sind diese angeblichen Schäden keineswegs bewiesen worden.

Nun wird die Abgabe von Klärschlamm an die Landwirtschaft nicht nur durch das Milchlieferungsregulativ erschwert. Auch die nassen Sommer der letzten Jahre haben die Verwendung von ausgefaultem Schlamm beeinträchtigt, indem die Wiesenböden auch ohne Begüllung schon zu nass waren. So zeigten sich zum Beispiel in der Kläranlage Winterthur (nach Mitteilung von Herrn Klärmeister MÜLLER) im Sommer I956 grosse Schwierigkeiten im Absatz flüssigen Klärschlamms. Die Bauern konnten infolge der Witterungsverhältnisse nicht einmal ihre eigene Gülle verführen. Mit Hilfe eines Schlammeindickers (Rüttelsieb) wurde jedoch der Schlamm in stichfeste Form gebracht, womit die Absatzschwierigkeiten behoben waren.

Diese sich immer mehr zeigenden Absatzhemmungen für den Klärschlamm sowie auch Überlegungen hygienischer Art haben im Verlauf der letzten Jahre dazu geführt, dass eine gemeinsame Aufarbeitung fester und flïsiger Abfallstoffe angestrebt werden sollte, sei es, dass der Klärschlamm in einen brennbaren Zustand gebracht und zusammen mit Müll verbrannt. wird oder dass der Klärschlamm gemeinsam mit dem Müll zu Kompost verarbeitet wird.

Dadurch, dass der Klärschlamm mit Hilfe der gemeinsamen Komposticrung mit Müll eine mehrere Wochen lang anhaltende Temperatur über 5o Grad durchläuft, werden pathogene Keime, Wurmeier und Unkrautsamen weitgehend unschädlich gemacht, was bei der gewöhnlichen Schlammfaulung bekanntlich nicht der Fall ist.

Ein weiterer Vorteil der Klärschlammbeigabe liegt auf dem Sektor der Kernnährstoffe, vielleicht auch der Spurenelemente, Hormone, Vitamine usw. Es ist bekannt, dass dem Stickstoff eine überragende Rolle als Düngerelement zufällt. Man verlangt Kompost oder andere organische Dünger mit hohem Stickstoffgehalt. Wenn nun das organische zu kompostierende Material sehr wenig Stickstoff und viel Kohlenstoff enthält, wie 
zum Beispiel beim Wintermüll, wenn mit anderen Worten das $\mathrm{C} / \mathrm{N}-$ Verhältnis weit ist, dann wird nicht nur der daraus entstehende Kompost sehr arm an Stickstoff und kann bei der Verwendung im Boden sogar eine Stickstoff-Festlegung herbeiführen, sondern der Kompostierungsvorgang selbst wird verzögert, auch wenn die sonstigen Lebensbedingungen für die Mikroorganismen günstig sind, denn diese benötigen Stickstoff, den sie dann in ihrem Körper im Eiweiss ablagern. Der Stickstoff stellt sozusagen den Betriebsstoff dar, der, je nach der Menge, in der er vorhanden ist, den Verlauf der Kompostierung beschleunigt. Im allgemeinen ist im Rohmüll wenig Stickstoff vorhanden. Die Beimischung des stickstoff- und phosphorreichen Klärschlammes ist also auch in dieser Beziehung vorteilhaft, und der daraus entstehende Kompost ist, das haben Versuche im Ausland genügend bewiesen, qualitativ besser als der gewöhnliche Müllkompost.

\section{Zweiter Teil}

\section{Versuche über die gemeinsame Verrottung von Müll und Klär- schlamm in der Dano-Anlage in Rüschlikon}

\section{A. Allgemeines}

Auf Grund einer Anregung und von Vorschlägen seitens der Gemeinde Horgen vom März I955 griff die Abteilung für Wasserbau und Wasserrecht des Kantons Zürich die Frage der gemeinsamen Aufarbeitung von Müll und Klärschlamm auf, um im Zusammenhang mit anderen Studien der Müllbeseitigung am linken Zürichseeufer weitere Unterlagen zu haben. Da in Rüschlikon eine neue Müllaufbereitungsanlage erstellt worden war, in welcher eine gemeinsame Verarbeitung von Müll und Klärschlamm prinzipiell möglich erschien, war es naheliegend, diese Versuche in der Dano-Anlage. Rüschlikon durchzuführen.

Sobald die mutmasslichen Kosten für diese Müll-Klärschlamm-Versuche überblickt werden konnten, wurde mit einigen Kantonen, für welche das Müll-Klärschlamm-Problem ebenfalls sehr aktuell ist, Fühlung aufgenommen, und es hatten sich dann in der Folge die fünf Kantone Zürich, Aargau, Bern, Thurgau und St. Gallen bereit erklärt, einen bestimmten Kostenbeitrag für diese Versuchsreihen zu leisten. Der Beitrag der EAWAG sollte in Form kostenloser Mitarbeit ihres Personals erfolgen. Am 4. November I955 wurden durch die EAWAG die verschiedenen 
Vertreter der Kantone, der Gemeinden, der Eidgenössischen Versuchsanstalten Wädenswil, Oerlikon und Bern-Liebefeld sowie die am Problem interessierten wissenschaftlichen Institute zu einer ersten Gesamtsitzung eingeladen. Nach der Konstituierung ciner Grossen Kommission, bestehend aus den anwesenden Vertretern und teilweise noch weiteren Mitgliedern (Präsident: Herr Prof. Dr. O. JAAG) und einer Betriebskommission, welche die Versuche durchführen sollte, wurde das von der EAWAG aufgestellte Rahmenprogramm für die Versuche genehmigt.

\section{B. Versuchsprogramm}

Das Versuchsprogramm, aus Abbildung I ersichtlich, ist in zwei Hauptgruppen aufgeteilt, nämlich in

I. Tecbniscbe Versucbe in der Dano-Anlage in Rüschlikon.

2. Pflanzpersucbe in den Eidgenössischen Versuchsanstalten sowie in Gärtnereibetrieben.

Im vorliegenden Bericht sind nur die technischen Versuche beschrieben. In einem späteren Bericht sollen die Resultate der Pflanzversuche bekanntgegeben werden.

$\mathrm{Da}$ in erreichbarer Nähe kein Klärschlamm aus einer mechanisch-biologischen Anlage zur Verfügung stand, mussten die Versuche auf die Beimischung von Klärschlamm der mechanischen Anlagen Werdhölzli-Zürich und Winterthur beschränkt werden. Somit standen uns die folgenden Ausgangskomponenten zur Verfügung:

I. Müll der Gemeinden Rüschlikon und Kilchberg.

2. Ausgefaulter Schlamm der mechanischen Kläranlage Werdhölzli-Zürich.

3. Ausgefaulter und frischer Schlamm der mechanischen Kläranlage der Stadt Winterthur, eingedickt mit dem dortigen Vibrationseindicker auf einen bestimmten Wassergehalt.

Die in Rüschlikon durchzuführenden Versuche sollten folgende Fragen abklären:

I. Kann bei der Müllvergärung in einer Gärtrommel anstelle der gewohnten Wasserzugabe, welche zur Erreichung der optimalen Feuchtigkeit für den Gärprozess notwendig ist, auch Klärschlamm beigegeben werden? Wenn ja, kann der Wassergehalt des Klärschlammes durch Eindickung so herabgesetzt werden, dass möglichst ein Äquivalent zwischen dem Müllanfall und dem Klärschlammanfall desselben Einzugsgebietes entsteht? 
I TECHNISCHE VERSUCHE:

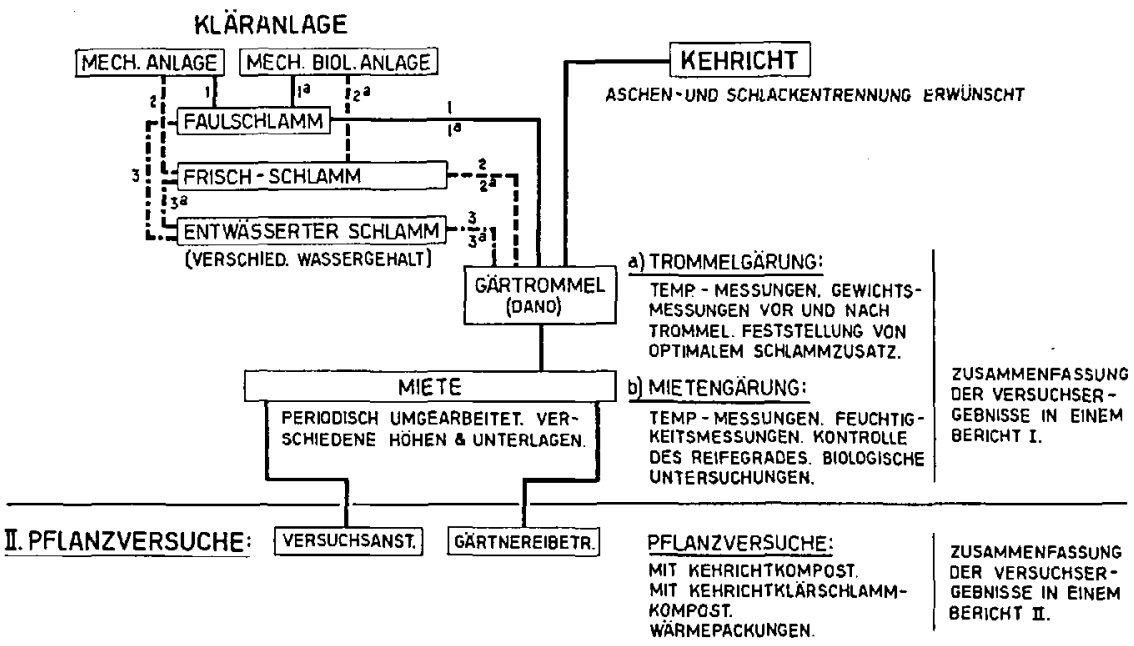

Abbildung 1

Schema der Versuche.

a) Wieviel Klärschlamm kann man dem Müll beimischen und in der Gärtrommel verarbeiten, ohne dass Störungen im Betrieb entstehen?

b) In welcher Form und Konzentration (uneingedickt, eingedickt, ausgefault oder frisch) soll der Klärschlamm beigegeben werden, ohne dass Störungen im Betrieb entstehen und dass das Müll-SchlammMaterial in der Trommel homogen und ohne Verpappung gemischt wird?

c) Welches ist die geeignetste Art der Zugabe des Klärschlammes in die Trommel?

2. Wie kann das Produkt aus dieser Gärtrommel in einen für die verschiedenen Zwecke brauchbaren Kompost übergeführt werden?

a) Welche Form und welche Höhe soll die Miete besitzen, in der das Kompostmaterial aus der Gärtrommel im Freien verrottet wird? Soll sie etappenweise mit zeitlichen Unterbrüchen aufgeschichtet werden oder bereits beim ersten Schub auf die endgültige Höhe?

b) Welches ist die günstigste Mietenunterlage (gelochter Betonboden, gestampfter Kiesboden oder Natur- bzw. Humusboden)? 
c) Kann durch Bestimmung der Kohlensäure und der Temperatur im Innern der Miete der Gang der Verrottung überprüft werden?

d) Ist die Durchlüftung der Miete genügend oder muss das Material während der Verrottung umgearbeitet werden? Wie wirkt sich die Umarbeitung aus auf die Verrottung?

e) Welchen Einfluss übt der Regen aus auf die Verrottung? Müssen die Mieten eventuell zeitweise bedeckt, das heisst vor Regen geschützt werden?

f) Wie lange muss die Verrottung durchgeführt werden? Besteht die Möglichkeit, die Verrottungszeit zu verkürzen? Gibt es Anhaltspunkte, den Reifegrad des Kompostes zu bestimmen?

3. Welches sind die Qualitäten dieses Müll-Klärschlamm-Kompostes, und wie unterscheidet er sich vom gewöhnlichen Müllkompost?

a) Ist eine Verunkrautung des Kompostes infolge Beimischung von Klärschlamm zu erwarten?

b) Ist eine Vernichtung der Wurmeier und pathogenen Keime durch die Vorgänge in der Trommiel und die Nachgärung in den Mieten gewährleistet?

c) Kann ein wesentlicher Unterschied festgestellt werden zwischen Müllkompost und Müll-Klärschlamm-Kompost

in chemischer Hinsicht?

in bezug auf das Pflanzenwachstum?

d) Wie soll der Kompost bewertet werden?

\section{Beschreibung der Versuchsanlage}

In Abbildung 2 ist die Versuchsanlage schematisch dargestellt: Der anfallende Müll gelangt vorerst in einen Silo und wird von hier durch ein Förderband in die Gärtrommel transportiert. Der eingedickte Schlamm wird im Silo dem Müll beigegeben. Der pumpfähige, nicht eingedickte Schlamm hingegen gelangt in die Schneckenkammer der Gärtrommel, und zwar an derselben Stelle, wo beim Normalbetrieb ohne Klärschlamm das Wasser zugegeben wird. Das Müll-Klärschlamm-Gemisch verbleibt nun 4-5 Tage in der stets langsam rotierenden Gärtrommel, welche mittels einer Ventilationsanlage die für die aerobe Gärung optimale Luftmenge erhält. Beim Austritt des Rohkompostes führt ein Förderband das Material über einen Elektromagneten, welcher die Eisenteile ausscheidet, sowie 
auf eine Rüttelsiebanlage, welche den feinen Rohkompost vom groben Rohkompost absondert. Eine spezielle Einrichtung entfernt einen wesentlichen Anteil der Scherben. Der feine Rohkompost gelangt auf die Mieten und macht nach der Vorgärung in der Trommel hier im Freien die mehrere Monate andauernde Hauptgärung durch.

Der grobe Siebrest gelangt je nach der Zusammensetzung entweder in den Ofen, wenn es sich um brennbare Anteile handelt, oder nochmals in die Gärtrommel, wenn es sich um etwas schwer kompostierbare Anteile handelt. Anorganische und nicht brennbare Anteile werden auf der Deponie abgelagert. Die Eisenteile (Büchsen, Nägel, Schrauben usw.) gelangen in eine Metallpresse und werden in Form von Metallpaketen einem Altstoffhändler zu bescheidenem Preis verkauft.

\section{Die Durchführung der Versuche}

Noch im Dezember I955 konnte mit der Herrichtung der Mietenplätze begonnen sowie die Installationsarbeiten für die Mischeinrichtungen in Auftrag gegeben werden. Anfangs Februar 1956 erfolgten die Installationen der Klärschlammbehälter sowie der Pumpeinrichtungen, und am 9. Februar konnte mit den ersten Pumpversuchen begonnen werden. Die bald darauf einsetzende abnorme Kälte zwang aber die Betriebskommission, die Versuche vorläufig abzubrechen. Da sämtliche Installationen nur behelfsmässig eingerichtet waren und zum Beispiel der Klärschlamm in grossen, offenen Behältern im Freien deponiert war, trat teilweise an den exponierten Stellen eine starke Vereisung ein, dic den weiteren Betrieb der Schlammbeigabe blockierte.

Um für die eigentlichen Grossversuche Anhaltspunkte bezüglich der zulässigen Klärschlammengen zu crhalten, wurden vorerst am 27. April 1956 die sogenannten Tastpersuche eingeleitet sowie die ersten Versuche mit der Anordnung und Form der Kompostmieten durchgeführt.

Nach der entsprechenden Auswertung der Erfahrungen aus den Tastversuchen begann am I I. Juni I956 der erste Grossversucb mit ausgefaultem eingedicktem Klärschlamm der Kläranlage Winterthur. Im Anschluss daran begann am 2.Juli I956 der zweite Grossversuch mit nicht eingedicktem, ausgefaultem Klärschlamm der Kläranlage Werdhölzli, und schliesslich wurde am I3. September 1956 der dritte Grossversuch mit eingedicktem Frischschlamm der Kläranlage Winterthur begonnen. 


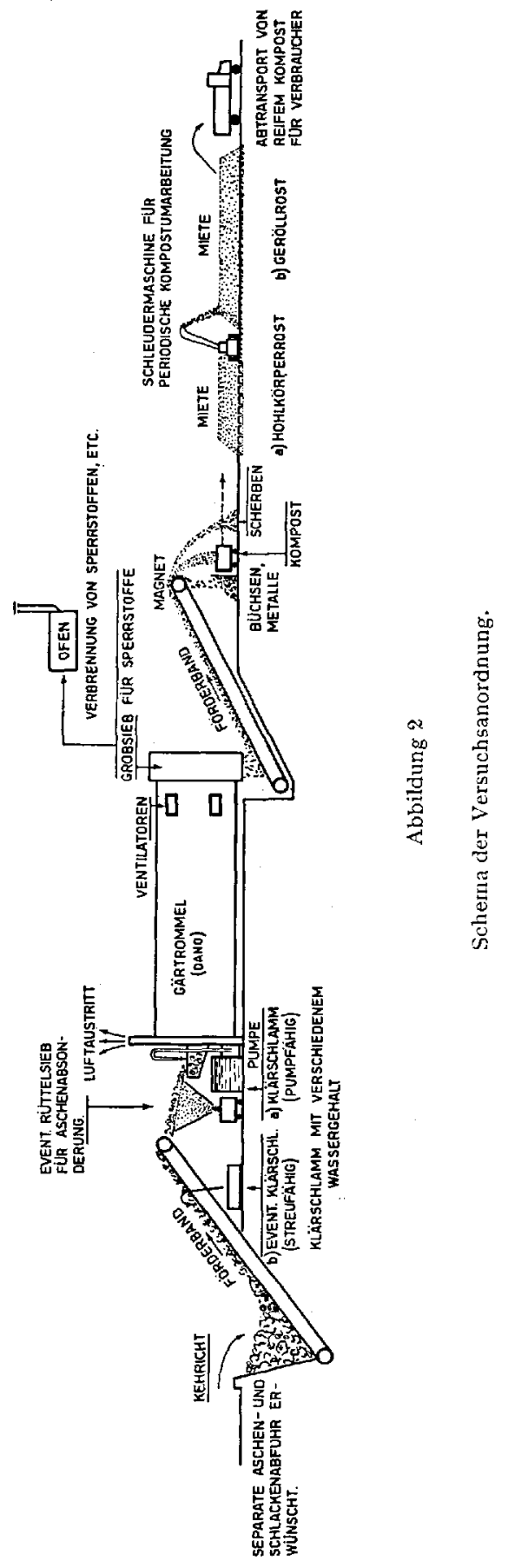




\section{Installationsarbeiten}

a) Klärscblammbeimiscbung Für die Beigabe von nicht eingedicktem Klärschlamm mussten Behälter mit einem Totalvolumen von etwa $5 \mathrm{~m}^{3}$ installiert werden (siehe Abbildung I5). Mit einer Pumpe sollte der Klärschlamm von diesen Behältern in die Gärtrommel eingeführt werden. Gemäss Plan war vorgesehen, den pumpfähigen Klärschlamm zwischen dem Förderband und der Gärtrommel, das heisst in der sogenannten Schneckenkammer, beizugeben. Vorerst wurde aber nach einem anderen Vorschlag der Klärschlamm direkt in die Trommel eingespritzt, und zwar an der jeweils von Müll freien Stelle. Infolge der Drehung der Trommel und des dadurch entstehenden Umwälzens des Trommelinhaltes zeigt sich diese müllfreie Stelle im oberen Drittel und auf der Seite.

Um nun auch über die Grössenordnung der beigegebenen Klärschlammmengen orientiert zu sein, wurde die Absenkung im Klärschlammbehälter pro Zeiteinheit während des Pumpbetriebes festgestellt und der Klärschlamm in einzelnen Intervallen mittels Pumpstössen dem Müll beigegeben.

Es zeigte sich in der Folge bald, dass Schwierigkeiten im Pumpsystem entstanden, indem sich Verstopfungen und Brückenbildungen in der Druckleitung und an den Düsen zeigten. Für die weiteren Versuche mit Klärschlamm wurde auf Grund dieser Erfahrungen die Installation in dem Sinne abgeändert, dass der Klärschlamm in einen über der Gärtrommel montierten Ausgleichsbehälter gepumpt wurde. Von hier aus gelangte der Klärschlamm in freiem Gefälle in den Einfülltrichter bzw. Schneckenraum der Gärtrommel. Mit einem einfachen mechanischen Schieber konnte die Klärschlammbeigabe dosiert und die Absenkung im Ausgleichsbehälter anhand einer einfachen, vollständig aus Müllabfallstoffen konstruierten Schwimmerübertragung abgelesen werden (siehe Abbildung 16). Diese Installationsanordnung bewährte sich in der Folge sowohl für ausgefaulten Klärschlamm wie auch für das Filtrat aus der Eindickungsanlage der Kläranlage Winterthur.

Für die Beigabe des eingedickten Klärschlammes mussten keine separaten Installationen vorgenommen werden, indem diese Schlammkomponente unmittelbar neben dem Müllsilo deponiert und im Schaufelwurf dosiert dem Müll beim Beginn des Förderbandes beigemischt werden konnte (siehe Abbildung I7).

b) Mietenplätze: Zur Abklärung der optimalen Bedingungen für die Mietenplätze wurden drei Varianten in Aussicht genommen, nämlich 
Mietenplatz mit gelochten Betonelementen (siehe Abbildung I8),

Mietenplatz mit einer Kiesunterlage von Io-I $5 \mathrm{~cm}$ Stärke,

Mietenplatz auf Naturboden, das heisst nicht weiter vorbereitetem Humusboden.

Bei den ersten Grossversuchen wurden jeweils die Mieten auf alle drei Unterlagen aufgeschichtet. Beim dritten Grossversuch wurden dann die Erfahrungen bezïglich der Mietenunterlagen in Anwendung gebracht und nur noch eine Miete auf Humusboden erstellt.

\section{Tast-Versuche}

Wir erstellten auf dem durchlöcherten Betonboden 5 Versuchsmieten von $60 \mathrm{~cm}$ Höhe, I, $5 \mathrm{~m}$ Breite und rund $5 \mathrm{~m}$ Länge. Diese Mieten besassen im Querschnitt dreieckige Form und enthielten folgendes Material (siche auch Tabelle I und Abbildungen I9 und 20):

Miete A: Gewöhnlicher Müllkompost ohne Klärschlamm, wie er beim Normalbetrieb der Anlage anfällt.

Miete B: Kompost aus der Mischung Müll+Klärschlamm aus der Anlage Wcrdhölzli mit einem Wassergehalt von $86 \%$, im Gewichtsverhältnis $5: \mathrm{I}$.

Miete C: Kompost aus der Mischung Müll + Klärschlamm aus der Anlage Werdhölzli mit einem Wassergehalt von $86 \%$, im Gewichtsverhältnis $4: \mathrm{I}$.

Miete D: Eingedickter Klärschlamm von Winterthur mit $65 \%$ Wassergehalt, ohne Müll.

Miete E: Kompost aus der Mischung Müll+eingedicktem Klärschlamm aus Winterthur mit einem Wassergehalt von $65 \%$, im Gewichtsverhältnis $2: \mathrm{I}$.

Das Material jeder dieser Mieten, mit Ausnahme der Miete D, wurde jeweils 5 Tage in der Gärtrommel behandelt.

\section{Beobacbtungen und Scblussfolgerungen}

Der gewöhnliche Müllkompost (Miete A) wies bei der Entnahme aus der Gärtrommel einen Wassergehalt von $26 \%$ auf. Periodisch durchgeführte Wassergehaltsbestimmungen des Kompostes aus dem Normalbetrieb der Anlage zeigten meistens einen Wassergehalt zwischen 25 und 
$30 \%$. Nach in- und ausländischen Erfahrungen wissen wir, dass der optimale Wassergehalt des zu kompostierenden Materials um 40-50\% herum liegt. Es wurde also beim Nornalbetricb der Anlage zu wenig Wasser zugegeben.

Der Kompost aus der Mischung Müll/Klärschlamm im Verhältnis 5:I (Miete B) war bei der Entnahme aus der Gärtrommel ebenfalls zu trocken (I $8 \%$ Wassergehalt). Das Material der übrigen Mieten wies einen normalen Wassergehalt von $40-4 \mathrm{I} \%$ auf.

Wenn wir den Gang der Temperatur in den verschiedenen Mieten verfolgen (siehe graphische Darstellung in Abbildung 3), so fällt uns auf, dass sich das Kompostmaterial im Innern in den ersten 1o-20 Tagen bis auf eine Temperatur von $60^{\circ}$ erwärmte. Aber diese hohen Temperaturen hielten sich nur ganz kurze Zeit! Nach wenigen Tagen sanken sie wieder $\mathrm{ab}$ auf $20-30^{\circ}$. Immerhin hat es den Anschein, dass durch die Beimischung von Klärschlamm die biologische Aktivität in den Mieten gesteigert wird, denn wir konnten beobachten, dass das Temperaturmaximum in kürzerer Zeit erreicht wurde, je grösser der Anteil an Klärschlamm war. Wir dürfen jedoch daraus keine zu weitgehenden Schlussfolgerungen ziehen, denn diesen Tastversuchen haftete noch cin schr grosser Unsicherheitsfaktor an, auf den wir weiter unten zu sprechen kommen.

Der Verlauf dieser Temperaturkurven deutet uns an, dass der Verrottungsvorgang im Innern der Miete nicht einwandfrei vor sich gegangen ist. Die erhöhten Temperaturen sollten viel längere Zeit andauern, schon allein aus hygienischen Gründen (Vernichtung der Unkrautsamen und Wurmeier). Die Kurven zeigen uns auch, dass die Lebensgemeinschaft der Rotteorganismen irgendwie gestört worden ist.

Wir schnitten daher die Mieten auf und untersuchten das Material (siehe Abbildung 20). Es war im Innern vollkommen ausgetrocknet, nur die Oberfläche bis in eine Tiefe von rund Io $\mathrm{cm}$ wies einen genügenden Feuchtigkeitsgehalt auf. Hingegen war die auf dem Betonboden aufliegende Unterseite der Mieten vollkommen nass und pappig. Offenbar bildete sich in der Berührungsschicht des Kompostes mit dem Betonboden Kondenswasser.

Die Ursache der viel zu kurz andauernden hohen Temperaturen lag also in einer weitgehenden Austrocknung des Kompostmaterials. Dadurch fehlte den Rotteorganismen die notwendige Feuchtigkeit, weshalb sie ihre Tätigkeit einstellten, was das Absinken der Temperatur zur Folge hatte.

Diese Mietenform schien uns daher ungünstig zu sein. Obschon der Sommer 1956 sehr feucht und reich an Niederschlägen war, trocknete das 


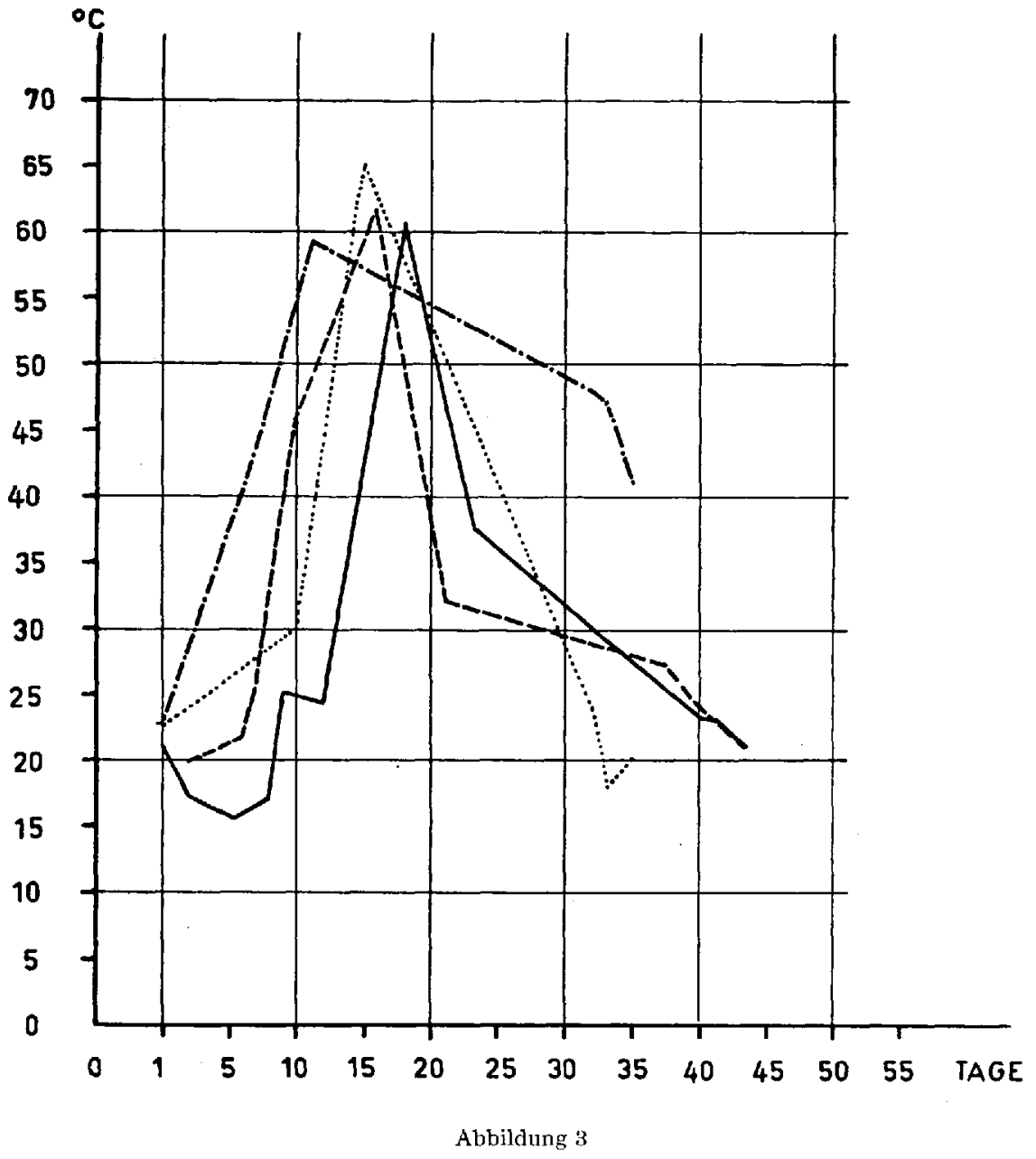

Tast-Versuche.

Mieten-Temperaturen: Dreieckige Form der Mieten: Höhe 0,60 m; Breite 1,50 m; Länge etwa $5 \mathrm{~m}$.

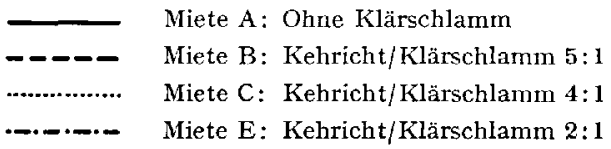




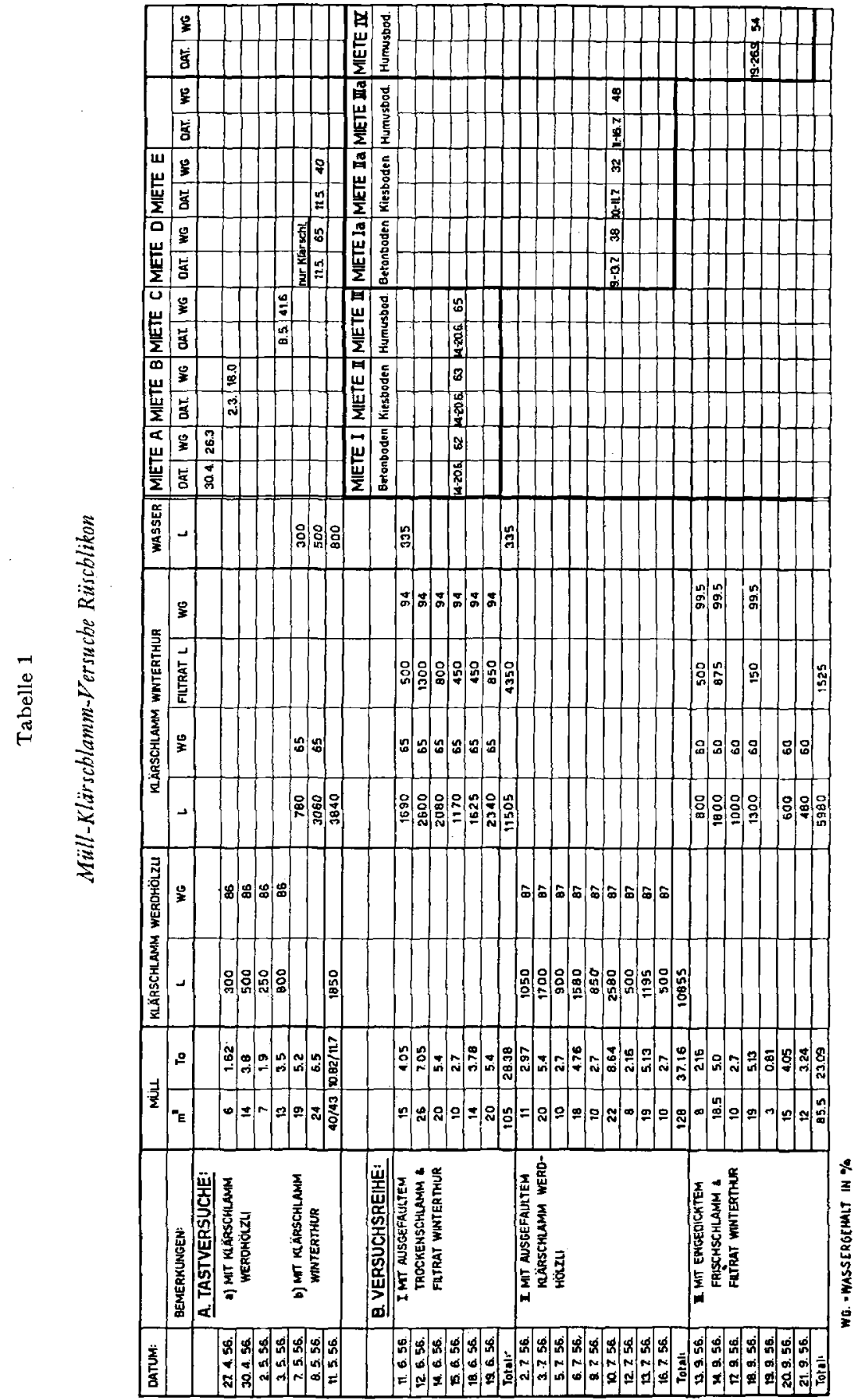


Material aus, das heisst, das Regenwasser floss oberflächlich an den Mieten $\mathrm{ab}$, nur die obersten $10 \mathrm{~cm}$ wurden genügend befeuchtet. Wir entschlossen uns daher, bei den Grossversuchen die Mietenform anders zu wählen, und zwar derart, dass das Regenwasser besser ausgenützt werden kann.

Die wichtigste Erkenntnis aus diesen Vorversuchen war dic, dass dic normalerweise 5 Tage dauernde Aufenthaltszeit des Müllmaterials in der Gärtrommel absolut unsicher ist. Wir markierten den Rohmüll bei der Zugabe in die Trommel mit verschiedenen Gegenständen, wie Gummibettflaschen, Ziegelsteinen, bunten Tüchern usw., also mit Material von verschiedener Form und verschiedenem Gewicht. Die einen Markierungsmerkmale erschienen bereits nach 24 Stunden, andere wiederum nach 3, 4 und 5 Tagen am Ende der Trommel. Wir mussten daher unsere Versuchsanordnung umstellen. Um sicher zu sein, wirklich mit dem Rohkompost der vorher erstellten Müll-Klärschlamm-Mischung zu arbeiten, blieb uns nichts anderes übrig, als 7-ro Tage lang mit ein und derselben Mischung Müll-Klärschlamm die Gärtrommel zu beschicken. Vom 5. Tag an nach Beginn des Versuches konnten wir dann damit rechnen, das Rohkompostmaterial der betreffenden Mischung der Trommel entnehmen zu können. Dieses Vorgehen bedingte natürlich einen viel grösseren Zeitaufwand als vorgesehen und eine Komplikation der jeweiligen Schlammtransporte von Winterthur nach Rüschlikon.

\section{Grossversuche}

Die Tabelle I orientiert über die bei den drei Grossversuchen verarbeiteten Mengen von Müll und Klärschlamm.

Beim 1. Grossversuch wurden verarbeitet: $105 \mathrm{~m}^{3}$ Müll, das heisst $28,38 \mathrm{t}$ Müll mit II 5051 ausgefaultem Klärschlamm der Anlage Winterthur, cingedickt auf einen Wassergehalt von $65 \%$, und 43501 Filtrat mit einem Wassergehalt von $94 \%$, mit einem Mischungsverhältnis MüllKlärschlamm gewichtsmässig $2: \mathrm{I}$.

Von diesem Material erstellten wir die Miete I auf Betonboden, Miete 2 auf Kiesboden und Miete 3 auf Humusboden. Auf Grund der Erfahrungen mit den Tastmieten erstellten wir die Mieten bei allen Grossversuchen trapezförmig mit einer Höhe von 90-100 cm, mit einer oberen Trapezbreite von $2 \mathrm{~m}$ (siche Abbildung 2I). Dadurch hatte das Regenwasser die Möglichkeit, gut ins Innere der Mieten einzudringen. Diese Mietenform hat sich in der Folge sehr gut bewährt; wir konnten keine Aus- 
trocknung des Materials mehr feststellen. Die Mieten I, 2 und 3 des ersten Grossversuches schichteten wir beim ersten Schub auf die endgültige Höhe auf.

Beim 2. Grossversuch wurden verarbeitet: $128 \mathrm{~m}^{3}$ Müll, das heisst 37 , I6 t

Müll mit ro855 l ausgefaultem Klärschlamm der Kläranlage Werdhölzli, mit einem Wassergehalt von $87 \%$, mit einem Mischungsverhältnis Müll-Klärschlamm gewichtsmässig 3,5:I.

Von diesem Material erstellten wir wiederum die Mieten ia auf Beton boden, 2a auf Kiesboden und 3a auf Humusboden. Diese Mieten schich teten wir im Gegensatz zum ersten Grossversuch etappenweise auf, erst auf eine Höhe von $30 \mathrm{~cm}$, nach ein paar Tagen auf 60, dann auf $90-100 \mathrm{~cm}$. Bcim 3. Grosspersuch wurden verarbeitet: $85,5 \mathrm{~m}^{3}$ Müll, das heisst 23,09 t Müll, mit 75051 eingedicktem Frischschlamm der Kläranlage Winterthur mit einem mittleren Wassergehalt von $68 \%$ und einem Mischungsverhältnis Müll-Klärschlamm gewichtsmässig 3:I.

Von diesem Material erstellten wir die Miete 4 nur noch auf Humusboden, weil wir inzwischen erkannt hatten, dass sich dieser am besten eignet als Mietenunterlage (Begründung folgt später). Auch diese Miete wurde etappenweise aufgeschichtet.

\section{Störungen im Betrieb}

Beim ersten und zweiten Grossversuch mit ausgefaultem Klärschlamm erfolgte keine Betriebsstörung; die Trommelgärung verlief vollkommen normal.

Beim dritten Grossversuch mit eingedicktem Frischschlamm hingegen wurde die Trommel vollständig durchnässt. Das Wasser tropfte aus allen Löchern und Fugen heraus, und die Temperatur in der Trommel, welche ja einen Gradmesser für den Gärprozess in der Trommel darstellt, sank sehr rasch ab.

Die bei den Versuchen mit Frischschlamm erwarteten starken Geruchsbelästigungen hielten sich in erträglichen Grenzen. Hingegen überraschte uns das ganz andere Verhalten des Frischschlammes in der Gärtrommel gegenüber dem ausgefaulten Schlamm. Der eingedickte Frischschlamm, der ja noch die Fettstoffe enthält, gab sein restliches Wasser beim Malmvorgang in der Trommel ausserordentlich rasch ab, was zu der oben beschriebenen "Überschwemmung" führte. Der ausgefaulte Schlamm dagegen wirkte wie ein ausgleichender Puffer, er gab das Wasser langsam $\mathrm{ab}$ und nahm lokal sich bildende Wasseransammlungen wieder auf. 
Die Menge des Frischschlammes musste dann bis auf $25 \%$ der ursprünglichen Zugabe reduziert werden, bis wieder einigermassen normale Betriebsverhältnisse eintraten.

\section{E. Vergleich der Müll-Klärschlamm-Mengen}

Im Diagramm (Abbildung 4) sind die Klärschlammengen in Funktion des Wassergehaltes aufgetragen, und zwar je eine Kurve für Frischschlamm und ausgefaulten Schlamm einer mechanischen sowie einer mechanisch-biologischen Reinigungsanlage. Im gleichen Diagramm sind ferner die Klärschlammengen der drei Grossversuche aufgezeichnet. Dabei wurde das spezifische Gewicht des Klärschlammes mit I eingesetzt und eine Müllmenge pro Kopf und Tag mit $0,55 \mathrm{~kg}$ zugrunde gelegt. Da die Angaben über den Anfall der Feststoffe einer Kläranlage etwas variieren, wurden mittlere Werte nach den Erfahrungen der EAWAG berücksichtigt, und zwar wie folgt:

\begin{tabular}{|l|l|l|}
\hline Kläranlage & \multicolumn{1}{|c|}{ Schlammart } & \multicolumn{1}{|c|}{$\begin{array}{c}\text { Feststoffanfall } \\
\text { Kopf/Tag }\end{array}$} \\
\hline Mechanische & & \\
Absetzanlage .... & Frischschlamm & $72 \mathrm{~g} / \mathrm{E} / \mathrm{T}$ \\
Mechanisch-biologische & Faulschlamm & $49 \mathrm{~g} / \mathrm{E} / \mathrm{T}$ \\
Anlage. ..... & Frischschlamm & $107 \mathrm{~g} / \mathrm{E} / \mathrm{T}$ \\
& Faulschlamm & $68 \mathrm{~g} / \mathrm{E} / \mathrm{T}$ \\
\hline
\end{tabular}

Um die beigegebenen Schlammengen in Beziehung zu den Müllmengen bringen zu können, wurde das Verhältnis zwischen der verarbeiteten Müllmenge $M$ zur totalen Schlammenge $S$ auf die Müllmenge $b$ pro Kopf und Tag bezogen. Daraus resultiert eine spezifische Schlammenge

$$
X=\frac{b}{M} S[\mathrm{l} / \mathrm{E} / \mathrm{T}]
$$

Beim ersten Grosspersuch wurden zwei Schlammkomponenten beigegeben, nämlich eingedickter Schlamm mit $65 \%$ Wassergehalt und Filtrat mit 94\% Wassergehalt. Dies entspricht den im Diagramm aufgeführten spezifischen Werten $A$ mit 0,22 $1 / \mathrm{E} / \mathrm{T}$ und $B$ mit $0,851 / \mathrm{E} / \mathrm{T}$. Das Mittel $C$ dieser beiden Schlammkomponenten liegt bei $73 \%$ Wassergehalt und weist einen spezifischen Wert von $0,3 \mathrm{I}$ 1/E/T auf. Aus dem Diagramm ist nun ersichtlich, dass der Anfall an ausgefaultem Schlamm mit einem 


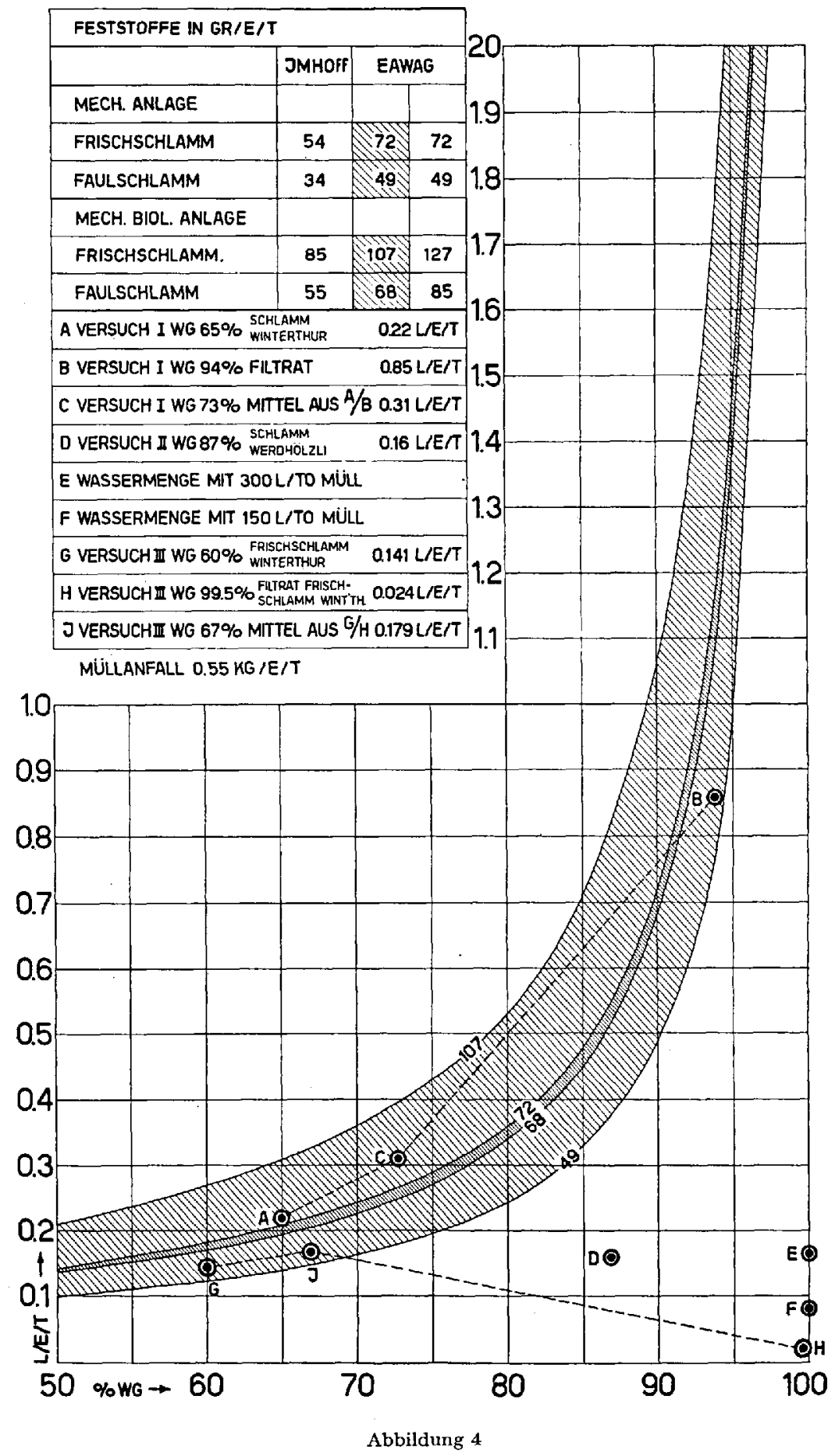

Klärschlammanfall. 
Wassergehalt von $73 \%$ einer mechanischen Anlage $0,181 / \mathrm{E} / \mathrm{T}$ und einer mechanisch-biologischen Anlage $0,25 \mathrm{l} / \mathrm{E} / \mathrm{T}$ beträgt. Somit können wir festhalten, dass die Schlammenge, welche in einer Müllgärtrommel ohne Störung des Gärprozesses verarbeitet werden kann, etwas höher liegt, als der Anfall aus einer mechanischen oder sogar einer mechanisch-biologischen Kläranlage beträgt.

Grössenordnungsmässig bedeutet dies, dass die äquivalenten Mengen von Müll und Klärschlamm des gleich grossen Einzugsgebietes gemeinsam verarbeitet werden können.

Beim zpeiten Grossversuch mit ausgefaultem, nicht cingedicktem Klärschlamm der Kläranlage Werdhölzli mit einem Wassergehalt von $87 \%$ liegt die spezifische Menge bei Punkt $D$ des Diagrammes mit 0,161/E/T. Dieser Wert liegt wesentlich tiefer als der Anfall in der Kläranlage pro Kopf und Tag, das heisst, bei diesem Wassergehalt des Klärschlammes kann nicht die äquivalente Schlammenge des gleichen Einzugsgebietes verarbeitet werden.

Beim dritten Grosspersuch, welcher wiederum zwei Schlammkomponenten $G$ und $H$ aufweist und deren Mittel mit einem Wassergehalt von $67 \%$ bei Punkt $\int$ des Diagrammes liegt, weist einen spezifischen Wert von 0,18 J/E/T auf. Der entsprechende Wert des anfallenden Frischschlammes einer mechanischen Anlage liegt bei o,22 $\mathrm{l} / \mathrm{E} / \mathrm{T}$ und einer mechanisch-biologischen Anlage bei 0,33 l/E/T. Abgesehen von der Tatsache, dass die beigegebene Frischschlammenge die Trommel überschwemmt und den Gärprozess unterbrochen hatte, ist aus dem Diagramm ersichtlich, dass der Punkt $J$ bereits unterhalb der Frischschlammkurve liegt sowohl für eine mechanische Anlage wie auch für eine mechanisch-biologische Kläranlage. Da erst bei ungefähr $25 \%$ der ursprünglich beigegebenen Schlammmengen keine Störungen mehr auftraten, könnten somit lediglich etwa I2,5\% des anfallenden Frischschlammes einer mechanisch-biologischen Anlage mit äquivalenten Müllmengen verarbeitet werden.

\section{F. Untersuchungsresultate und Beobachtungen}

\section{Untersucbungsmetbodik}

a) Periodiscbe Mietenkontrolle: Unmittelbar nach dem Aufschichten der einzelnen Mieten erfolgte die periodische Kontrolle, anfänglich durch tägliche, später durch 2-3malige Kontrollen pro Woche. Dabei wurden folgende Bestimmungen durchgeführt: 
Temperatur: innerhalb der Mieten, und zwar in $30 \mathrm{~cm}$ Tiefe und $20 \mathrm{~cm}$ ob Boden. Ferner wurde die Temperatur der Luft gemessen. Für die Bestimmung der Mietentemperatur verwendeten wir zuerst einen üblichen Heustockthermometer mit Quecksilberfaden. Dieser hat sich insofern nicht bewährt, als es sehr lange Zeit (20 bis 25 Minuten) dauerte, bis sich dieQuecksilbersäule auf die betreffende Temperatur einstellte, denn die Glaskapillare mit dem Quecksilberfaden musste durch einen dicken Stahlmantel vor Bruch geschützt werden, so dass die Wärmeübertragung zu lange dauerte. Wir verwendeten daher Bimetallthermometer, die sich sehr gut bewährten. Nach 2-3 Minuten konnte die Temperatur jeweils abgelesen werden.

Wassergebalt: Die übliche Labormethode der Wassergehaltsbestimmung geschieht in der Weise, dass eine abgewogene Kompostprobe bei Ioo- $105^{\circ} \mathrm{C}$ im Trockenschrank bis zur Gewichtskonstanz getrocknet und anschliessend wieder gewogen wird. Der Gewichtsverlust ergibt den Wassergehalt. Diese Methode verwendeten wir bei der Durchführung der chemischen Totalanalysen. Für die periodischen Mietenkontrollen brauchten wir dagegen eine handliche Feldmethode, die wenig Zeit in Anspruch nimmt und bei der wir nicht an ein Laboratorium gebunden waren. Wir fanden diese Methode in dem neuen, von der Firma Riedel-De Haen entwickelten sogenannten «CM-Gerät», das ursprünglich für die Wassergehaltsbestimmung von Baumaterialien bestimmt war. Dieses Gerät besteht aus einer Druckflasche aus Stahl mit Manometerverschluss. Eine abgewogene Kompostprobe wird in die Flasche gebracht mitsamt einer Glasampulle mit Kalziumkarbid und einer Stahlkugel. Die luftdicht verschlossene Flasche wird kräftig geschüttelt, wodurch die Ampulle zerstört wird. Das aus der Feuchtigkeit des Kompostes und aus Karbid sich bildende Azetylengas, bzw. dessen Druck, wird am Manometer abgelesen und durch Umrechnung der Wassergehalt bestimmt.

Koblensäure: Wie bereits im ersten Teil des Berichtes erwähnt wurde, liefert die Bestimmung der Kohlensäure im Innern der Mieten einen Fingerzeig über den Gang der Verrottung, denn die Kohlensäure ist ja cines der Stoffwechselprodukte der Mikroorganismen. Für diese Bestimmung brauchten wir ebenfalls cine Feldmethode, die wenig Zeit in Anspruch nimmt. Die Orsat-Apparatur, die üblicherweise für Gasanalysen verwendet wird, erfüllte diese Forderung sehr gut. Das Prinzip dieser Methode ist folgendes: Eine Metallsonde, die an ihrem vorderen Ende durchlöchert ist, wird in die Miete gesteckt bis in die gewünschte Tiefe. Die Sonde ist mit einem Gummischlauch mit der Orsat-Apparatur verbunden. Mit einem Gummi- 
ball werden genau $100 \mathrm{~cm}^{3}$ Mietengas in die Apparatur gesaugt, das Gas mehrmals durch kohlensäureabsorbierende Kalilauge geführt und die Volumenverminderung festgestellt. Diese Verminderung ergibt die Kohlensäuremenge direkt in Prozentgehalt. Auch diese Bestimmung führten wir in den Mieten in $30 \mathrm{~cm}$ Tiefe und $20 \mathrm{~cm}$ ob Boden durch.

Schroefelwasserstoff: Um zu entscheiden, ob in den Mieten erwünschte aerobe Verrottung oder unerwünschte anaerobe Fäulnis herrscht, haben wir eine einfache Prüfmethode entwickelt. Wir verwenden dazu $\mathrm{I}, 5 \mathrm{~m}$ lange und $5 \mathrm{~mm}$ dicke Eisenstäbe, die wir versilbern liessen. Diese Silberstäbe stecken wir an verschiedenen Stellen in die Mieten bis zum Grunde. An derjenigen Stelle, wo anaerobe Fäulnisvorgänge stattfinden, färbt sich der Silberstab infolge Bildung von Schwefelwasserstoff bzw. Schwefelsilber tiefschwarz. Auf diese Weise können wir auch lokale Fäulnisherde feststellen. Bleibt der Stab innerhalb von 4 Tagen blank, so geht die Verrottung normal vor sich. Die Silberstäbe können zwecks Beschaffung von Dokumentationsmaterial auch photographiert werden. Mit einem Silberputzmittel können die Stäbe leicht wieder gereinigt werden.

b) Chemische Untersucbung des Kompostes: Bei den chemischen Untersuchungen wurden folgende Bestimmungen durchgeführt:

Wassergehalt Úbliche Methode mit Trocknung bei $105^{\circ} \mathrm{C}$.

Glübperlust Durch Glühen der Trockensubstanz im Muffelofen bei $600^{\circ} \mathrm{C}$.

Stickstoff Kjeldahl-Methode.

Phosphor Nach LoRENz.

Kalium Spektralanalyse, durchgeführt von der Landwirtschaftlichen Versuchsanstalt Oerlikon.

Koblenstoff Nasse Verbrennung, durchgeführt von der Landwirtschaftlichen Versuchsanstalt Oerlikon.

Kalk Bestimmt als $\mathrm{Ca}$, umgerechnet auf $\mathrm{CaO}$.

pH-Wert Nach GESSNER (Aufschwemmung in aqua destillata).

Wirksame organische Substanz, Humusstoffe und Humuskoble

Nach SPRINGER [2]. Die wirksame organische Substanz bestimmten wir als Differenz von gesamter organischer Sub$\operatorname{stanz}$ (Glïhverlust) und inaktiver Substanz (Humuskohle). 


\section{Der Gang der Verrottung in den Mieten}

(Resultate der periodischen Kontrollen)

a) Erster Grosspersucb: Aus dem Rohkompostmaterial der Mischung MüllKlärschlamm im Verhältnis 2: I (siehe Tabelle I) erstellten wir die Mieten I, 2 und 3.

Miete 1: Sie wurde auf dem durchlöcherten Betonboden aufgeschichtet, und zwar beim ersten Schub auf die endgültige Höhe von 0,9-I m. Aus der graphischen Darstellung (Abbildung 5 ) sind der Temperaturverlauf und die Kohlensäureentwicklung in verschiedenen Tiefen der Miete, ebenso die Regenmengen und Lufttemperaturen ersichtlich.

Nach der Entnahme aus der Trommel besass das Material einen Wassergehalt von $62 \%$, es war also eher zu feucht. Bereits am 7. Tag nach dem Aufschichten erreichte die Temperatur in $30 \mathrm{~cm}$ Tiefe eine Höhe von $55^{\circ} \mathrm{C}$. In den tieferen Schichten sank sie etwas ab, was vielleicht auf die abkühlende Wirkung des Betonbodens zurückzuführen ist. Die Kohlensäureproduktion stieg gleich nach der Aufschichtung, parallel zur Temperatur, sehr rasch an, was den Beginn einer intensiven biologischen Zersetzungstätigkeit anzeigt. Am I4. Tag wurde die Miete zum ersten Mal von Hand umgearbeitet. Dabei zeigte es sich, dass der untere Teil der Miete viel zu nass und pappig war, dass also die Belüftung ungenügend war. Auf derAuflagefläche des Betonbodens waren bereits kleine schwarze Flecken von Schwefeleisen sichtbar, ein Zeichen der lokalen Bildung von Schwefelwasserstoff. Während der Umarbeitung sank die Temperatur erwartungsgemäss sehr stark $a b$, um unmittelbar nachher um so rascher wieder anzusteigen bis zu einem Maximum von $74^{\circ} \mathrm{C}$. Die Umarbeitung wirkte sich also sehr stark intensivierend aus auf die Verrottung infolge einer neuen Sauerstoffzufuhr. Die hohen Temperaturen hielten sich nur ganz kurze Zeit (knapp I Tag) und fielen dann im Verlaufe der nächsten 30 Tage in Form einer steilen Kurve mehr oder weniger gleichmässig ab.

Die Kohlensäureproduktion stieg nach der Umarbeitung nicht in gleichem Masse an wie die Temperatur. Immerhin kam auch dort die vermehrte Tätigkeit der Mikroorganismen zum Ausdruck. Bei allen Versuchen zeigte es sich, dass die Kohlensäureentwicklung in den tiefern Schichten höher war als in $30 \mathrm{~cm}$ Tiefe, was vermutlich im besseren Gasaustausch der oberen Schichten mit der Atmosphäre begründet liegt.

Am 55. Tag stieg nun plötzlich die Temperatur, vor allem aber die Kohlensäureproduktion, auffallend rasch an bis zu einem Kulminations- 


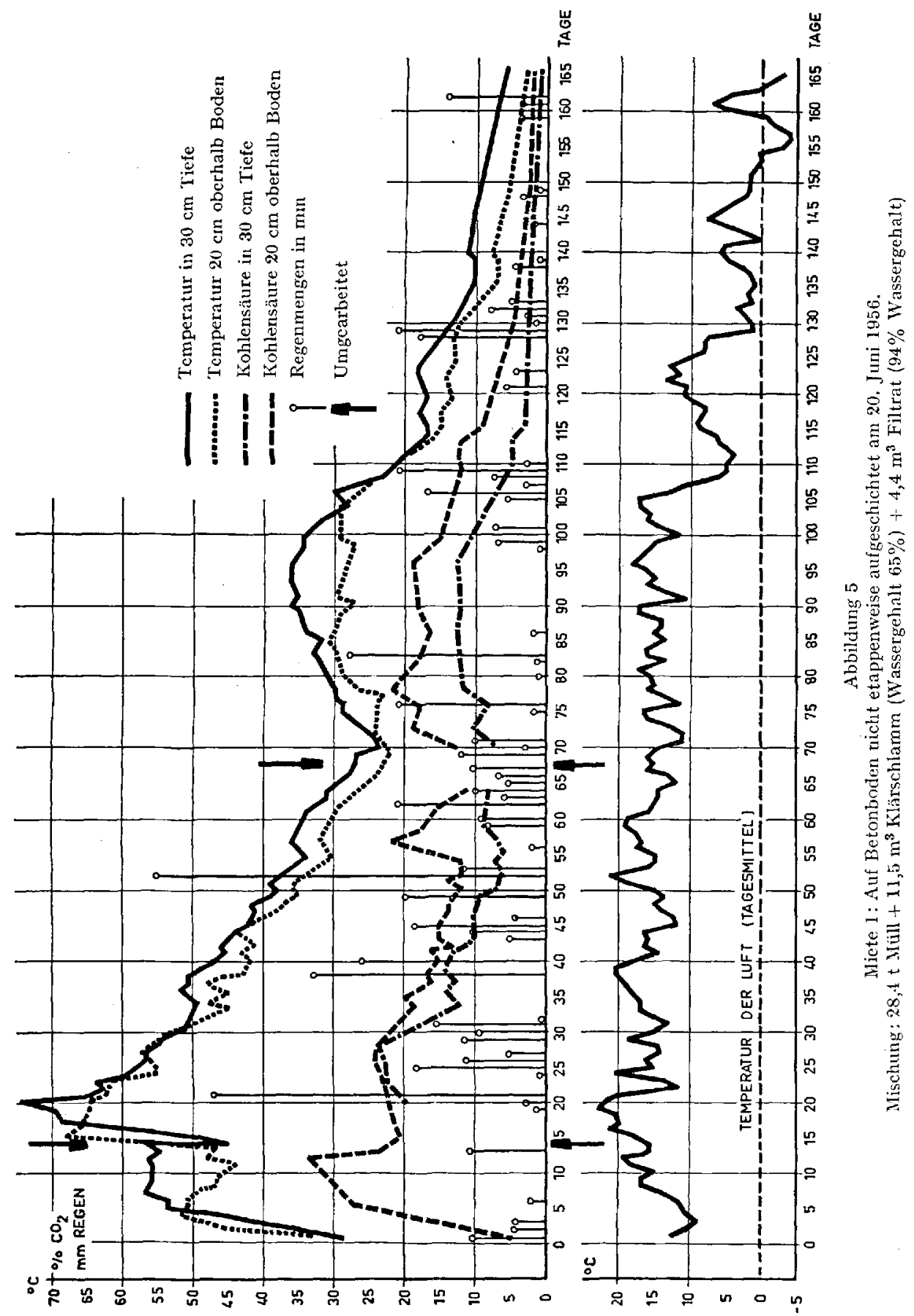


punkt am 57. Tag. Wir konnten uns diesen Anstieg nicht anders erklären als durch die Wirkung der am 52 . Tag gefallenen sehr starken Niederschläge ( $55 \mathrm{~mm}$ in wenigen Stunden). Es bleibt jedoch die Frage offen, ob sich der Regen, also die zusätzliche Feuchtigkeit, wirklich intensivierend auf die biologische Tätigkeit auswirkte oder ob einfach durch den nassen Mantel der Miete der Gasaustausch mit der Atmosphäre vermindert war und das Entweichen der Kohlensäure erschwerte. Wir möchten eher der letzten Version zustimmen, denn die Feuchtigkeit des Materials war ja schon beim Aufschichten der Miete eher zu hoch.

Vom 64. bis zum 70. Tag sind die Kohlensäurekurven (Abbildung 5 ) unterbrochen, weil uns ein äusserst starker Sturm die Orsat-Apparatur zerschlug!

Am 68. Tag wurde die Miete zum zweiten Male umgearbeitet. Dabei zeigte es sich, dass die Miete bis in eine Höhe von $70 \mathrm{~cm}$ nicht nur vollkommen zusammengepappt, sondern mit grossen schwarzen Schwefeleiseninseln durchsetzt war. Der untere Teil der Miete war durchgehend schwarz, ebenso der Betonboden an der Auflagefläche der Miete. Diese vollkommen ungenügende Durchlüftung der Miete und die seit der ersten Umarbeitung eingetretenen Fäulnisvorgänge konnten wir bereits vor der zweiten Umarbeitung mit Hilfe der Silberstäbe feststellen.

Nach der zweiten Umarbeitung stieg die Temperatur wieder rasch an, jedoch nicht mehr auf dieselbe Höhe wie nach dem ersten Umarbeiten. Auch die Kohlensäureproduktion stieg deutlich an. Einige Tage nach der Umarbeitung besserten sich die Belïftungsverhältnisse, was wiederum mit den Silberstäben festgestellt werden konnte. Nach dem Ioo. Tag sanken sowohl die Temperatur als auch die Kohlensäureproduktion langsam ab. Zwischen dem I Io. und 125. Tag war dieser Abfall besonders deutlich, offenbar als Folge des raschen Absinkens der Aussentemperatur, denn die Kurven der Mietentemperatur und der mittleren Lufttemperatur verliefen während dieser Zeit auffallend parallel. Am 165. Tage wurden die Messungen abgebrochen, weil sich die Miete abgekühlt hatte und die Kohlensäureproduktion praktisch zu Ende war.

Miete 2: Aus demselben Material und auf dieselbeWeise wie Miete I wurde die Micte 2 aufgeschichtet, und zwar auf dem gestampften Kiesboden. Aus der graphischen Darstellung (Abbildung 6) sind wiederum die Kurven der verschiedenen Messungen ersichtlich.

Auch in der Miete 2 erfolgte unmittelbar nach der Aufschichtung ein sehr rascher Anstieg der Temperatur und der Kohlensäure. Am I2. Tag wurde die Miete zum ersten Mal umgearbeitet. Auch hier zeigte es sich, 


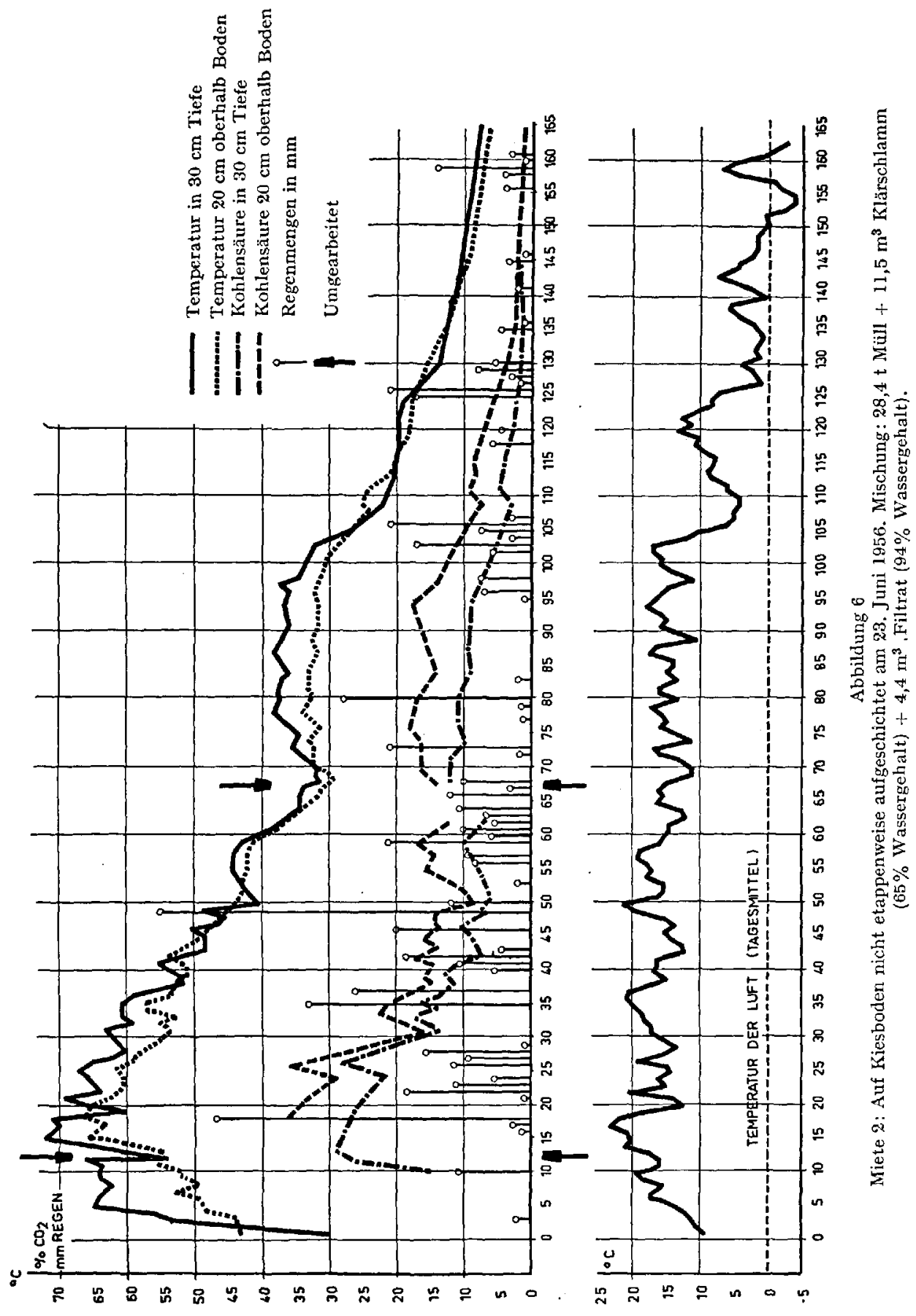


dass im unteren Teil das Material sehr feucht war. Hingegen war die Verpappung lange nicht so stark wie bei Miete I. Es konnten noch keinerlei Anzeichen von Schwefeleisenbildung festgestellt werden. Die Belüftungsverhältnisse in dieser Miete auf Kiesboden waren also etwas besser als bei Miete I auf Betonunterlage.

Nach der ersten Umarbeitung stieg auch in Miete 2 die Temperatur sehr rasch wieder an und erreichte am I5. Tag den Maximalwert von $72^{\circ} \mathrm{C}$. Wie bei Miete I hielt sich auch in Miete 2 diese hohe Temperatur nur ganz kurze Zeit. Am 4. Tag nach der Umarbeitung sank sie plötzlich rasch auf $60^{\circ}$, stieg dann aber sofort wieder an, wahrscheinlich als Folge der ebenso plötzlich sinkenden und wieder steigenden Mitteltemperatur der Luft. Bis zum 49. Tag zeigte die Temperaturkurve langsam fallende Tendenz. Hingegen am so. Tag erfolgte wiederum ein auffallender Anstieg sowohl der Temperatur als auch der Kohlensäure. Dies war, genau wie bei Miete I, die Folge des starken Regengusses vom 48. Tag.

Am 67. Tag wurde die Miete zum zweiten Male umgearbeitet. Der untere Teil war wiederum etwas zu feucht, hingegen wurden, im starken Gegensatz zu Miete I, nur ganz vereinzelt kleine schwarze Schwefeleisenflecken wahrgenommen. Nach der Umarbeitung verliefen die Temperaturund Kohlensäurekurven analog wie bei Miete I. Auch bei Miete 2 war die Wirkung des plötzlichen Rückganges der Mitteltemperatur der Luft auf die Mietentemperatur deutlich feststellbar.

Miete 3: Auf dem Humusboden wurde aus demselben Material wie Miete $I$ und 2 die Miete 3 erstellt. Die Messungen sind in Abbildung 7 graphisch dargestellt.

Der allgemeine Verlauf der Kurven dieser Miete weicht kaum ab von demjenigen der Mieten I und 2. Nach der am 9. Tag erfolgten ersten Umarbeitung stieg die Temperatur wiederum auf die Maximalhöhe von $72^{\circ} \mathrm{C}$. Am 15 . Tag war plötzlich ein Rückgang der Temperatur und der Kohlensäure zu verzeichnen, unmittelbar darnach setzte wieder ein starker Anstieg ein. Es war wiederum ein starker Regen, der diesen Knick in der Kurve verursachte. Auch der 55-mm-Regen am 26. Tag hatte dieselbe deutliche Einwirkung.

Sowohl bei der ersten als auch bei der am 65. Tage erfolgten zweiten Umarbeitung war das Kompostmaterial der Miete 3, im Gegensatz zu Mieten $\mathrm{x}$ und 2, mehr oder weniger regelmässig mit Feuchtigkeit durchsetzt, wenn auch der untere Teil der Miete etwas feuchter war als die oberen Schichten. Das Material war aber bei weitem nicht so pappig wie in Miete I. Schwefeleisenbildung konnte nicht festgestellt werden. Wir müs- 


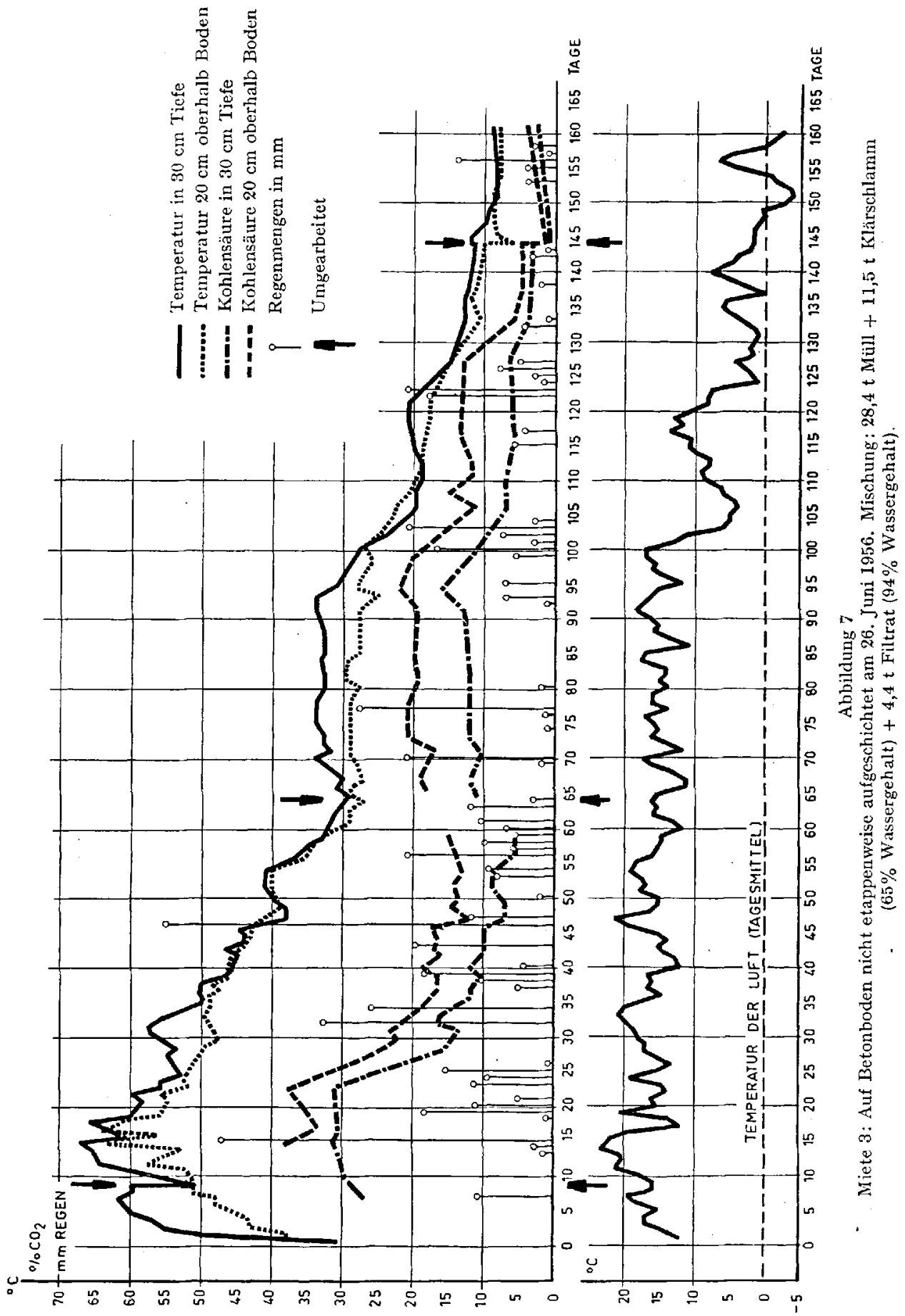


sen also daraus schliessen, dass die Durchlüftungsverhältnisse in Miete 3 besser waren als in den Mieten I und 2.

Der Verlauf der Kurven nach der zweiten Umarbeitung war ungefähr gleich wie in den Mieten I und 2. Auch bei Miete 3 war zwischen dem 100. und 120. Tag die Wirkung der plötzlich sinkenden und wieder ansteigenden Lufttemperatur auf die Mietentemperatur auffallend.

Um einen Fingerzeig zu erhalten über den Grad der Verrottung, arbeiteten wir die Miete 3 am I45. Tag zum dritten Mal um. Nach einem kurzen Absinken während des Umschaufelns stieg die Temperatur und die Kohlensäureproduktion wieder auf dic vor der Umarbeitung erreichte Höhe an, jedoch nicht höher! Durch die dritte Umarbeitung konnte also keine nennenswerte Erhöhung der Temperatur und der Kohlensäureentwicklung mehr erreicht werden, das heisst, durch die neuerliche $\mathrm{Zu}$ fuhr von Sauerstoff wurde die biologische Tätigkeit nicht mehr aktiviert. Dies ist ein Zeichen, dass das Material in der Miete weitgehend verrottet, das heisst "reif» war. Die Erkennung dieses Reifegrades ist für die Praxis sehr wichtig, denn der Kompost sollte aus Gründen der Platzersparnis, aber auch aus nährstofftechnischen Gründen nicht länger als bis zur Erreichung des Reifegrades gelagert werden. Auf diesen Punkt werden wir später noch zu sprechen kommen.

b) Zmeiter Grosspersucb: Aus dem Rohkompostmaterial der Mischung MüllKlärschlamm im Verhältnis 3,5:I (siehe Tabelle I) erstellten wir die Mieten Ia, 2a, und 3a. Das Material hatte nach der Entnahme aus der Gärtrommel einen Wassergehalt von $38 \%$.

Miete 1a: Sie wurde auf dem Betonboden, unmittelbar neben der Miete I, erstellt. Im Gegensatz zu Miete I wurde sie jedoch etappenweise aufgeschichtet: Am ersten Tag bis auf eine Höhe von $30 \mathrm{~cm}$, am dritten Tag bis $60 \mathrm{~cm}$ und am fünften Tag bis zur endgültigen Höhe von $90 \mathrm{~cm}$. Die graphische Darstellung der Messresultate ist aus Abbildung 8 ersichtlich.

Dieses etappenweise Aufschichten der Miete hatte einen deutlichen Einfluss auf den Verlauf der Temperaturkurve. Wenn wir diese mit den Kurven der Miete I vergleichen (siehe Abbildung 5), so erkennen wir, dass in der etappenweise aufgeschichteten Miete ra die Temperatur nach der ersten Umarbeitung am 22. Tag nicht mehr dieselbe Höhe erreicht wie in Miete I (nämlich $70^{\circ}$ und mehr), sondern nur noch die Maximalhöhe von $60^{\circ}$. Auch der Anstieg der Kohlensäurekurve ist nicht mehr so deutlich. Während jedoch in den Mieten I, 2 und 3 die Temperaturen nach Erreichen des Maximums ziemlich rasch abfielen, ist es auffallend, 


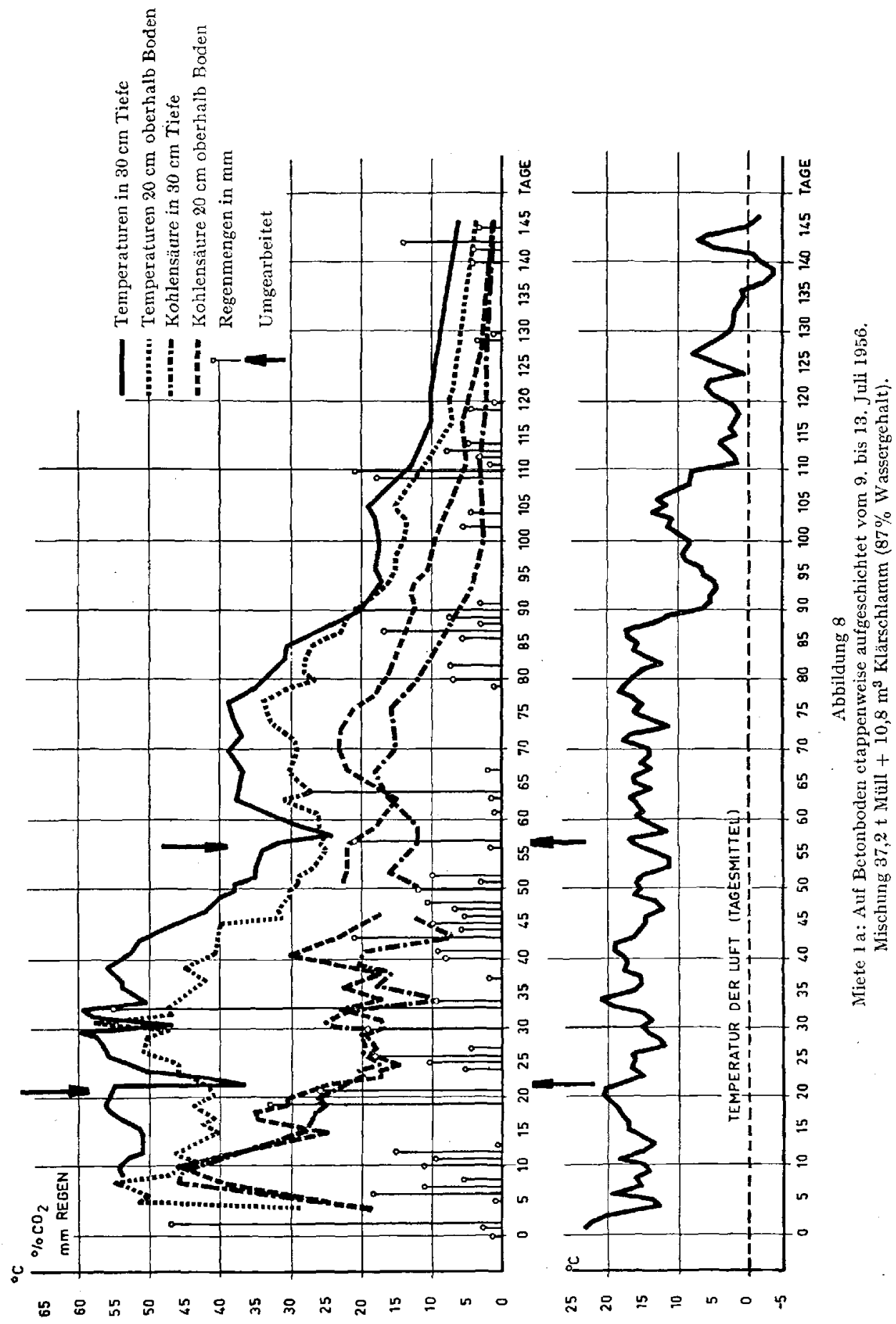




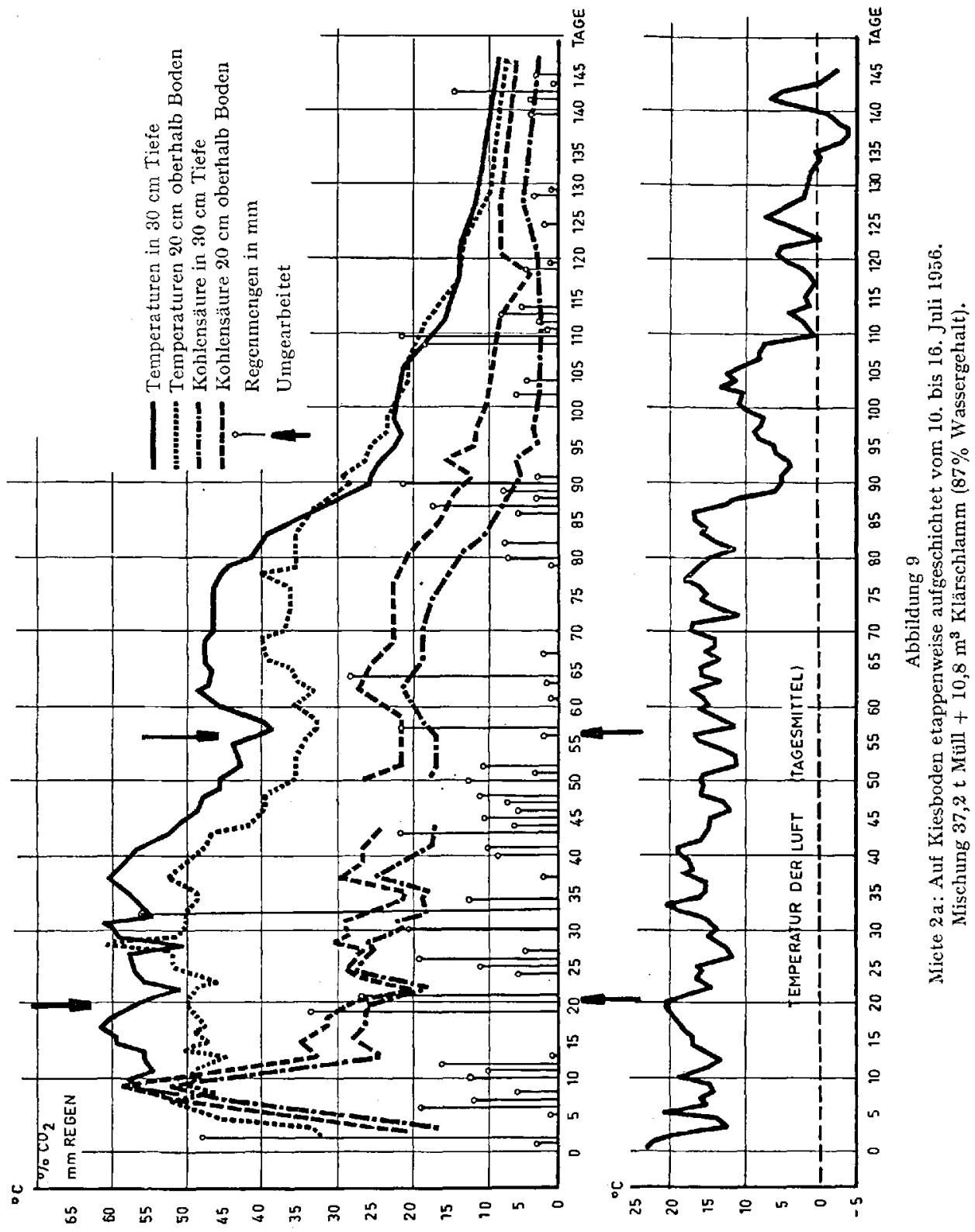


dass in den etappenweise aufgeschichteten Mieten Ia, 2a und $3 \mathrm{a}$ der erhöhte Temperaturbcreich um $50^{\circ}$ herum länger andauert. Dieser Temperaturverlauf scheint uns günstiger zu sein als der rasche Anstieg und plötzliche Abfall, wie er in den nicht schichtweise erstellten Mieten typisch war, denn offenbar werden bei Temperaturen um $70^{\circ}$ herum gewisse Organismengruppen so stark geschädigt, dass der Verrottungsvorgang gehemmt wird. Mit Hinsicht auf hygienische Belange sollten die Maximaltemperaturen von $60^{\circ}$, wie wir sic in den Mieten Ia, 2a und 3a feststellten, genügend sein. Wir werden auf das hygienische Problem noch zu sprechen kommen.

Auch bei der Miete ra bewirkten dic beiden Umarbeitungen den normalen Anstieg der Temperatur. Das Bild bei der ersten Umarbeitung am 22. Tag war genau dasselbe wie bei Miete $I$ : Der untere Teil der Miete war viel zu nass und pappig, obschon der Rohkompost beim Aufschichten der Miete einen Wassergehalt von bloss 38\% aufwies. Durch die abkühlende Wirkung des Betonbodens bildete sich offenbar Kondenswasser. Die Durchlüftung war vollkommen ungenügend. Nach der zweiten Umarbeitung am 52. Tag war der Aspekt wieder derselbe wie bei Miete I : Der untere Teil der Miete war sehr stark schwarz gefärbt von Schwefeleisen, die Auflagefläche der Miete war durchgehend schwarz!

Der deutliche Einfluss starker Regengüsse im Sinne einer Erhöhung der Temperatur und der Kohlensäureproduktion war auch bei Miete Ia, wie auch bei den vorgenannten Mieten, sehr gut bemerkbar. Die abkühlende Wirkung der plötzlich abfallenden Aussentemperatur auf die Mietentemperatur war ebenfalls bei Miete Ia zwischen dem 87. und I05. Tag auffallend deutlich.

Miete $2 a$ : Auch diese Miete wurde etappenweise aufgeschichtet aus demselben Material wie Miete Ia, und zwar auf dem Kiesboden unmittelbar neben der Miete 2. Abbildung 9 zeigt die graphische Darstellung der durchgeführten Messungen. Der Charakter dieser Kurven gleicht praktisch demjenigen der Miete Ia; auch hier wiederum eine Maximaltemperatur von nur $60^{\circ} \mathrm{C}$, dafür ein längeres Verweilen der höheren Temperaturen. Der allgemeine Aspekt nach den beiden Umarbeitungen entsprach ziemlich genau demjenigen der Miete 2: Stellenweise Bildung von Schwefeleisen, Material im unteren Teil der Miete etwas zu nass. Die Belüftungsverhältnisse der Miete $2 \mathrm{a}$ waren also etwas besser als bei Miete Ia. Der Einfluss des Regens und der Aussentemperatur kommt in den Kurven der Miete 2a ebenfalls gut zum Ausdruck, namentlich der bereits mehrmals zitierte 55-mm-Regen am 33. Tag. 


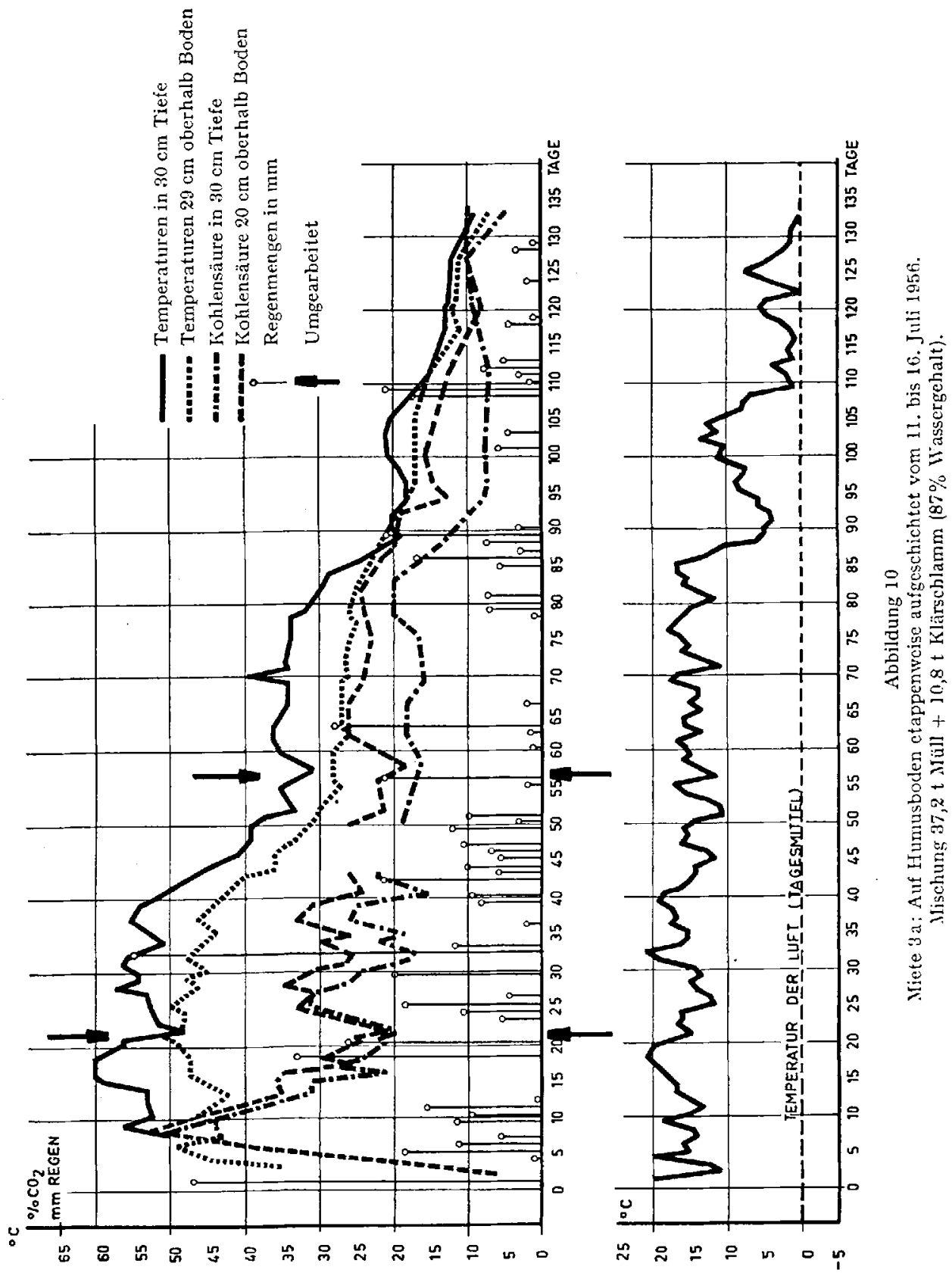


Miete $3 a$ : Sic wurde aus dem gleichen Material wie Miete Ia und 2a auf dem Humusboden, unmitcelbar neben Miete 3, erstellt. Auch Miete $3 \mathrm{a}$ wurde etappenweise aufgeschichtet. In Abbildung Io sind die Messungen graphisch dargestellt.

Das allgemeine Kurvenbild gleicht wiederum demjenigen der Mieten 2a und ra und braucht nicht weiter diskutiert zu werden. Auch der Einfluss des Regens am 22. Tag und der Aussentemperatur vom 85. bis IO2. Tag ist deutlich aus den Kurven ersichtlich. Das Bild nach den beiden Umarbeitungen entspricht ziemlich genau demjenigen der Miete 3 : Bessere Durchlüftung, keine Bildung von Schwefeleisen, also auch keine nennenswerten anaeroben Fäulnisvorgänge.

c) Dritter Grosspersuch: Aus dem Rohkompostmaterial der Mischung MüllFrischschlamm im Verhältnis 3:I (siehe Tabelle I) erstellten wir die Miete 4. Das Material besass nach der Entnahme aus der Gärtrommel einen Wassergehalt von $54 \%$. Da es sich bei den ersten beiden Grossversuchen zeigte, dass der Humusboden die geeignetste Mietenunterlage darstellt und dass das etappenweise Aufschichten der Miete am günstigsten für den Verlauf der Verrottung ist, wurde die Miete 4 etappenweise nur noch auf Humusboden aufgeschichtet. Die Messresultate sind aus der graphischen Darstellung (Abbildung II) ersichtlich.

Obschon die Miete etappenweise errichtet war, stieg die Temperatur bis auf eine Höhe von $67^{\circ} \mathrm{C}$. Ob dies auf eine stärkere Aktivität des frischen gegenüber der des ausgefaulten Schlammes zurückzuführen ist, vermögen wir nicht zu sagen. Die erste Umarbeitung wurde absichtlich etwas später als bei den vorangehenden Mieten, nämlich erst am 32. Tag, vorgenommen, um den Temperaturverlauf vor der Umarbeitung länger verfolgen zu können. Während dieser Zeitspanne konnten wir folgende Feststellungen machen:

Nach Erreichen des Temperaturmaximums von $67^{\circ}$ am I4. Tag fiel die Temperatur abrupt $a b$ auf $54^{\circ}$, um nachher allmählich wieder anzusteigen. Wir haben für diesen unerwarteten Abfall der Temperatur zwei Erklärungsversuche: Wahrscheinlich wurde bei der Temperatur von $67^{\circ}$ bereits ein Teil des Organismenbestandes so stark geschädigt, dass der Verrottungsvorgang plötzlich verzögert wurde, wodurch die Temperatur absank. Dafür spricht auch das ebenso rasche Absinken der Kohlensäureproduktion. Nachher verlief die Kohlensäurekurve wieder ansteigend, parallel zur Temperaturkurve. Es scheint, als ob sich der Organismenbestand nach dem I8. Tag wieder etwas «erholte». Die zweite Erklärung für das Abfallen der Temperatur nach dem I4.Tag ist die der Beeinflussung durch 

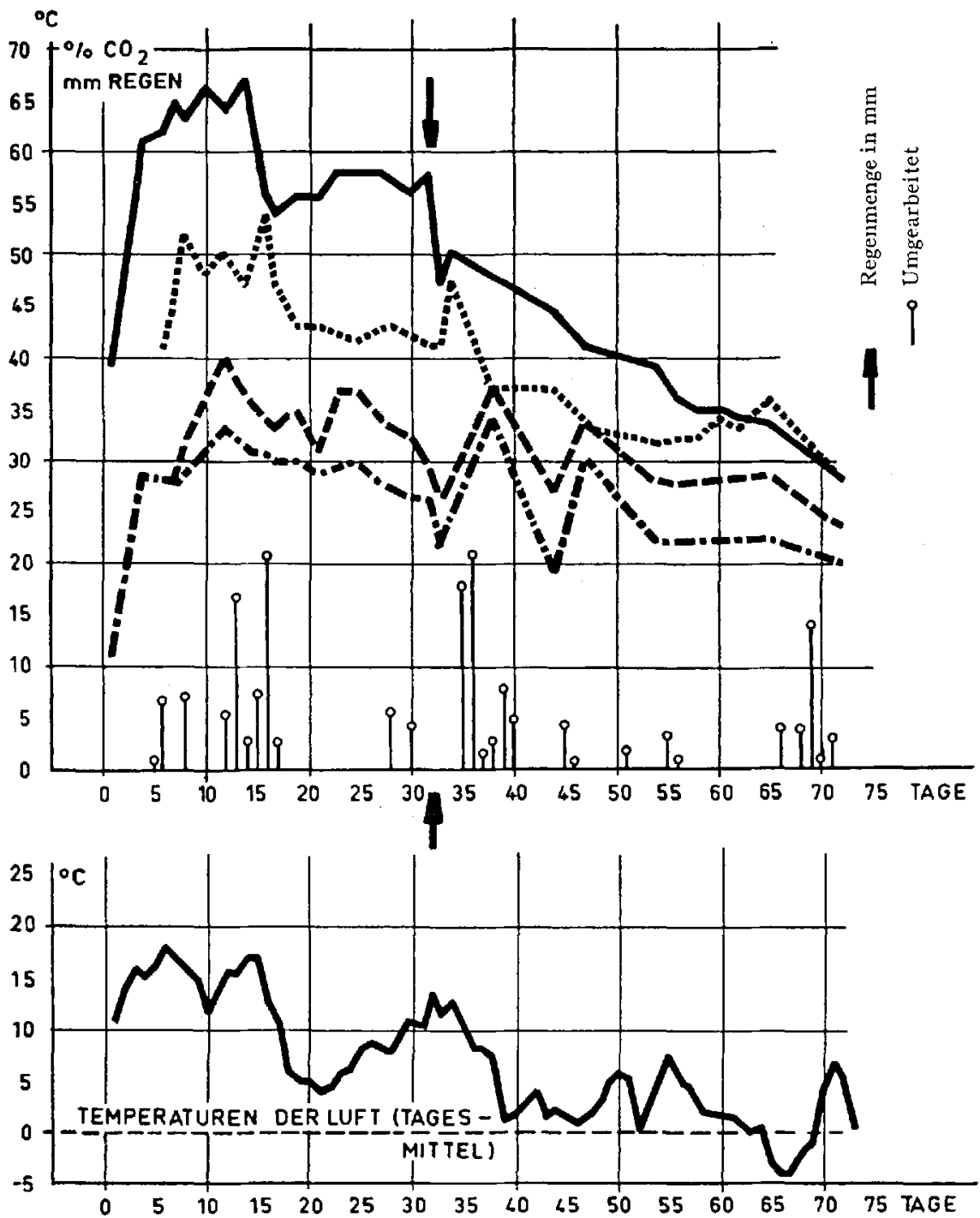

Abbildung 11

Miete 4: Auf Humusboden etappenweise autgeschichtet vom 19. bis 26. Juli 1956 . Mischung: $23 \mathrm{t}$ Müll $+6 \mathrm{~m}^{3}$ Klärschlamm (60\% Wassergehalt) $+1,52 \mathrm{~m}^{3}$ Filtrat $(99,5 \%$ Wassergehalt $)$.

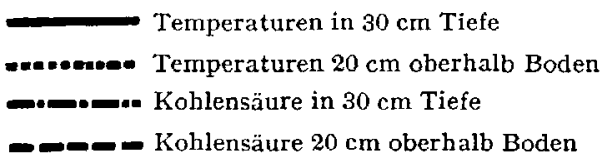


die Aussentemperatur. Schon bei allen andern besprochenen Kurvenbildern spiegelte sich das "Tief» der Kurve der Aussentemperatur auch in den Kurven der Mietentemperaturen. Der Einfluss dieses «Tiefes» der Aussentemperatur konnte jedoch bei den bisher besprochenen Mieten nicht so stark sein, weil das Material schon einen fortgeschritteneren Grad der Verrottung aufwies, als dies bei Miete 4 der Fall war, die erst viel später aufgeschichtet worden ist. Man könnte daraus die Schlussfolgerung ziehen, dass jüngeres Kompostmaterial empfindlicher reagiert auf plötzliche Temperaturstürze der Aussenluft als älteres.

Die erste Umarbeitung der Miete wurde am 32. Tag vorgenommen. Es zeigten sich keinerlei Anzeichen von anaeroben Fäulnisvorgängen. Der allgemeine Aspekt des Kompostes (Farbe, Krümelstruktur usw.) war gut, so dass prinzipiell die Beimischung von Frischschlamm zum Müll durchaus positiv zu bewerten ist. Der Fettgehalt des Frischschlammes scheint also keine nachteiligen Folgen auf den Verrottungsvorgang in der Miete auszuüben. Die Störungen während der Vorgärung in der Trommel wurden bereits erwähnt.

\section{G. Die chemische Zusammensetzung und die Bewertung des Kompostes}

Seit Jahren schon beschäftigen sich die Fachleute in den verschiedenen Ländern mit der Frage, wie der Kompost bewertet werden soll. Man kann ihn chemisch analysieren, den Gehalt an Stickstoff, Phosphor und Kali bestimmen und daraus den absoluten Düngerwert unter vergleichender Gegenüberstellung mit anorganischen Düngersalzen errechnen. Sicher wird dadurch nur ein Teil des Wertes des Kompostes erfasst. Die wirksame organische Substanz, der Gehalt an Humusstoffen und humusbildenden Stoffen, die Krümelstruktur, das Wasserhaltevermögen, die Speicherung und langsame Abgabe der organisch gebundenen Nährstoffe, die durch den Kompost gesteigerte biologische Aktivität des damit behandelten Bodens, alle diese Faktoren sollten berücksichtigt werden, wenn man den Kompost wirklich bewerten will. Bei verschiedenen Stellen herrscht die Auffassung, dass allein nur der Gehalt an Stickstoff, Phosphor und Kali massgebend sein sollte für die Bewertung des Müllkompostes. Man will daher für den Müllkompost nicht mehr bezahlen, als man für die entsprechende Menge von Stickstoff, Phosphor und Kali in Form anorganischer Handelsdünger zahlen müsste. Dass diese Bewertungsgrundlage nicht ganz konsequent ist, geht schon daraus hervor, dass 
man zum Beispiel für den Stallmist weit mehr bezahlt, als die in ihm enthaltenen Kernnährstoffe wert sind.

Nun ergibt sich jedoch die Schwierigkeit, die bereits aufgezählten übrigen wertvollen Eigenschaften des Kompostes zahlenmässig zu erfassen. Es fehlen uns heute noch weitgehend allgemein anwendbare Testmethoden, um die Qualität eines Kompostes zu bestimmen. Allerdings gibt es Laboratorien, in denen der Kompost auf biologischer Grundlage untersucht und dessen «lebendige Kraft» test-und zahlenmässig bestimmt wird. Diese Leute können oder wollen uns aber meist nicht sagen, was sie darunter verstehen und wie sie die Untersuchungen durchführen. Es ist weder der Müllbeseitigung im allgemeinen noch der Komposticrung im besonderen damit gedient, wenn man den Kompost mit einem Schleier der Mystik umgibt! Wir müssen uns bei der Lösung der uns gestellten Probleme mit Tatsachen auseinandersetzen. Wir müssen seriöse Untersuchungsmethoden anwenden, die überall anwendbar sind und die reproduzierbare Resultate liefern, sonst kommen wir keinen Schritt weiter.

Eine absolut sichere Beurteilung des Wertes eines Kompostes ist nur im langjährigen Feldversuch möglich, wobei nach Abschluss des Versuches zugleich die Veränderungen des Bodens in chemischer, physikalischer und biologischer Hinsicht festzustellen sind, wie zum Beispiel Kohlenstoff- und Nährstoffhaushalt, Bodenstruktur, Sorptionsvermögen, Mikroflora und -fauna. Diese Bewertung durch langjährigen Feldversuch ist aber für uns wenig geeignet, denn wir können nicht mehr Jahre warten, bis wir einen bestimmten Kompost bewerten können.

Wenn wir nun im folgenden etwas eingehender die Resultate unserer chemischen Analysen behandeln, möchten wir doch darauf hinweisen, dass dadurch der tatsächliche Wert des Kompostes aus den obgenannten Gründen noch nicht erfasst ist. Die chemische Analyse kann uns jedoch wertvolle Vergleichsmöglichkeiten liefern zwischen gewöhnlichem Müllkompost und Müll-Klärschlamm-Kompost, ferner kann sie uns bei der Bestimmung des Reifegrades, auf den wir noch zu sprechen kommen, behilflich sein.

Es würde den Rahmen dieses Berichtes sprengen, wollten wir über die I 40 durchgeführten chemischen Bestimmungen eingehend diskutieren. Wir beschränken uns daher auf einige Durchschnittswerte, die uns für die Behandlung der einzelnen Fragen wertvoll erscheinen. 


\section{Der Wassergebalt}

In sämtlichen Mieten der Grossversuche war während der Verrottung der Wassergehalt des Kompostmaterials etwas zu hoch, nämlich zwischen 50 und $60 \%$. Bei dieser hohen Feuchtigkeit besteht die Gefahr, dass Fäulnisvorgänge auftreten, weil dann die Luftzirkulation erschwert ist. Was also bei den Tastmieten zu wenig, war bei den endgültigen Trapezmieten eher zu viel! Aber selbst durch den zu hohen Wassergehalt kam es, wenigstens in den Mieten auf Humusboden, nicht zu Fäulnisvorgängen, was in erster Linie auf die 2-3malige Umarbeitung zurückzuführen ist. Wir halten nach wie vor die Trapezform der Miete für günstiger, damit das Regenwasser wirklich eindringen kann. Aber wenn die Verrottung ihrem Ende entgegengeht, wenn die Mietentemperaturen sinken und demzufolge nicht mehr so viel Wasser verdampfen kann, besteht die Gefahr, dass die Mieten zu nass werden. Wir erachten es daher für vorteilhaft, nach der 2. oder 3. Umarbeitung die Mieten mit dreieckigem Querschnitt aufzuschichten. Dann können sie auch höher, etwa 2-3 $\mathrm{m}$ hoch gehalten werden, weil dann (nach der 2. oder 3. Umarbeitung) die Hauptverrottung beendet ist und daher der Sauerstoffbedarf stark herabgemindert ist. Dieser Punkt ist wichtig für die Praxis, in erster Linie wegen des Platzbedarfes.

\section{Glübverlust, mirksame organische Substanz, Humusstoffe}

Die Bestimmung des Glühverlustes gibt allgemein in der Bodenchemie einen Anhaltspunkt über den Gehalt an verbrennbarer organischer Substanz, wobei jedoch zu berïcksichtigen ist, dass unter Umständen auch anorganische Verbindungen beim Glühen sich verflüchtigen können. In einem Bodenmaterial ohne nennenswerte Fremdbestandteile mag diese Bestimmungsmethode angebracht sein. In manchen Laboratorien wird jedoch auch für den Müllkompost diese Methode verwendet und daraus Rückschlüsse auf den Gehalt an organischer Substanz gezogen. Diese Rückschlüsse sind aber irreführend, denn im Müllkompost sind noch erhebliche Mengen verbrennbarer Anteile enthalten, wie Kohleteilchen, Kautschuk- und Lederabfälle, Kunststoffe usw., welche als inaktive Substanzen zu bezeichnen und für den Boden absolut nutzlos sind. Ein von uns untersuchter Müllkompost wies zum Beispiel einen Glühverlust von $50 \%$ auf. In Wirklichkeit waren aber bloss etwa $25 \%$ wirksame organische Substanz vorhanden, der Rest bestand aus inaktiven Ballaststoffen. Wenn 
also der Glühverlust bestimmt wird, muss zugleich auch die inaktive organische Substanz, die sogenannte "Humuskohle» nach SPRINGER mitbestimmt werden. Erst die Differenz dieser beiden Werte ergibt die wirksame organische Substanz.

Die Bestimmung der laugenlöslichen Humusstoffe gibt uns einen Anhaltspunkt über den Gehalt an echten Humusstoffen und Humusvorstufen. In der folgenden Tabelle sind einige dieser Werte aufgezeigt:

Tabelle 2

Wirksame organiscbe Substanz und Humusstoffe

Durchschnittswerte

(alle Zahlenangaben beziehen sich auf die Trockensubstanz)

\begin{tabular}{|c|c|c|c|c|}
\hline & $\begin{array}{c}\text { Glühverlust } \\
\%\end{array}$ & $\begin{array}{c}\text { Humuskohle } \\
\%\end{array}$ & $\begin{array}{c}\text { Wirksame } \\
\text { organische } \\
\text { Substanz } \\
\%\end{array}$ & $\begin{array}{c}\text { Laugen- } \\
\text { lösliche } \\
\text { Humusstoffe } \\
\%\end{array}$ \\
\hline $\begin{array}{l}\text { Müllkompost ohne } \\
\text { Klärschlamm . . . }\end{array}$ & 28,0 & 16,0 & 12,0 & 8,4 \\
\hline $\begin{array}{l}\text { Mall-Klärschlamm- } \\
\text { Kompost. . . . . } \\
\text { 1. Grossversuch . . . } \\
\text { 2. Grossversuch. . . } \\
\text { 3. Grossversuch . . . }\end{array}$ & $\begin{array}{l}47,4 \\
46,0 \\
56,3\end{array}$ & $\begin{array}{l}18,2 \\
18,6 \\
20,5\end{array}$ & $\begin{array}{l}29,3 \\
27,3 \\
27,3\end{array}$ & $\begin{array}{l}14,2 \\
14,3 \\
14,3\end{array}$ \\
\hline $\begin{array}{l}\text { Müllkompost } \\
\text { La Chaux-de-Fonds . . }\end{array}$ & 42,0 & 12,0 & 30,0 & 4,0 \\
\hline
\end{tabular}

$\mathrm{Zu}$ Vergleichszwecken haben wir auch je einen gewöhnlichen Müllkompost der Anlage Rüschlikon und der Egsetor-Anlage in La Chauxde-Fonds zugezogen. Das betreffende Kompostmaterial stammt aus der gleichen Jahreszeit, so dass Vergleiche möglich sind.

Es fällt uns sofort der deutliche Unterschied zwischen den beiden Müllkomposten einerseits und den Müll-Klärschlamm-Komposten anderseits auf. Der durchschnittliche Gehalt an wirksamer organischer Substanz betrug im Kompost aus dem I. Grossversuch 29,3\%, im Kompost aus dem 2. Grossversuch 27,3\% (infolge der geringeren Klärschlammzugabe). Das Kompostmaterial der Miete 4 (3. Grossversuch) mit Zugabe von Frischschlamm hatte ebenfalls einen Gehalt an organischer Substanz von 
$27,3 \%$, obschon die Zugabe von Frischschlamm beim 3. Versuch bedeutend geringer war als diejenige von ausgefaultem Schlamm beim I. und 2. Versuch. Mit der Zugabe, von Frischschlamm liesse sich vermutlich der Gehalt an wirksamer organischer Substanz noch bedeutend steigern.

Der ungefähr zur gleichen Zeit untersuchte Müllkompost ohne Klärschlamm wies einen Gehalt an organischer Substanz von nur I2\% auf! Einen auffallend hohen Gehalt von 30\% konnten wir jedoch im Kompost aus La-Chaux-de-Fonds feststellen. Hier handelte es sich jedoch nur um zerkleinerten Müll, der praktisch noch keine Verrottung durchgemacht hatte. Der niedrige Gehalt an laugenlöslichen Humusstoffen (4\%) weist ebenfalls darauf hin.

Auch in den eigentlichen Humusstoffen kommt der starke Unterschied zwischen Müllkompost und Müll-Klärschlamm-Kompost sehr deutlich zum Ausdruck. Der durchschnittliche Gehalt an laugenlöslichen Humusstoffen war in allen Müll-Klärschlamm-Komposten ungfähr gleich, nämlich I4,3\%. Es konnte praktisch kein Unterschied festgestellt werden in bezug auf die verschiedenen Mengen von zugegebenem Klärschlamm. Der Gehalt an Humusstoffen im Müllkompost ohne Klärschlamm hingegen betrug bloss $8,4 \%$, derjenige des Rohkompostes aus La-Chaux-de-Fonds sogar nur $4,0 \%$ !

Wir können also schon anhand dieser Analysenresultate festhalten, dass der Müll-Klärschlamm-Kompost zweifellos im Hinblick auf den Gehalt an Humusstoffen und humusbildenden Stoffen bedeutend wertvoller ist.

\section{Der Gebalt an Stickstoff, Phosphor und Kali}

Aus der Tabelle 3 sind die Durchschnittswerte der Analysen ersichtlich.

Durch die Beimischung von Klärschlamm zum Müll konnte nur eine geringfügige Erhöhung des Stickstoffgehaltes im Kompost von I,2 auf durchschnittlich $1,45 \%$ erzielt werden. Dieses Ergebnis stimmt überein mit den Untersuchungen holländischer Fachleute. Die Zugabe von Frischschlamm scheint uns wiederum wirkungsvoller zu sein, was die Erhöhung des Stickstoffgehaltes anbetrifft. In fast allen Mieten konnten wir eine geringe Erhöhung der Stickstoffmenge im Laufe der Verrottungszeit feststellen, was auf eine Anreicherung von Luftstickstoff durch die Mikroorganismen hindeuten würde. Unsere Untersuchungsergebnisse reichen jedoch nicht aus, um hierüber endgültige Schlussfolgerungen zu ziehen.

Die Erhöhung des Gehaltes an Phosphorverbindungen war durch die Zugabe von Klärschlamm zu Müll ziemlich deutlich. 
Tabelle 3

Stickstoff, Pbospbor und Kali (bezogen auf Trockensubstanz)

\begin{tabular}{|l|c|c|c|}
\hline & $\begin{array}{c}\text { Kjeldahl- } \\
\text { Stickstoff } \\
\%\end{array}$ & $\begin{array}{c}\text { Phosphor } \\
\text { als } \mathrm{P}_{2} \mathrm{O}_{5} \\
\%\end{array}$ & $\begin{array}{c}\text { Kali } \\
\text { als } \mathrm{K}_{\mathbf{2}} \mathrm{O} \\
\%\end{array}$ \\
\hline Müllkomposte ohne Klärschlamm . . & 1,2 & 0,5 & 0,9 \\
\hline Muill-Klärschlamm-Kompost & & & \\
1. Grossversuch . . . . . . . . . & 1,4 & 1,4 & 0,8 \\
2. Grossversuch. . . . . . . . . & 1,4 & 0,8 & 0,9 \\
3. Grossversuch. . . . . . . . . & 1,6 & 0,7 & 0,9 \\
\hline
\end{tabular}

Während der gewöhnliche Müllkompost einen Phosphorgehalt (berechnet als $\mathrm{P}_{2} \mathrm{O}_{5}$ ) von durchschnittlich nur $0,5 \%$ aufwies, konnten wir im Müll-Klärschlamm-Kompost des I. Grossversuches einen Gehalt von durchschnittlich $\mathrm{I}, 4 \%$ feststellen. Der Kompost des 2. Grossversuches mit weniger Klärschlamm enthielt bloss $0,8 \% \mathrm{P}_{2} \mathrm{O}_{5}$. Auch beim 3. Grossversuch mit Frischschlamm konnten wir nur eine geringe Erhöhung des Phosphorgehaltes erzielen.

Der Kaligehalt konnte durch die Zugabe von Klärschlamm zum Müll nicht erhöht werden, aus dem einfachen Grunde, weil die Hauptmenge an Kali aus dem Müll stammt!

Noch ein kurzes Wort über das Kohlenstoff-Stickstoff-Verhältnis, das ein Mass für den Grad der Verrottung und für die allgemeine Relation zwischen Energiestoff $(\mathrm{C})$ und Betriebsstoff $(\mathrm{N})$ darstellt. Das C/N-Verhältnis im gewöhnlichen Müllkompost ohne Klärschlamm lag zwischen 20 und 29, das heisst, im Vergleich zu Stickstoff war sehr viel Kohlenstoff vorhanden. Derart weite $\mathrm{C} / \mathrm{N}-$ Verhältnisse sind im allgemeinen unerwünscht. Die landwirtschaftliche Versuchsanstalt Zürich-Oerlikon führte eine Totalanalyse des Müll-Klärschlamm-Kompostes von Miete 3 durch (Ktr.-Nr. 59682) und bestimmte dabei ein C/N-Verhältnis von II, I. Dieses Resultat kann als gut bezeichnet werden.

\section{Der Kalkgebalt und der pH-Wert}

In Tabelle 4 sind die Durchschnittsresultate dieser Bestimmungen dargestellt. Durch die Klärschlammzugabe zum Müll wird der Kalkgehalt eindeutig erhöht. Im Frischschlammversuch (Miete 4) kommt dies aller- 
dings nicht zum Ausdruck. Diese Ausnahme können wir uns vorläufig noch nicht erklären.

Anderseits aber vermag die Klärschlammbeigabe den pH-Wert etwas $\mathrm{zu}$ erniedrigen. Dieser scheinbare Widerspruch erklärt sich aus der Tatsache, dass durch die erhöhte Kohlensäureproduktion in der Miete eine Umwandlung der Kalziumbindungen stattfindet. Dadurch werden dieKalziumverbindungen im Kompost auf einer stabileren Phase angereichert, ähnlich wie dies im Boden der Fall ist. Dafür spricht auch die von uns gemachte Beobachtung, dass der pH-Wert während der Verrottung um durchschnittlich 0,2 bis 0,3 Einheiten absinkt!

Tabelle 4

Dir Kalkgebalt und der pH-Wert

\begin{tabular}{|c|c|c|}
\hline & $\begin{array}{c}\text { Kalkgehalt } \\
\text { als } \mathrm{CaO} \\
\%\end{array}$ & pH-Wert \\
\hline Müllkompost ohne Klärschlamm & 4,8 & 7,7 \\
\hline 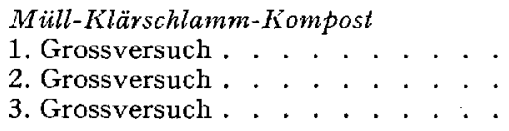 & $\begin{array}{l}7,0 \\
6,9 \\
4,0\end{array}$ & $\begin{array}{l}7,5 \\
7,5 \\
7,6\end{array}$ \\
\hline
\end{tabular}

\section{Fremdbestandteile}

Anlässlich der bereits im ersten Teil dieses Berichtes erwähnten Fragebogen-Aktion stellte es sich heraus, dass einer der Hauptgründe der Beanstandungen die im Kompost enthaltenen Fremdbestandteile, wie Glasund Keramikscherben, Eisenstücke, Stanniolpapier, Kunststoffe usw., sind. Rund 35\% sämtlicher Bezüger von Dano-Kompost der beiden Anlagen Rüschlikon und Küsnacht beschweren sich darüber. Tatsächlich bilden diese Bestandteile nicht nur unnötigen Ballast, sondern vermögen unter Umständen den Kompost unbrauchbar oder zumindest wenig attraktiy zu machen.

Dem Gärtner, der ständig mit den Händen in Berührung kommt mit dem Kompost, sind Glasscherben äusserst hinderlich. Auf Wiesen, besonders mit weidenden Kühen, sind Glasscherben gefährlich. Beim Mähen, 
besonders wenn dies maschinell geschieht, können Eisenstücke und andere harte Bestandteile des Kompostes die Klingen beschädigen, und im Ackerbau sind unverrottbare Nylonstrümpfe ebenfalls hinderlich beim Eggen und anderen Arbeiten. Wir müssen also diesem Problem ebenfalls unsere volle Beachtung schenken.

In Holland unterscheidet man im Hinblick auf diese Fremdbestandteile zwischen Gartenbau- und Landbaukompost. An und für sich handelt es sich dabei um dasselbe Produkt, der Unterschied liegt allein in der Siebanalyse. Beim Gartenbaukompost darf der Gehalt an Glasscherben nicht mehr als $0,5 \mathrm{~kg} / \mathrm{t}$ betragen. Derselbe maximale Gehalt gilt auch für Keramikscherben. Der Gehalt an Kohleteilchen und Schlacken darf $s \mathrm{~kg} / \mathrm{t}$ nicht überschreiten. Scherben und Kohleteilchen werden bestimmt mit Hilfe eines Siebes mit runden Löchern von 6,8 mm Durchmesser. Eisen darf überhaupt nicht vorkommen. Für den Landbaukompost sind die Anforderungen in Holland nicht so hoch. Die betreffenden noch zugelassenen Gehalte an den erwähnten Fremdbestandteilen sind etwa Iomal höher als für den Gartenbaukompost.

Bei uns dürften diese Anforderungen, speziell für den Gartenbaukompost, noch strenger sein als in Holland. So werden zum Beispiel Glasscherben von weniger als 6,8 $\mathrm{mm}$ Grösse, die also durch das von den Holländern angewandte 'Testsieb noch durchgehen, ebenfalls beanstandet. Eine der Aufgaben der neugegründeten Internationalen Arbeitsgemeinschaft für Müllforschung wird es sein, auch im Hinblick auf diese Fremdbestandteile internationale Richtlinien auszuarbeiten.

Wir haben an unseren in Rüschlikon hergestellten Komposten ebenfalls diese Analysen der Fremdbestandteile durchgeführt. Der durchschnittliche Gehalt betrug

an Glas- und Keramikscherben: $0,7-1 \%$ (7-1o kg/t),

an Steinen und Schlacken: $3-4,5 \%(30-45 \mathrm{~kg} / \mathrm{t})$,

an Metall, Stanniolpapier usw.: $0,08-0,1 \%(0,8-\mathrm{I} \mathrm{kg} / \mathrm{t})$.

Diese Gehalte, namentlich an Glasscherben, sind zweifellos viel zu hoch. Sie liegen viel höher als die von den Holländern festgesetzten Normen. Dabei ist jedoch zu betonen, dass wir bei unseren Analysen auch die Scherben unter $6,8 \mathrm{~mm}$ Grösse erfasst haben!

Der Maschinenindustric fällt also dic Aufgabe zu, entsprechende Maschinen zu entwickeln, um das Scherbenproblem zu lösen. Dies ist zum Teil auch bereits geschehen. Für die im Bau begriffene Kompostierungsanlage der Stadt Chur soll die Scherbenfreiheit des Kompostes garantiert worden sein. 
Wir möchten noch betonen, dass mit einer getrennten Scherbenabfuhr nicht viel geholfen ist. In Rüschlikon werden bekanntlich die Scherben getrennt abgeführt, und trotzdem ist der Gehalt an diesen Stoffen noch viel $\mathrm{zu}$ hoch!

Die Entfernung von Zentralheizungsrückständen aus dem Müll vor der Kompostierung (Schlacke und Asche) ist sehr zu begrüssen, wirken doch diese Anteile bloss als Ballast. Durch grössere Mengen dieser Stoffe besteht die Gefahr, dass der Kompost zu alkalisch wird. Die Entfernung der Aschebestandteile in der Kompostierungsanlage selbst ist ein technisch durchaus lösbares Problem (Rüttelsieb oder Rotiertrommel).

\section{H. Der Reifegrad des Kompostes}

Eine der wichtigsten Fragen für die Praxis ist diejenige der Verrottungszeit. Je länger der Kompost bis zur Erreichung des Reifegrades gelagert werden muss, desto grösser ist auch der Platzbedarf einer Mietenanlage. Wir möchten daher diesem Problem unsere besondere Beachtung schenken. Bisher wurde einerseits die Auffassung vertreten, dass das Kompostmaterial mindestens 8-ro Monate lang gelagert werden müsse, um einen reifen Kompost zu erhalten. Andererseits wurde auch vermutet, der aus der Gärtrommel entnommene, 4-5 Tage lang vorvergärte Rohkompost sei ausgereift!

Auch über diese Frage herrschen in der Literatur und unter den Fachleuten geteilte Meinungen. Frischer, unausgereifter Rohkompost kann nur Verwendung finden als Wärmespendẹr für Treibbeete. Dadurch soll ja die von den Mikroorganismen erzeugte Wärme beim Rotteprozess ausgenützt werden. Als eigentlicher Freilanddünger sollte der Kompost hingegen reif, das heisst weitgehend verrottet sein. Aber welche Kriterien sind massgebend für den Reifegrad? - Der Gärtner prüft seinen Kompost mit Hilfe der Regenwürmer: Wenn sie sich im Kompost angesiedelt haben, bezeichnet er ihn als « reif».

Wir versuchten, den Reifegrad des Kompostes mit Hilfe der Temperatur und der Kohlensäureproduktion nach der jeweiligen Umarbeitung sowie nach der Form des im Kompost vorhandenen Stickstoffs zu bestimmen.

Wie wir bereits anhand der periodischen Kontrollen festgestellt haben (Abbildungen 5-II), erhöht sich nach der Umarbeitung der Mieten die Kohlensäureproduktion und die Temperatur sehr deutlich, weil durch die Umarbeitung neuer Sauerstoff zugeführt und demzufolge die biologische Aktivität gesteigert wird. Dieser Anstieg war jeweils nach der 
ersten Umarbeitung besonders stark, nach der zweiten nur noch schwach. Wenn nun die Temperatur und die Kohlensäure nach einer weiteren Umarbeitung nicht mehr ansteigt, ist dies ein Zeichen, dass die Verrottungsprozesse weitgehend zum Stillstand gekommen sind und demzufolge der Kompost reif ist.

Die Miete 3 wurde am I45. Tag zum dritten Mal umgearbeitet (siehe Abbildung 7). Wir konnten anschliessend keine nennenswerte Erhöhung der Kohlensäureproduktion und der Temperatur mehr beobachten. Auf Grund dieser 'Tatsache können wir also feststellen, dass unser Kompost nach einer Verrottungszeit von 145 Tagen ausgereift war.

Neben dieser soeben besprochenen Möglichkeit der Bestimmung des Reifegrades versuchten wir noch, mit Hilfe der Stickstoffanalyse den Grad der Verrottung zu erkennen. Solange der Abbauprozess in vollem Gange ist, wird der Stickstoff, da er ja den eigentlichen Betriebsstoff darstellt, gänzlich von den Mikroorganismen beschlagnahmt, das heisst, er wird ausschliesslich in organischer Form im Kompost vorhanden sein. Bis er in mineralischer Form vorliegt, muss er oft den Weg über manche Organismenleiber durchlaufen. Erst wenn der Verrottungsprozess praktisch zu Ende ist, besteht die Möglichkeit der Bildung von anorganischem Stickstoff, also von Ammonium- bzw. Nitrit- und Nitratstickstoff. Diese Annahmen sind nur gültig unter der Voraussetzung, dass der Verrottungsprozess ungestört vor sich geht, was wir anhand der Temperatur- und der Kohlensäureentwicklung, des Wassergehaltes und mit Hilfe der Silberstabmethode feststellten können. Sobald wir also im Kompost Nitrite und Nitrate nachweisen können, ist dies ein Zeichen, dass der Kompost reif ist, das heisst, dass bei seiner Verwendung als Freilanddünger im Boden keine unerwünschte Stickstoff-Festlegung mehr stattfindet.

Wir konnten im Kompost sämtlicher Mieten (mit Ausnahme der Miete 4) nach I45 Tagen Nitrite und Nitrate deutlich nachweisen, und zwar in Mengen bis zu so $\mathrm{mg} / \mathrm{kg}$ Trockensubstanz. Im Material der Miete 4, die damals erst etwa 90 Tage alt war, konnte noch keine Spur von Nitraten festgestellt werden.

Wir haben also diesen Endpunkt der Verrottung auf zwei ganz verschiedene Arten übereinstimmend festhalten können. Dass sich auch die Regenwürmer programmässig einstellten, sei nur am Rande erwähnt!

Die Kompostierung sollte also an jenem Zeitpunkt beendet werden, wo sich Nitrate bilden. Wird die Kompostierung vorher beendet, besteht die Gefahr der Stickstoff-Festlegung im Boden. Sie aber noch über den Endpunkt auszudehnen, wäre ebenfalls ein Nachteil, weil dann die Nitrate 
durch Regen ausgewaschen werden und dadurch ein Stickstoffverlust entstehen würde. Wenn es praktisch nicht möglich ist, den ausgereiften Kompost sofort an die Verbraucher abzugeben, wird eine Stapelung in Form höherer Mieten in Dreieckform vorteilhaft sein, erstens um eine zu starke Durchnässung der Mieten und eine Auswaschung zu verhindern, zweitens um Platz zu sparen.

\section{J. Die hygienische Frage und die Verunkrautungsgefahr}

Da wir aus arbeitstechnischen Gründen nicht in der Lage waren, Untersuchungen im Hinblick auf die hygienischen Belange durchzuführen, sind wir grösstenteils auf ausländische Erfahrungen angewiesen.

Tatsache ist, dass dic Hygieniker den Müll bisher für keinen gesundheitsschädlich besonders gefährlichen Stoff halten. Der Müllarbeiter als «'Testobjekt» weist nicht häufiger Wundinfektionen oder übertragbare Krankheiten auf als andere Arbeiter. Selbst durch intensiven Müllstaub erfolgen keine nachhaltigen Wirkungen, was durch ausgedehnte Untersuchungen in Berlin festgestellt worden ist. Auch die Entwicklung einer sogenannten Silikose-Staublunge wurde nicht festgestellt. Bei Verbrennungsanstalten besteht nach Ansicht einiger Fachleute unter Umständen eine Silikosegefahr.

Auch die rein bakteriellen Gefahren, dic vom Müll ausgehen sollten, werden von den Hygienikern verneint. Dass Abfälle von Spitälern, ärztlichen, zahnärztlichen und tierärztlichen Praxisräumen nicht oder nur in sterilisiertem Zustand zur Kompostierungsanlage gelangen sollten, ist selbstverständlich. Diese Abfälle müssen an den Anfallstellen selbst unschädlich gemacht werden.

Selbst die manuelle Vorsortierung des Mülls ist nach Ansicht der Fachleute keineswegs mit direkten gesundheitlichen Schäden oder Gefahren verbunden. Allerdings muss sie als unästhetisch bezeichnet werden.

In bezug auf die Abtötung wichtiger Krankheitserreger spricht sich KNORR [3] folgendermassen aus:

a) Im Müll kommt von den sporenbildenden übertragbaren Keimen nur der Milzbrand in Frage. Die Sporen werden sicher nicht abgetötet, selbst bei einwandfreier Kompostierung. Deshalb empfiehlt KnORR den Gerbereischlamm, in welchem diese Keime unter gewissen Umständen vorhanden sein können, nicht zur Kompostierung.

Für schweizerische Verhältnisse sind jedoch, wie uns das Eidgenössische Gesundheitsamt in Bern mitteilte, diese Befürchtungen unbegründet, denn 
bei uns ist die Wahrscheinlichkeit ausserordentlich gering, dass Gerbereien Abfälle liefern, die mit Milzbrand infiziert sind.

b) Von den nicht sporenbildenden, übertragbaren Krankheiten (zum Beispiel Mycob. tbc. und Salmonellen) werden die im Kern der Miete, jedoch nicht in der peripheren Zone vorhandenen Keime schon in den ersten Tagen der Kompostierung abgetötet. Es ist daher wichtig, dass die oberflächlichen Schichten der Miete durch Umarbeitung auch in den Mietenkern gelangen. Eine guteDurchfeuchtung des Mietenmaterials zu Beginn der Kompostierung ist notwendig, denn trockene Keime, wie sie zum Beispiel im Staubsaugerunrat cingeschlossen sind, werden selbst bei Temperaturen von $70^{\circ} \mathrm{C}$ nur teilweisc vernichtet. Genügende Feuchtigkeit, langanhaltende Temperaturen um $60^{\circ}$, antibiotisch wirkende Kräfte der Rotteorganismen, mit andern Worten: eine einwandfreie Kompostierung, selbst unter Zugabe von Klärschlamm, gewährt die notwendige Sicherheit in hygienischer Beziehung.

Was die Vernichtung der Wurmeier anbetrifft, die namentlich im Klärschlamm enthalten sind, haben zahlreiche Untersuchungen ergeben, dass bei einwandfreier Kompostierung eine Verwurmungsgefahr durch Anwendung von Kompost nicht besteht.

Wir haben den ganzen Fragenkomplex anlässlich einer Besichtigung unserer Versuche in Rüschlikon mit Herrn Prof. Dr. MOOSER, dem Direktor des Hygieneinstitutes der Universität Zürich, besprochen. Auch er sieht in einer einwandfreien Kompostierung keinerlei hygienische Gefahren.

Um die Frage nach der Vernichtung der in erster Linie im Klärschlamm enthaltenen Unkrautsamen abzuklären, haben wir folgenden Versuch angestellt:

Wir erstellten eine Versuchsmiete, die nur aus eingedicktem Klärschlamm der Kläranlage Winterthur bestand. Unmittelbar daneben wurde eine Miete aufgeschichtet, die aus einer Mischung von Müll und demselben Klärschlamm gemäss dem ersten Grossversuch bestand. Schon nach wenigen Tagen war die Klärschlamm-Miete mit einem grünen Rasen von Un'kräutern überzogen, unter denen junge Tomatenpflänzchen dominierten. Nach rund 2 Wochen beherrschten die Tomaten vollkommen das Feld, und nach einigen weiteren Wochen erhielten wir einen reinen Bestand von rund $80 \mathrm{~cm}$ hohen Tomatenstauden, welche die KlärschlammMiete vollkommen überdeckten. Die unmittelbar danebenstehende MüllKlärschlamm-Miete zeigte kcine Spur von Unkräutern, wie dies in Abbildung 22 ersichtlich ist.

Damit dürfte der Beweis erbracht sein, dass durch die Beimischung 
von Klärschlamm zum Müll mit anschliessender Trommel- und Mietengärung die Unkrautsamen restlos vernichtet und dadurch die dem gewöhnlichen Klärschlamm anhaftenden Nachteile behoben werden können.

\section{Dritter Teil}

\section{Schlussfolgerungen für die Praxis}

\section{A. Beimischung von Klärschlamm}

I. Auf Grund der durchgeführten Untersuchungen ist es möglich, den in einem bestimmten Einzugsgebiet anfallenden Müll mit äquivalenten Mengen von Klärschlamm einer mechanischen oder einer mechanischbiologischen Kläranlage gemeinsam in einer Kompostierungsanlage nach dem Gärtrommelverfahren zu verarbeiten, ohne dass Störungen in der Gärtrommel zu befürchten sind. Voraussetzung aber ist, dass der Klärschlamm ausgefault und auf einen Wassergehalt von $70-75 \%$ eingedickt ist (siehe Diagramm, Abbildung 4). Alle diese Versuche wurden mit Sommermüll durchgeführt. Es ist anzunehmen, dass unter Verwendung des eher trockeneren Wintermülls dic Klärschlammbeigabe sogar noch gesteigert werden kann. Inwieweit man Klärschlamm mit Müll gemeinsam kompostieren kann in Anlagen, die nicht nach dem Gärtrommelverfahren arbeiten (zum Beispiel Gärzellen-, Raspel-, Zerkleinerungs-, Egsetor-Verfahren usw.), muss durch Versuche in anderen Kompostierungsanlagen festgestellt werden.

2. Es ist möglich, in der Gärtrommel auch uneingedickten, ausgefaulten Klärschlamm mit zu verarbeiten, jedoch in Mengen, die wesentlich unter dem Äquivalent liegen (siehe Diagramm, Abbildung 4).

3. Prinzipiell kann auch Frischschlamm mit reduziertem Wassergehalt gemeinsam mit Müll in der Gärtrommel verarbeitet werden, ohne dass eine starke Geruchsbelästigung eintritt, jedoch nur in Mengen, die wesentlich unter dem Äquivalent liegen (siehe Diagramm, Abbildung 4). Durch die plötzliche Wasserabgabe und durch die verminderte Wasseraufnahmefähigkeit des frischen Schlammes infolge des hohen Fettgehaltes können in der Gärtrommel Störungen eintreten. Wir schlagen daher vor, gegebenenfalls den Frischschlamm wenige Tage anzufaulen, um den Abbau der Fettsubstanzen in die Wege zu leiten und erst dann mit dem Müll $\mathrm{zu}$ verarbeiten. 
4. Bei der gemeinsamen Kompostierung von Müll und Klärschlamm nach dem Gärtrommelverfahren fallen somit die Faulräume einer Kläranlage nicht weg. Durch die in Ziffer 3 erwähnte reduzierte Faulzeit dürfte jedoch eine Reduktion des Faulraumvolumens möglich sein.

5. Die einfachste Art der Zugabe des Klärschlammes in die Gärtrommel scheint uns darin zu bestehen, dass Klärschlamm mit einem Wassergehalt von $70-75 \%$ direkt aufs Förderband gegeben wird, im analogen Mischungsverhältnis, wie es sich im ersten Grossversuch ergeben hat, und zwar auf $550 \mathrm{~g}$ Müll (= Tagesanfall pro Einwohner) eine auf $70-75 \%$ Wassergehalt eingedickte Schlammenge von 0,31 . Im Diagramm (Abbildung 4) ist ersichtlich (unter Anwendung der mittleren Feststoffmengen), dass aus einer mechanischen Anlage 0,I 81 und aus einer mechanisch-biologischen Anlage 0,251 ausgefaulten Schlammes von $73 \%$ Wassergehalt zu erwarten sind. Diese Zahlengegenüberstellung zeigt wiederum, dass aus dem gleichenEinzugsgebiet die Müllmenge grösser ist als dieSchlammenge, welche wasseranteilmässig in der Gärtrommel verarbeitet werden kann. Ein allfällig entstehendes Feuchtigkeitsmanko könnte durch Zusatz von Wasser oder Filtrat, wie es beim Schlammeindicker in Winterthur anfällt, kompensiert werden.

\section{B. Die Mietengärung}

\section{Die Mietenunterlage}

Als günstigste Mietenunterlage hat sich gewöhnlicher Humusboden erwiesen. Das Gelände, auf dem die Mieten erstellt werden, sollte wenn möglich ein leichtes Gefälle besitzen, damit sich ansammelndes Oberflächenwasser abfliessen kann. Auf alle Fälle muss dafür gesorgt werden, dass sich keine grösseren Wasserlachen um die Mieten bilden (eventuell Drainagegräben ziehen).

\section{Die Mietenform}

Auf Grund unserer Versuche scheint uns eine flache Miete mit trapezförmigem Querschnitt von etwa $\mathrm{I}-\mathrm{I}, 5 \mathrm{~m}$ Höhe am günstigsten zu sein. Das Regenwasser sollte während der Verrottung in die Mieten eindringen können, da sonst Gefahr der Austrocknung besteht. Eine etappenweise Aufschichtung (2-3 Etappen) scheint uns vorteilhaft zu sein, weil dadurch extrem hohe Temperaturen (über $65^{\circ}$ ) vermieden werden können. Bei allzu hohen Temperaturen besteht die Möglichkeit, dass gewisse Mikro- 
organismen absterben, wodurch der Verrottungsvorgang verzögert wird. $\mathrm{Zu}$ hoch darf die Miete nicht aufgeschichtet werden, weil sonst die Durchlüftung mangelhaft wird und demzufolge die Verrottungsvorgänge in Fäulnis umschlagen können.

Ferner ist es sehr zu empfehlen, die frisch aufgeschichteten Mieten mit einer rund $5 \mathrm{~cm}$ dicken Lage fertig verrrotteten Kompostes zu übedecken. Diese Bedeckung bietet folgende Vorteile:

Die der Sonnenstrahlung ausgesetzten äussersten Schichten des Mietenmaterials verrotten erfahrungsgemäss viel langsamer als das tieferliegende Material. Ferner wird die biogene Wärme der äusseren Schichten laufend an die Aussenluft abgegeben, so dass diese Schichten nie in den höheren Temperaturbereich gelangen, wenn nicht durch eine sorgfältige Umarbeitung dafür gesorgt wird, dass das peripher gelegene Kompostmaterial in grössere Tiefen gelangt. Bei einer Kompostierungsanlage nach dem Gärtrommelverfahren wird zwar das auf die Mieten verbrachte Material bereits mehrere Tage bei einer Temperatur von etwa $50^{\circ}$ vorbehandelt. Bei anderen Verfahren ohne diese Vorgärung bietet jedoch die erwähnte Bedeckung mit reifem Kompost den Vorteil, dass auch die äussersten Schichten des frischen Materials in den höheren Temperaturbereich gelangen. Dies ist namentlich wichtig, wenn hygienisch nicht einwandfreier Klärschlamm beigemischt wird.

Wenn das Material in den Mieten einwandfrei verrottet ist (was bei unseren Versuchen nach I40-I 50 Tagen der Fall war) und wenn es nicht möglich ist, den Kompost sofort an die Verbraucher abzugeben, empfehlen wir zur Stapelung eine Mietenform mit dreieckigem Querschnitt und einer Höhe von 2-3 $\mathrm{m}$ zu wählen, denn der reife Kompost benötigt nicht mehr so viel Sauerstoff wie das in Verrottung begriffene Material. Durch diese dreieckige Stapelfrom wird der Kompost weniger durchnässt, und der Platzbedarf für die Mieten reduziert sich ganz bedeutend. Noch besser wäre es, den fertigen Kompost durch Bedachung vor Regen und starker Sonnenbestrahlung zu schützen. Dies wird aber infolge der Kosten in den wenigsten Fällen möglich sein.

\section{Die Unarbeitung}

Es hat sich gezeigt, dass das zu kompostierende Material während der Verrottungszeit mindestens zweimal umgearbeitet werden muss, um durch Zufuhr von Sauerstoff der Verrottung einen neuen Impuls zu geben und um eventuell sich bildende Fäulnisherde zu vernichten. Die erste Um- 
arbeitung sollte spätestens $4-5$ Wochen nach der Aufschichtung der Miete erfolgen, weil in den ersten Wochen der Abbauvorgang und demzufolge der Sauerstoffbedarf besonders intensiv ist. Zur Kontrolle empfehlen wir die Silberstabmethode. Zeigen die Silberstäbe (versilberte Eisenstäbe) schon vor Ende der 4. Woche starke Schwefelwasserstoffbildung an, so muss die erste Umarbeitung früher vorgenommen werden. Dieser Fall kann eintreten, wenn das Ausgangsmaterial zu nass ist. Für dic Praxis scheint uns eine periodische Kontrolle der Kohlensäureproduktion nicht notwendig zu sein. Hingegen muss die Mietentemperatur in den ersten paar Wochen täglich, nachher zweimal wöchentlich gemessen werden. Dazu empfehlen wir etwa $80 \mathrm{~cm}$ lange Steckthermometer (Bimetallthermometer). Quecksilberthermometer haben sich weniger gut bewährt. Die Temperatur sollte jeweils in einer Tiefe von $20-30 \mathrm{~cm}$ unter der Oberfläche sowie etwa $20 \mathrm{~cm}$ ob Terrain gemessen werden. Steigt die Temperatur trotz etappenweiser Aufschichtung der Miete auf über $65^{\circ}$, so sollte das Material umgearbeitet werden.

Abbildung 23 zeigt eine ausgesprochen schlecht aufgeschichtete Miete. Sie war etwa 2 Meter hoch und wurde nie umgearbeitet. Nach einjähriger Lagerung haben wir sie aufgeschnitten und dabei festgestellt, dass der ganze untere Teil der Miete bis in eine Höhe von etwa $\mathrm{I}, 6 \mathrm{~m}$ vollkommen verpappt und mit schwarzem Schwefeleisen durchsetzt war. Nach einjähriger Lagerung war also das Material noch nicht verrottet, sondern war zum grössten Teil verfault. Auf der Photo (Abbildung 23) sieht man deutlich den von Schwefeleisen tiefschwarz gefärbten unteren Teil der Miete.

Ebenfalls unerlässlich ist eine periodische Kontrolle des Feuchtigkeitsgehaltes der Miete. Das Ausgangsmaterial sollte einen Wassergehalt von $40-50 \%$ besitzen. Ein höherer Gehalt kann zu Fäulnis, ein niedriger zu Austrocknung führen. Während der Verrottung sollte der Wassergehalt ebenfalls $40-50 \%$ betragen. Falls er absinkt, muss die Miete besprengt werden. Die Bestimmung des Wassergehaltes sollte also im Ausgangsmaterial erfolgen, nachher einmal wöchentlich. Wir empfehlen dazu das einfach zu bedienende, im Kapitel «Untersuchungsmethodik» beschriebene CM-Gerät, das zwar nicht so genau arbeitet wie die Laboratoriumsmethode, für unsere Zwecke jedoch genügend sein dürfte.

Die Umarbeitung der Mieten kann bei kleineren Anlagen von Hand vorgenommen werden. Für grössere Anlagen wird sich dies jedoch kaum lohnen. Es wurden bereits Versuche mit einem Snowboy, einer Schneeschleuder, unternommen, die erfolgversprechend verlaufen sind. Auch mit 
einem Trax oder ähnlichen Maschinen kann die Umarbeitung vorgenommen werden. Auf jeden Fall ist es empfehlenswert, eine Maschine zu verwenden, mit der man zugleich Umarbeiten und den fertigen Kompost verladen kann.

\section{Die Bestimmung des Reifegrades}

Wenn die Mietentemperatur nach der zweiten oder dritten Umarbeitung nicht mehr deutlich ansteigt, kann der Kompost als ausgereift betrachtet werden. Dies wird in der Regel frühestens nach 4 Monaten der Fall sein. Im Zweifelsfalle ist es zweckmässig, eine Prüfung auf Nitrit-Nitrat-Stickstoff vornehmen zu lassen (siehe Abschnitt H, Der Reifegrad des Kompostes). Ferner empfehlen wir eine periodische Analyse des Kompostes im Hinblick auf seinen Gehalt an wirksamer organischer Substanz, Humusstoffen und Kernnährstoffen. Der Kompost sollte zum Zwecke der Freilanddüngung nur in einwandfreier Qualität und in einwandfrei verrottetem Zustand an die Verbraucher abgegeben werden!

\section{Die Qualität des Müll-Klärscblamm-Kompostes}

Der Müll-Klärschlamm-Kompost ist qualitativ bedeutend besser als der gewöhnliche Müllkompost. Durch das im ersten Grossversuch (Miete I bis 3) angewandte Mischungsverhältnis Müll/Klärschlamm erhielten wir einen Kompost, dessen Gehalt an wirksamer organischer Substanz mehr als doppelt so hoch und dessen Gehalt an laugenlöslichen Humusstoffen etwa $50 \%$ höher war als im gewöhnlichen Müllkompost. Auch nährstoffmässig bedeutet die Klärschlammbeimischung eine bedeutende Verbesserung.

\section{Einige Erfabrungszablen aus dem Betrieb der Anlage Rüschlikon}

Zurzeit angescblossene Eimmobner (Gemeinden Rüschlikon und Kilchberg): 10700

$\begin{array}{llc}\text { Anfall Robmïll } & \text { Montag (Kilchberg) } & \text { rund } 35 \mathrm{~m}^{3} \\ & \text { Dienstag (Rüschlikon) } & \text { rund } 22 \mathrm{~m}^{3} \\ \text { Mittwoch } & - \\ \text { Donnerstag (Kilchberg) } & \text { rund } 40 \mathrm{~m}^{3} \\ \text { Freitag (Rüschlikon) } & \text { rund } 15 \mathrm{~m}^{3} \\ \text { Samstag } & - \\ & \text { Total } & \text { rund } 100-115 \mathrm{~m}^{3} \text { pro Woche }\end{array}$


Raumgewicht des Robmülls (Durchschnittswert): $270 \mathrm{~kg} / \mathrm{m}^{3}$

Getrennte Scberben und Sperrstoffabfubr

Hergestellte Robkompostmenge pro Woche:

rund $22-25 \mathrm{~m}^{3}$

Raumgemicht des der Trommel entnommenen

Rohkompostes:

Normaler Wassergebalt des Rohkompostes: $\quad 40 \%$

$700-750 \mathrm{~kg} / \mathrm{m}^{3}$

Von einer Tonne Rohmüll erhalten wir rund:

$600 \mathrm{~kg}$ Rohkompost;

$30 \mathrm{~kg}$ Metalle;

$70 \mathrm{~kg}$ verbrennbares Material, wie Lumpen, Kautschukabfälle, alte Bücher, Kunststoffe usw., das im Ofen der Anlage verbrannt wird;

$80 \mathrm{~kg}$ nicht kompostierbare und nicht brennbare Anteile, die auf die Deponie gelangen;

$220 \mathrm{~kg}$ des Rohmülls entweichen während der Vorgärung in der Trommel in Form von Wasser und Kohlensäure.

\section{Vorschläge für die Weiterentwicklung}

Auf Grund der in Rüschlikon durchgeführten Versuche besteht die Möglichkeit einer gemeinsamen Verarbeitung der festen und der flüssigen Abfallstoffe einer Gemeinde. Das Problem der Abfallstoffbeseitigung im allgemeinen ist somit auf eine neue Ebene zu stellen. Über die Art der Beseitigung der füssigen Abfallstoffe, das heisst bei der Abwasssercinigung, gehen heute die Meinungen kaum mehr stark auseinander. Schwierigkeiten können erst bei der Beseitigung oder Wiederverwendung der grossen Schlammengen auftreten. Je nach Art der Abwässer und hauptsächlich in Berücksichtigung des Selbstreinigungsvermögens des Vorfluters werden die Abwässer in einer mechanischen Absetzanlage oder in einer mechanisch-biologischen Reinigungsanlage behandelt, wobei immer noch verschiedene Möglichkeiten in der Detailausführung je nach den örtlichen Verhältnissen bestehen.

Bei der Beseitigung der festen Abfallstoffe hingegen stellt sich immer wieder die Frage, ob der Müll zu Kompost verarbeitet oder verbrannt werden soll. Für grössere Städte scheint es ausser Diskussion zu stehen, dass eine Verbrennung im Vordergrund liegt. Handelt es sich hingegen um Landstädte, Landgemeinden oder Gemeindegruppen, so sollte die 
Frage nicht mit entweder oder, sondern mit sowohl als auch beantwortet werden.

Betrachten wir in Abbildung I2 den Müll bezüglich seiner jahreszeitlichen Zusammensetzung, so sehen wir, dass die Kurve der organischen Anteile im Sommer eine Spitze aufweist, der untere Heizwert dagegen im Winter eine obere Grenze erreicht. Aus der in Abbildung I2 ersichtlichen Kurvenschar ist zu entnehmen, dass sich der Müll in den Wintermonaten eher für eine Verbrennung und in den übrigen Monaten eher für eine Kompostierung eignet. Es wäre aber kaum zu verantworten, für mittlere und kleinere Anlagen ausser eines Kompostwerkes auch noch eine komplette Verbrennungsanlage $z u$ erstellen. In letzter Zeit sind nun verschicdene Verfahren entwickelt worden, die eine Verarbeitung des Mülls zu brennbaren Briketts ermöglichen. Der Müll wird in einer Zerfaserungsmaschine zerkleinert, eventuell getrocknet, und anschliessend in einer Presse mit hohem Druck zu Briketts verarbeitet. Diese Briketts weisen einen Heizwert auf, der annähernd demjenigen der Braunkohle entspricht. Somit muss die bei der Verbrennung des Mülls entstehende Wärmeenergie nicht mehr in Form von Dampf transportiert werden, sondern der Energietransport erfolgt in Form von Heizbriketts. Zudem kann auf diese Art die Wärmeenergie gespeichert und im günstigsten Zeitpunkt ausgenützt werden. Dadurch wird die Standortfrage einer Müllbeseitigungsanlage in bezug auf den Wärmeenergieabnehmer sehr vereinfacht.

In Abbildung I3 sind die Verhältnisse in einem Schema einer kombinierten Anlage für die Früblings-, Sommer- und Herbstmonate dargestellt: Der Müll gelangt vorerst in einen Silo und wird durch ein Förderband über eine Aschensiebstufe in den Schneckensilo der Gärtrommel transportiert. In den Schneckensilo wird zugleich aus einem darüber montierten Klärschlammbehälter mittels einer einfachen Abschälvorrichtung der auf etwa $73 \%$ Wassergehalt eingedickte (eventuell nur angefaulte) Klärschlamm im gewichtsmässigen Verhältnis Müll/Klärschlamm von 2 : I dosiert beigegeben. In der langsam rotierenden Gärtrommel erfolgt während 4-5 Tagen die Vorgärung mit Temperaturen von $50-60^{\circ}$, wobei die Gewähr geboten ist, dass der gesamte Anfall des beigegebenen Klärschlammes diese Temperaturgrenze erreicht. Diese Forderung ist in bezug auf die Vernichtung der Wurmeier, der pathogenen Keime und Unkrautsamen von grosser Bedeutung.

Anschliessend erfolgt eine Ausscheidung der Eisenmetallteile, der Scherben und des Siebrestes. Der feine Frischkompost gelangt auf die Mietenplätze zur Verrottung. Sobald er reif ist, kann er in lockerer Form an die 


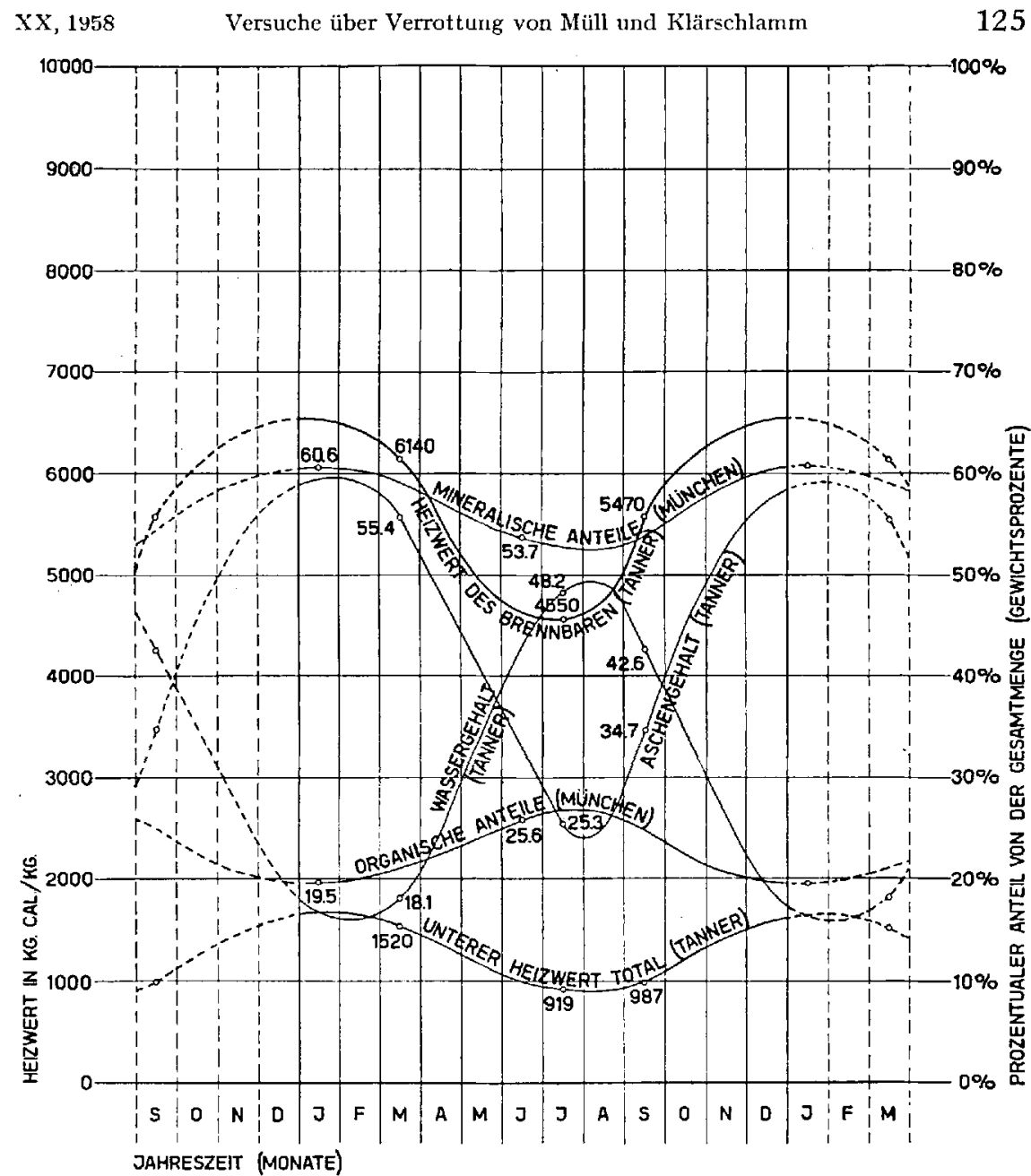

Abbildung 12

Jahreszeitliche Änderung des Hausmüls.

Verbraucher abgegeben werden, er könnte aber auch mit Hilfe einer Presse zu Kompostbriketts verarbeitet und in dieser Form an die Konsumenten abgegeben werden. Anderseits kann der Frischkompost unmittelbar nach der Entnahme aus der Gärtrommel für Wärmepackungen abgegeben werden.

Durch den Brikettierungsvorgang wird das Volumen des Kompostes auf etwa I/ro herabgesetzt, was den Transport wesentlich erleichtert und auch eine Lagerung beim Konsumenten ohne grosse Raumbeanspruchung 
ermöglicht. Auf diese Art könnte der Kompostabsatz wesentlich verbreitert werden. Kompostbriketts liessen sich je nach Bedarf auch beim extensiven Ackerbau verwenden, indem sie mittels einer einfachen fahrbaren Raspelmaschine direkt auf den Acker gegeben werden. Auch für den Rebbau und die Baumschulen könnten diese Briketts in Betracht kommen, da sie unter dem Einfluss der Witterung zerfallen.

Die Verhältnisse für die $W$ intermonate sind im Schema (Abbildung I4) dargestellt: Der Müll gelangt wiederum in den Silo und passiert eine erste Siebstufe, bei welcher die Sperrstoffe ausgeschieden werden. Nach dem Zerfaserungsprozess gelangt das Material nach Passieren einer zweiten Siebstufe in die Presse und wird zu Briketts verarbeitet. Dabei wird das Material je nach Verfahren vor dem Pressen heissgetrocknet oder nach dem Pressen luftgetrocknet. Diese Briketts können für Industriebrand, für Hausbrand oder für interne Verwendung in der Müllverarbeitungsanlage oder Kläranlage benützt werden. Es besteht fernerhin die Möglichkeit, entwässerten Schlamm für Heizzwecke zu brikettieren, was jedoch in der Praxis noch restlos abgeklärt werden sollte. Der in den Wintermonaten anfallende Klärschlamm könnte, sofern eine Brikettierung oder andere VerVerwendung nicht in Frage kommt, über einen Bandtrockner im Heissluftgegenstrom in ein streufähiges Produkt übergeführt werden. Durch die Wärmecinwirkung, die die $60^{\circ}$-Grenze weit übersteigt, wird somit der Schlamm in hygienischer Beziehung einwandfrei.

Diese Anordnung bedingt zusätzliche Anlageteile einerseits in der Kläranlage. Ein Bandtrockner für eine Kläranlage von etwa 30000 Einwohnern liegt kostenmässig in der Grössenordnung von etwa Fr. 30000.-. Die Betriebskosten beschränken sich auf die eigentlichen Wintermonate. Anderseits belaufen sich die zusätzlichen Kosten bei einer Kompostierungsanlage mit Gärtrommel für die Zerfaserung und Brikcttierung auf etwa Fr. 60000.-, unter Berücksichtigung der Möglichkeit der gemeinsamen Verwendung bestimmter Anlageteile, wie zum Beispiel zweite Siebstufe und Metallausscheidung. Alle diese Zahlenangaben beziehen sich auf eine Anlage für rund 60000 Einwohner.

Dieser Vorschlag einer gemeinsamen Aufbereitung flüssiger und fester Abfallstoffe gestattet einerseits eine bessere Anpassung an die saisonbedingten Verschiedenheiten des Ausgangsmaterials, hauptsä̈chlich der Müllkomponente, anderseits kann auch eine wesentlich bessere Anpassung auf der Abnehmerseite erreicht werden, seien es nun Wärme- oder Kompostabnehmer. Zudem wird der Kreis der Konsumenten erweitert und dadurch die Absatzfrage erleichtert. 


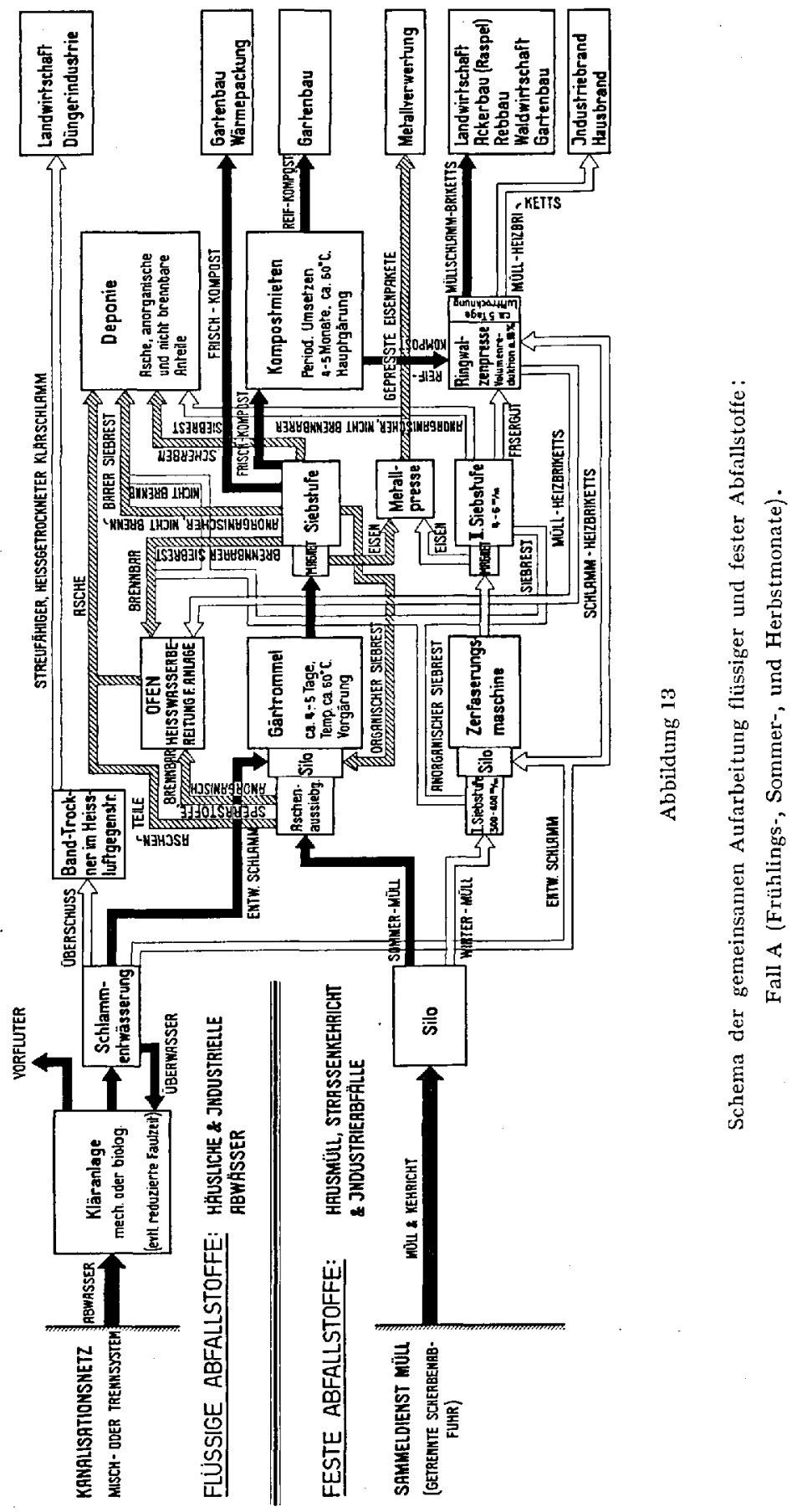




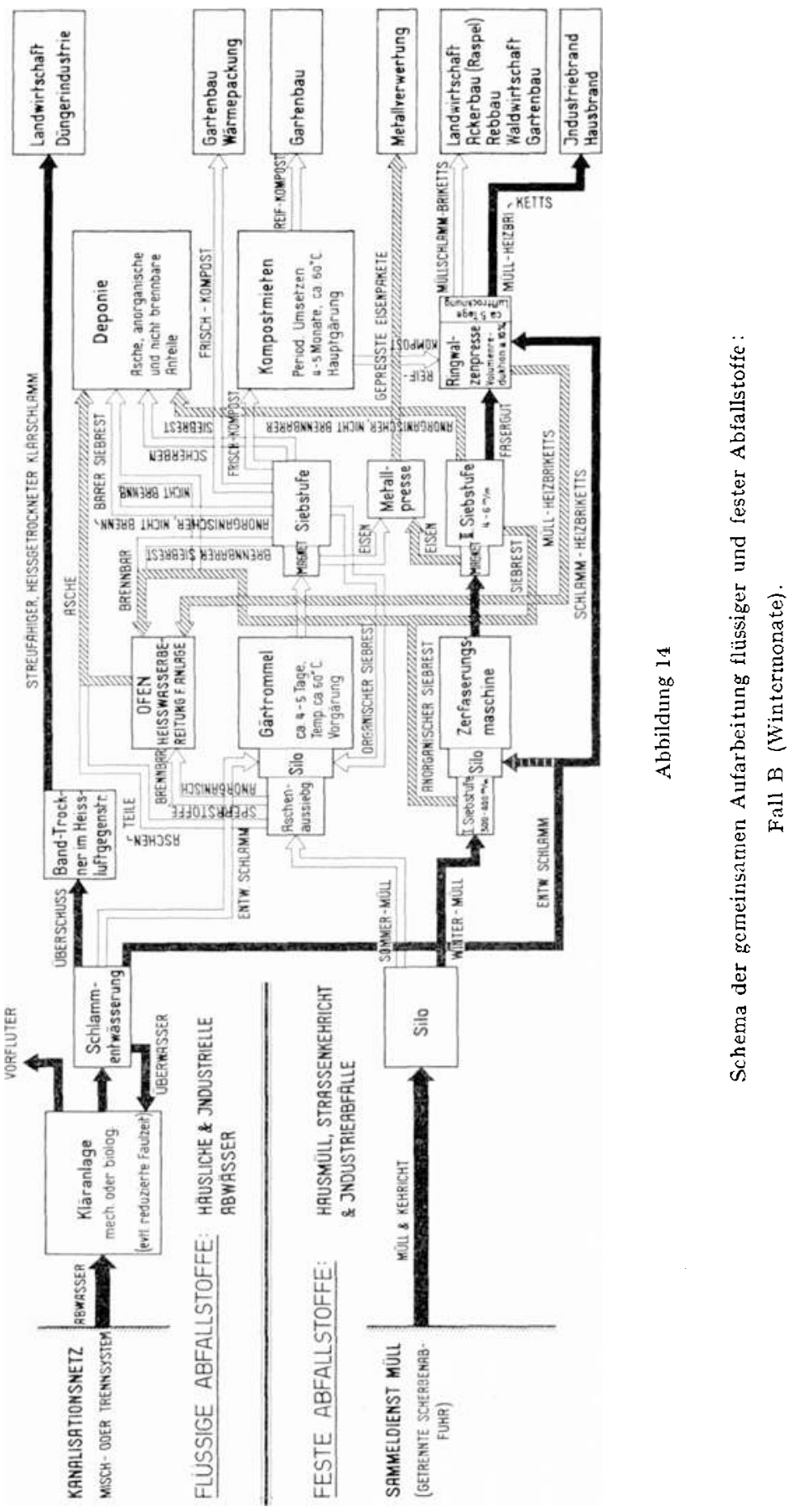


Zusammenfassend kann festgestellt werden, dass die ganze Frage der Abfallstoff beseitigung insofern auf eine neue Ebene gestellt werden sollte, als es Sache des projektierenden Ingenieurs ist, aus der Vielfalt der von der Industrie entwickelten Anlageteile die für die speziellen örtlichen Verhältnisse günstigste und wirtschaftlichste Lösung festzulegen.

Zum Schluss unseres Berichtes möchten wir es nicht unterlassen, der Gemeinde Rüschlikon bestens zu danken, dass sie uns entgegenkommenderweise gestattet hat, diese Untersuchungen in ihrer Müllverwertungsanlage durchzuführen.

Unser grosser Dank gilt auch den Herren Stadtingenieur TEXTOR und Klärmeister MüLLER aus Winterthur. Herr MüLLER hat uns mit dem in seiner Kläranlage stehenden Vibrationseindicker Schlamm in jeder gewünschten Menge und Konzentration produziert und stand uns mit seinen mehr als zweijährigen wertvollen Erfahrungen mit diesem Eindicker zur Seite.

Auch der Stadtverwaltung Zürich und Herrn Klärmeister JüNI sind wir zu Dank verpflichtet für die Lieferung von uneingedicktem Klärschlamm aus der Anlage Werdhölzli.

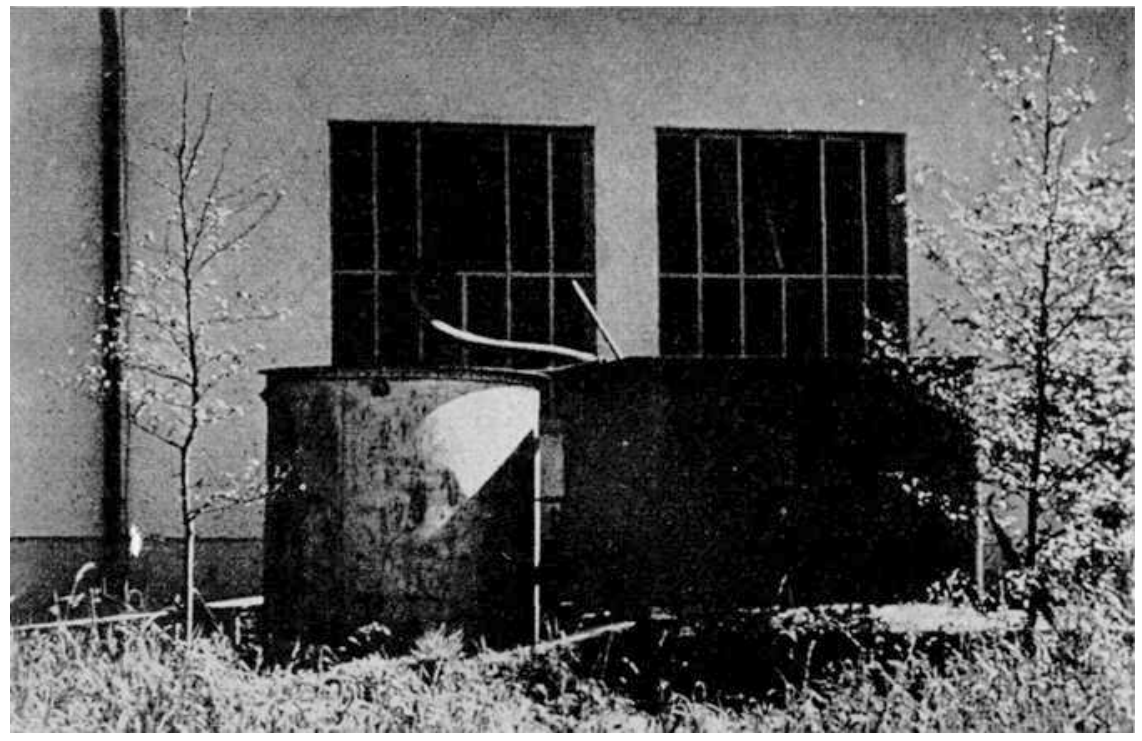

Abbildung 15

Schlammbehälter, insgesamt $5 \mathrm{~m}^{3}$ Inhalt. 


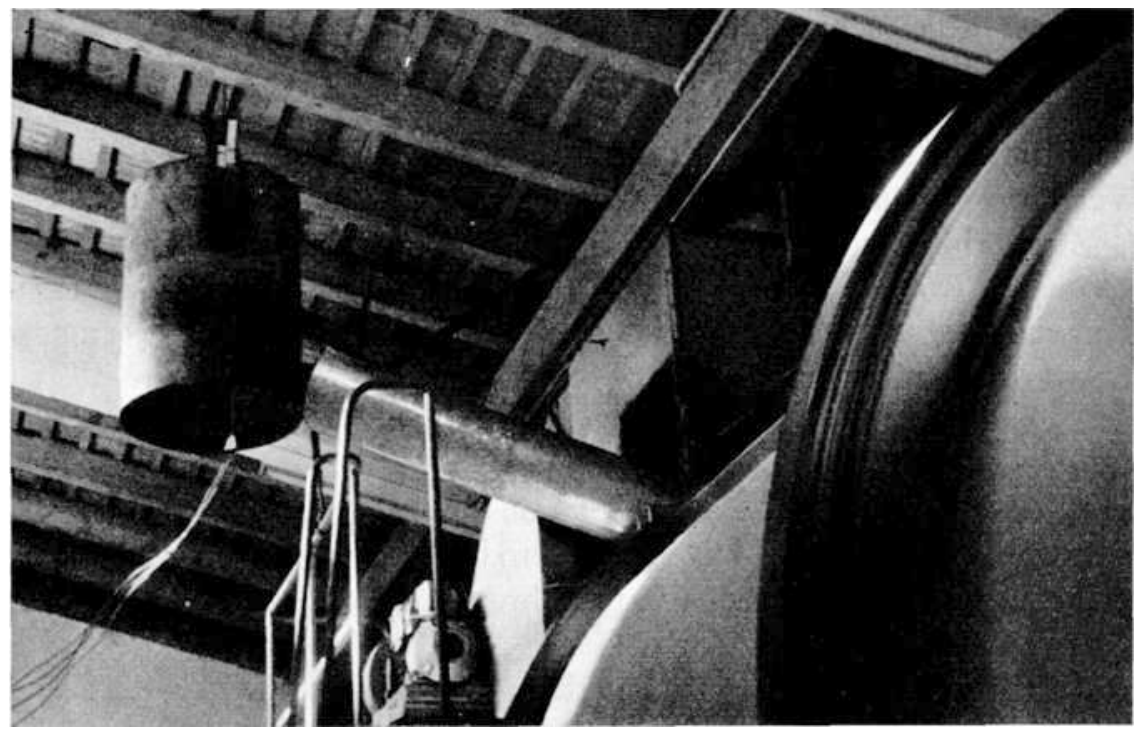

Abbildung 16

Schlammbehälter für Filtrat.

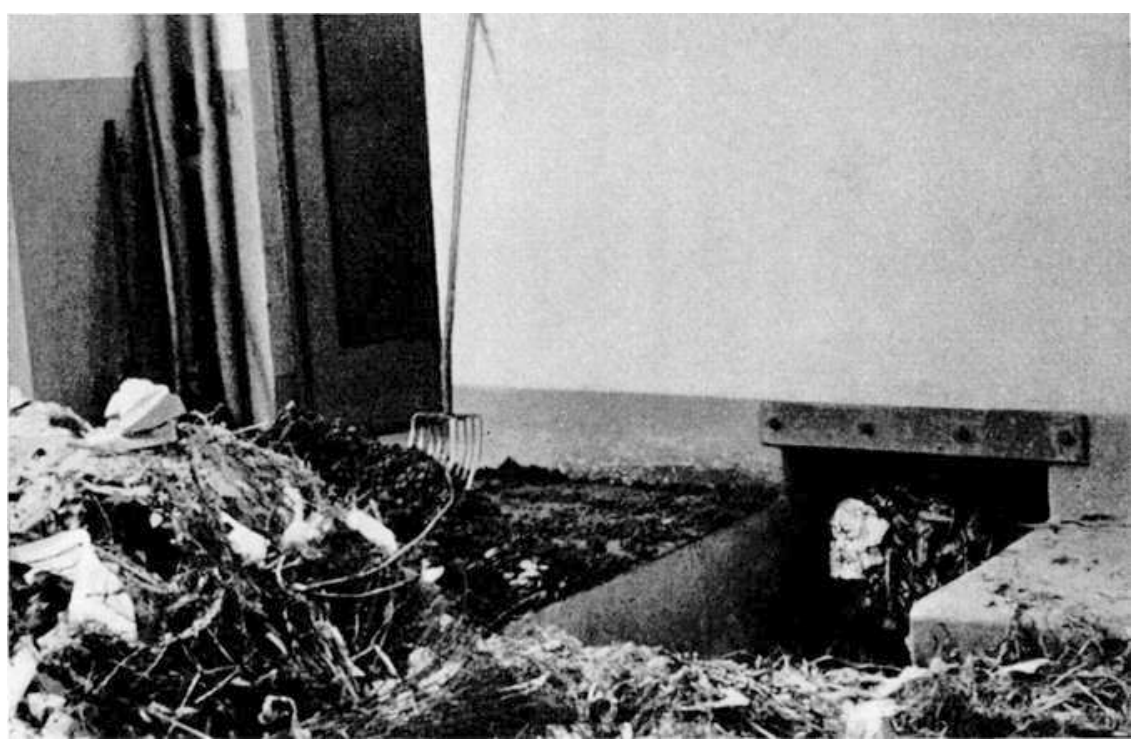

Abbildung 17

Rohmüll und Dickschlamm vor Silo. 


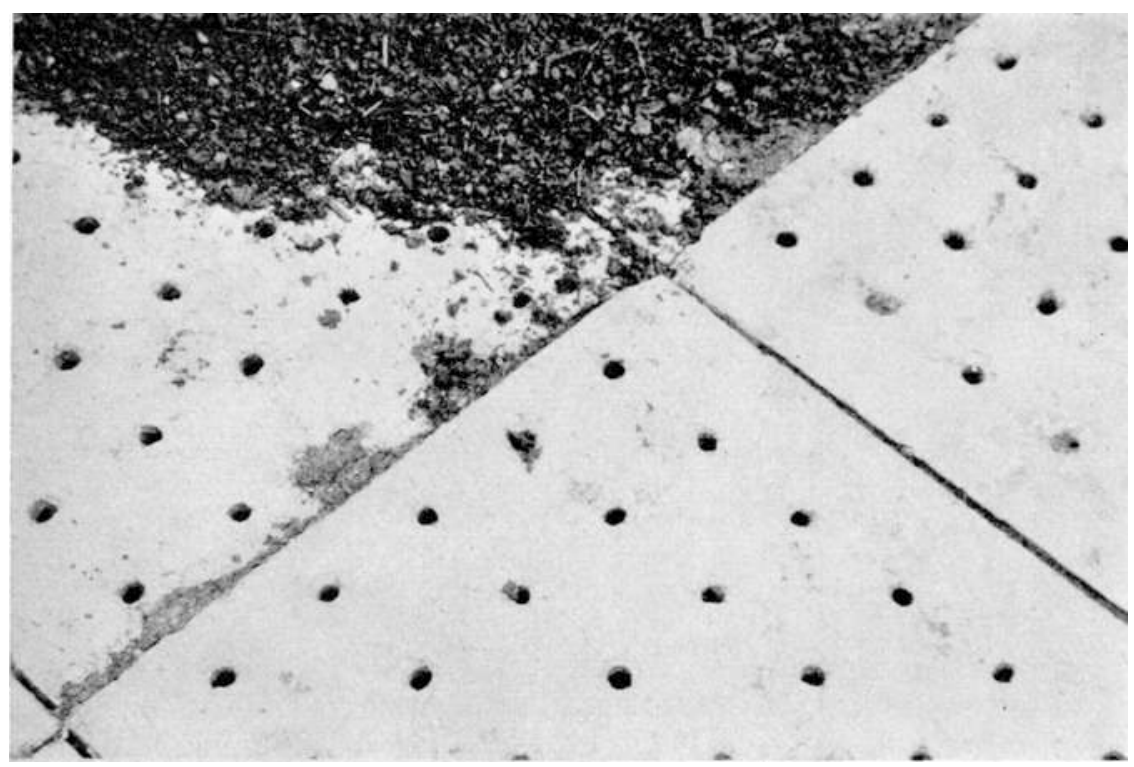

Abbildung 18

Mietenunterlage aus gelochten Kabelsteinen.

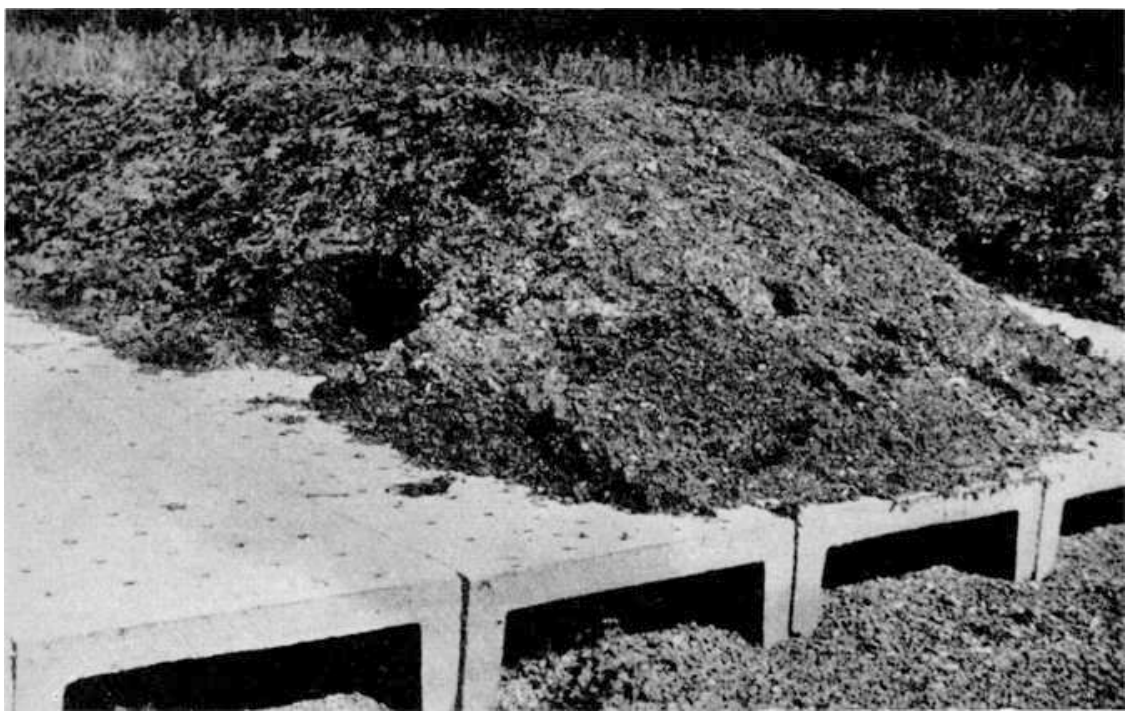

Abbildung 19

Tastmiete. 


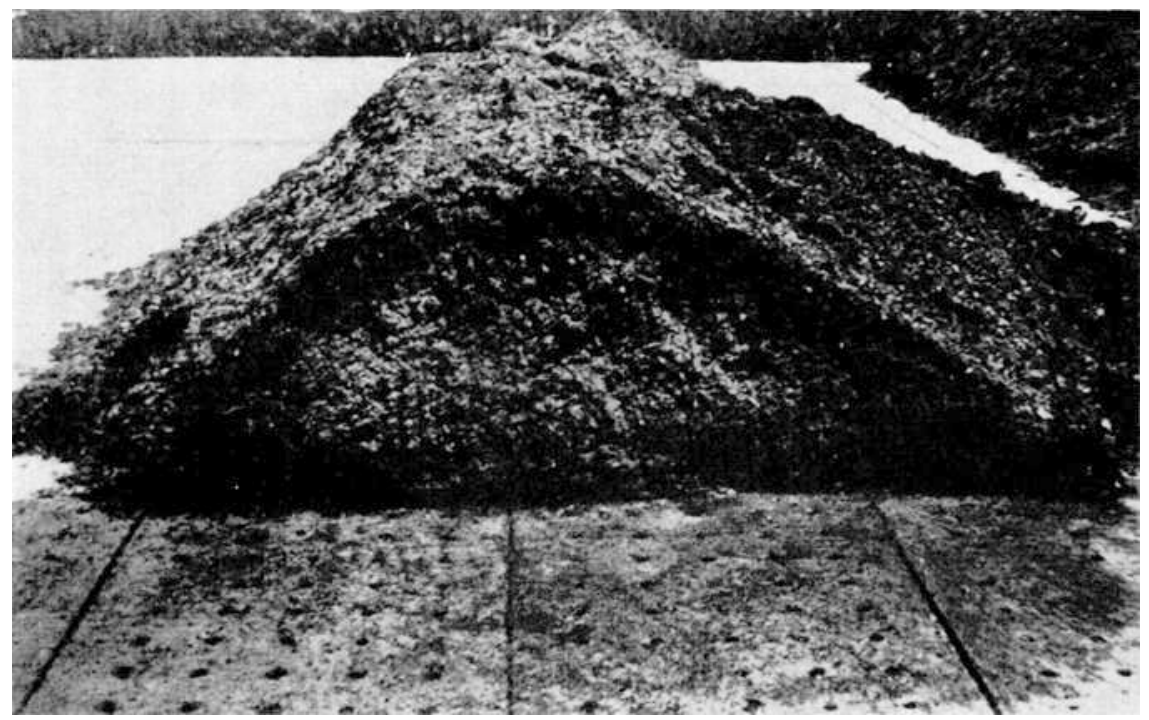

Abbildung 20

Tastmiete aufgeschnitten.

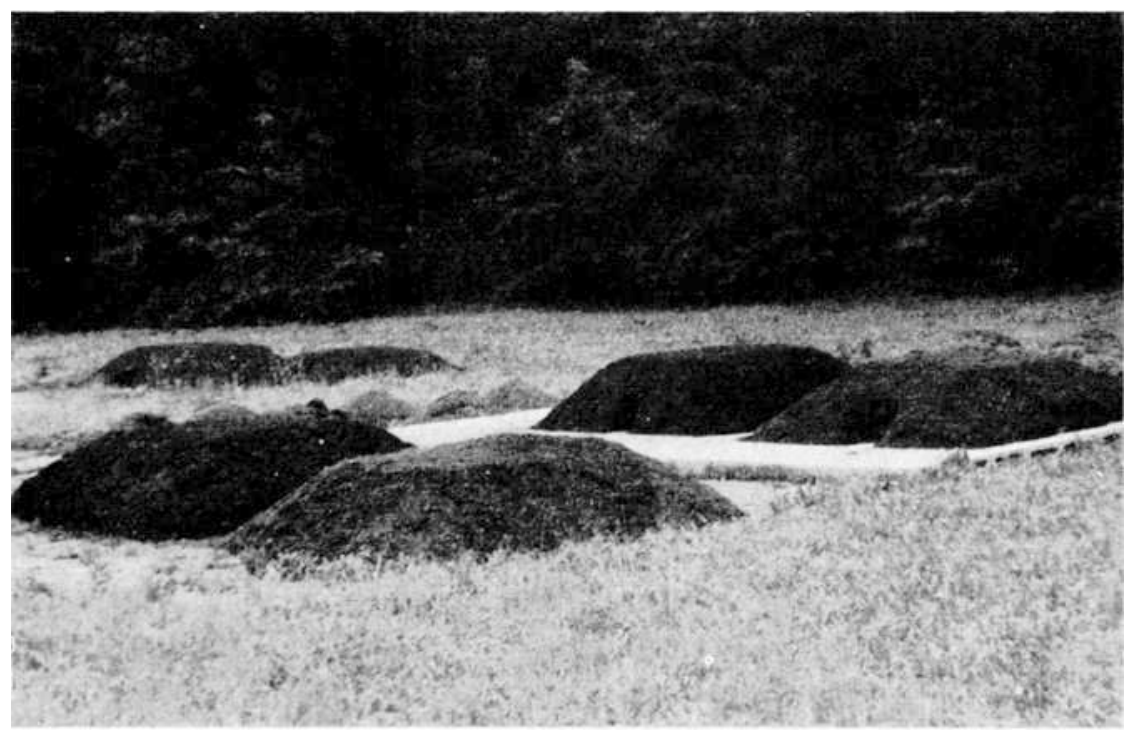

Abbildung 21

Gesamtansicht der Mieten. 


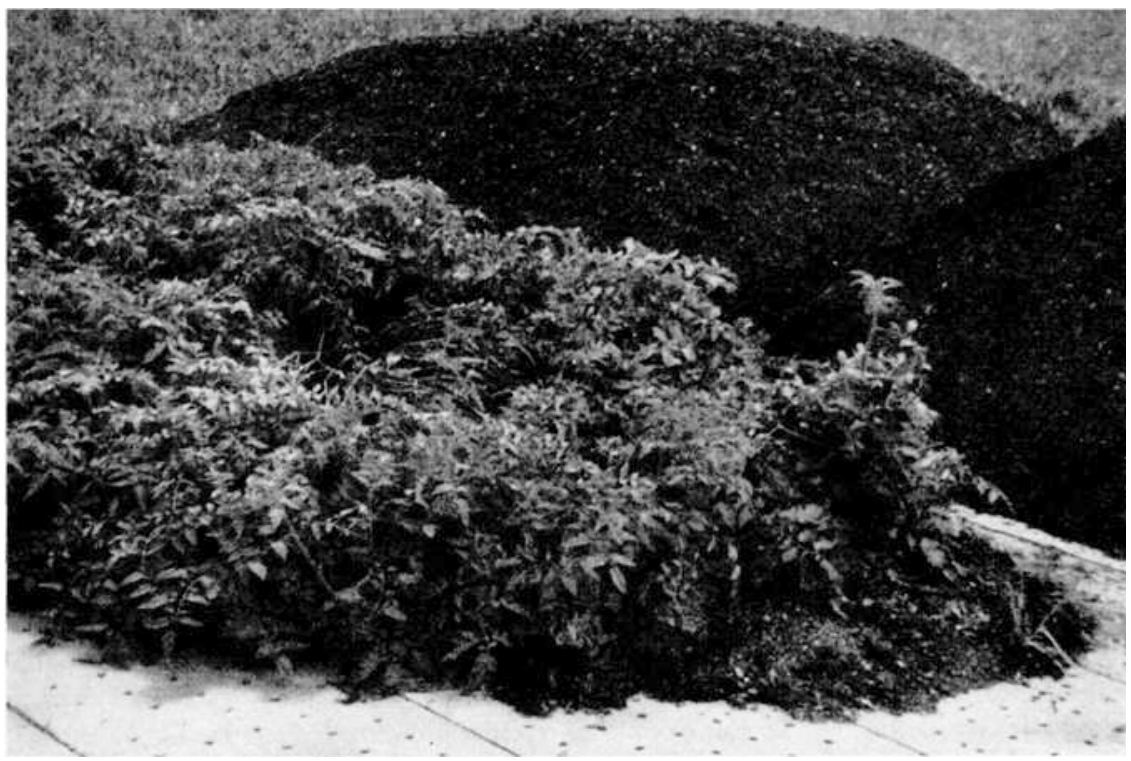

Abbildung 22

Klärschlamm-Miete mit Tomatenkultur.

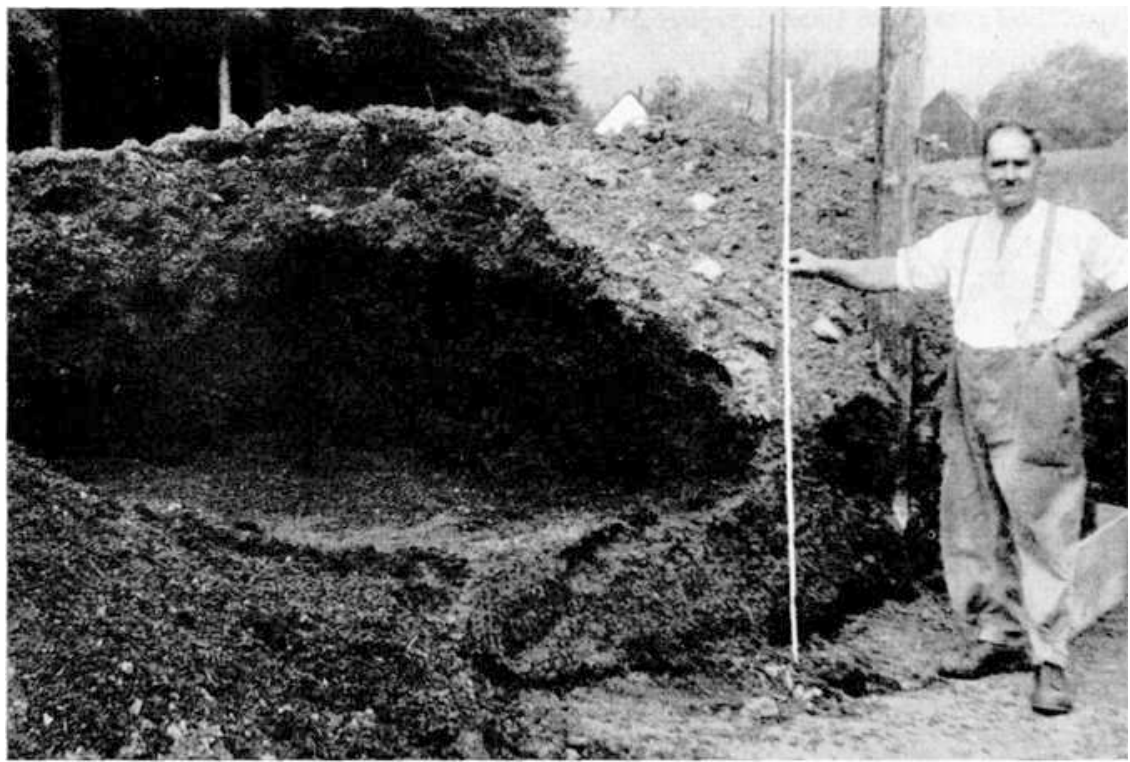

Abbildung 23

Beispiel einer schlechten Kompostierung. 
Die Firma Hunziker AG in Brugg (Herr Direktor BACHMANN) hat uns in verdankenswerter Weise den zur Abklärung der geeignetsten Mietenunterlage verwendeten Betonboden kostenlos geliefert.

Der Gemeinde Horgen gebührt unser Dank für die zuverlässig durchgeführten Schlammtransporte von Zürich und Winterthur nach Rüschlikon.

Die Durchführung dieser Untersuchungen wäre ohne die grosszügige finanzielle Unterstützung seitens der Kantone Aargau, Bern, St.Gallen, Thurgau und Zürich nicht möglich gewesen, weshalb wir den betreffenden Regierungsstellen zu besonderem Dank verpflichtet sind.

Unsere Untersuchungen haben aus verschiedenen technischen Gründen viel länger gedauert, als ursprünglich vorgesehen war. Für das uns entgegengebrachte Verständnis und die Geduld seitens der Grossen Kommimission und deren Präsidenten, Herrn Prof. Dr. O. JAAG, möchten wir abschliessend ebenfalls bestens danken.

\section{LITERATURVERZEICHNIS}

[1] Ak_A-Tagungsbeft Düsseldorf (1957) (Arbeitsgemeinschaft für kommunalc Abfallwirtschaft, Baden-Baden).

[2] Informationsblatt Nr. 1 (November 1956) der Internationalen Arbeitsgemeinscbaft für Muillforscbung (IAM) (Sekretariat: Physikstrasse 5, Zürich).

[3] Knorr, M., Hygienische Probleme um den Müll, Vortrag am Symposium über aktuelle Fragen der Müllbeseitigung, -aufbereitung und -verwertung (ETH, Zürich I955).

[4] Schweiz. Z. Hydrol. 17, Fasc. 2 (1955).

[5] WIтtICH, W., Der beutige Stand unseres Wissens pom Humus und neue Wege zur Lösung

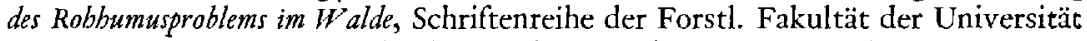
Göttingen, Bd. 4 (J. J. Sauerländers Verlag, Frankfurt a. M. 1952). 